\title{
The Dynamics of Collaboration in Universal Pre-K Counties of West Virginia
}

Kimberly S. Miller

West Virginia University

Follow this and additional works at: https://researchrepository.wvu.edu/etd

\section{Recommended Citation}

Miller, Kimberly S., "The Dynamics of Collaboration in Universal Pre-K Counties of West Virginia" (2011). Graduate Theses, Dissertations, and Problem Reports. 4754.

https://researchrepository.wvu.edu/etd/4754

This Dissertation is protected by copyright and/or related rights. It has been brought to you by the The Research Repository @ WVU with permission from the rights-holder(s). You are free to use this Dissertation in any way that is permitted by the copyright and related rights legislation that applies to your use. For other uses you must obtain permission from the rights-holder(s) directly, unless additional rights are indicated by a Creative Commons license in the record and/ or on the work itself. This Dissertation has been accepted for inclusion in WVU Graduate Theses, Dissertations, and Problem Reports collection by an authorized administrator of The Research Repository @ WVU.

For more information, please contact researchrepository@mail.wvu.edu. 
The Dynamics of Collaboration in Universal Pre-K Counties of West Virginia

Kimberly S. Miller

Dissertation submitted to the

\title{
College of Human Resources and Education
}

at West Virginia University

in partial fulfillment of the requirements

for the degree of

Doctor of Education

in

Educational Leadership Studies

\author{
Paul Chapman, Ph.D., Chair \\ David L. Lancaster, Ed.D. \\ Neal Shambaugh, Ph.D. \\ Ted Price, Ph.D.
}

Department of Educational Leadership Studies

Morgantown, West Virginia

2011

Keywords: Universal Pre-K, collaboration, West Virginia, early education, qualitative descriptive case study

Copyright 2011, Kimberly S. Miller 


\title{
Abstract \\ The Dynamics of Collaboration in Universal Pre-K Counties of West Virginia
}

\author{
Kimberly S. Miller
}

West Virginia Senate Bill 247 mandated that local school systems develop and implement universal preschool programs for all four-year-old children and three-year-old children as mandated by federal law. This mandate was the impetus for West Virginia Policy 2525: West Virginia's Access to a Quality Early Education System. Within policy, local school systems are mandated to collaborate with licensed childcare providers and Head Start to make up at least $50 \%$ of the preschool classrooms. This descriptive qualitative case study investigated how the experience of compulsory collaboration required by WV policy 2525 is described by early education providers. The description of the experience by participants of collaboration among county school systems, local licensed childcare providers, and Head Start in counties in the state of West Virginia was studied. Through purposeful and criterion based sampling, and utilizing interviews, direct participant observations and a review of relevant documents a descriptive qualitative case study was researched. The findings rendered a highly descriptive picture of how these teams experience their work. This study includes detailed information from licensed childcare workers, Head Start, local school administrators, and community members to provide an in depth understanding of the collaborative sites. Yin (2009) wrote that "...high quality analysis requires attending to all the evidence collected" (p. 126). Results from the study can be used to inform policymakers, school superintendents, universal preschool program stakeholders, and early childcare providers. 


\section{Dedication}

I dedicate this dissertation to my girls: Kayley, Kamryn, and Karringtyn. I hope this experience taught them that anything is possible with hard work and dedication. Each of you means the world to me and I am grateful for your understanding and patience.

I also want to dedicate this paper and thank my parents, Santo and Kathy Santoro for always believing in me and supporting me. You have always encouraged me to be my best and pursue my dreams. I also want to dedicate this paper to Larry and Sally Miller for their encouragement for helping me to see that this experience will help me to grow in my profession.

Finally, I dedicate this paper to my husband, David. His love, support, and strength never faltered. I appreciate your patience and I am truly blessed to have you in my life. I love you, and I thank you. 


\section{Acknowledgements}

This journey would not have been possible without the continual support of my family and closest colleagues. I want to extend my deepest gratitude to Dr. Paul Chapman, my chairperson, my cheerleader, and my friend. He was influential in guiding me through many tough times and never wavered in his support, and I am appreciative.

Thank you to my committee members, Dr. Paul Chapman, Dr. Neal Shambaugh, Dr. Ted Price, and Dr. David Lancaster. Their combined wisdom and guidance was instrumental in encouraging me to push myself to make wise decisions in this process. I am most grateful for the ongoing encouragement of my friend, mentor, and colleague, Dr. David Lancaster. Your kind words were influential in this process.

I want to thank Ohio County Schools Superintendent, George S. Krelis for his patience, understanding and encouragement - all necessary components in making this dream a reality. Mr. Clayton Burch kindly shared his wealth of knowledge about the implementation of Policy 2525 with me.

I also want to thank Dr. Larry Stead, his experience, wisdom, and guidance provided me with essential tools to complete this dissertation and learn more about myself.

Lastly, I want to thank my dear friend, Ms. Peggy Clifford. This experience has been both rewarding and enlightening due to her support and inspiration. 
Dedication

\section{Table of Contents}

Acknowledgements

iii

Table of Contents

iv

List of Figures

$\mathrm{V}$

List of Tables

Chapter One: Collaborative Dynamics

Background of the Study

Problem Statement

Purpose of the Study

Overview of the Method

Limitations of the Study $\quad 9$

Definitions of Key Terms 10

Organization of the Dissertation $\quad 12$

Chapter Two: Early Childhood Education 14

$\begin{array}{ll}\text { Early Childhood Education } & 14\end{array}$

Important Theorists and Theories 15

Collaboration $\quad 34$

Organizational Culture $\quad 38$

Case Study: Uchida $\quad 41$

Case Study: Grandinetti $\quad 44$

Chapter Three: Method $\quad 48$

Qualitative Research Design $\quad 48$

Qualitative Research $\quad 53$

Case Study Research $\quad 54$

Worldview $\quad 54$

$\begin{array}{ll}\text { Researcher Bias } & 58\end{array}$

$\begin{array}{ll}\text { Purposeful Sampling } & 61\end{array}$

$\begin{array}{ll}\text { County Selection Criteria } & 65\end{array}$

Research Participants $\quad 66$

Data Collection $\quad 66$

Interview Process $\quad 67$

Observation Guide $\quad 68$

Summary $\quad 74$

Chapter Four: Analysis of Data $\quad \mathbf{7 5}$

\begin{tabular}{ll} 
Introduction & 75 \\
\hline
\end{tabular}

Overview of the Method $\quad 76$

$\begin{array}{lr}\text { Organization of the Data Analysis } & 80\end{array}$

Presentation of Descriptive Characteristics of Universal Counties $\quad 81$

$\begin{array}{ll}\text { Researcher Impressions } & 85\end{array}$

$\begin{array}{lr}\text { Coding Procedures } & 90\end{array}$

Findings: Emerging Themes in the Responses 94

Emerging Themes by County 95

$\begin{array}{ll}\text { Summary } & 97\end{array}$

Chapter Five: Summary Discussion and Conclusion 99 
Emerging Themes $\quad 99$

$\begin{array}{lr}\text { Discussion } & 109\end{array}$

$\begin{array}{lr}\text { Researcher Reflections } & 120\end{array}$

Application $\quad 122$

$\begin{array}{lr}\text { Suggestions for Further Research } & 123\end{array}$

$\begin{array}{ll}\text { References } & 125\end{array}$

Appendices $\quad 135$

Appendix A: West Virginia's Policy 2525 135

Appendix B: Request for County Participation 166

Appendix C: Request for Participation 167

Appendix D: Universal Pre-k Stakeholder Protocol 168

Appendix E: Stanford University's Interview Protocol 169

$\begin{array}{ll}\text { Appendix F : Interview and Observation Forms } & 174\end{array}$

Appendix G: Explanatory Coding Tables 180

$\begin{array}{ll}\text { Appendix H: Curriculum Vitae } & 184\end{array}$ 


\section{List of Figures}

Figure 1 Schein's Three Levels of Culture 39

Figure 2 Graphic Design of a Case Study 56

$\begin{array}{llll}\text { Figure } 3 & \text { Collaboration Summary } & 62\end{array}$

Figure 4 Collaboration per location Summary 63

Figure 5 Sampling Diagram 64

Figure $6 \quad$ Graphic Design of a Case Study by Robert E. Stake 78

$\begin{array}{llll}\text { Figure } & 7 & \text { Thematic disposition of descriptions of compulsory collaboration } & 79\end{array}$

$\begin{array}{llll}\text { Figure } & 8 & \text { Persons under five years old } & 82\end{array}$

$\begin{array}{llll}\text { Figure } & 9 & \text { Percentage of households by county } & 83\end{array}$

$\begin{array}{llll}\text { Figure } & 10 & \text { Participation Rates } & 84\end{array}$

$\begin{array}{llll}\text { Figure } & 11 & \text { Federal Spending } & 85\end{array}$

Figure 12 The Coding Process 92

Figure 13 Lightening County: Percentage of Responses by Theme 95

Figure 14 Sunshine County: Percentage of Responses by Theme 96

Figure 15 Wave County: Percentage of Responses by Theme 96

Figure 16 Thematic Layers of the Onion of Collaboration 100

$\begin{array}{llll}\text { Figure } 17 & \text { Institutional Authority-Patterns of Responses } & 102\end{array}$

$\begin{array}{llll}\text { Figure } & 18 & \text { Organizational Culture: patterns of responses } & 106\end{array}$

$\begin{array}{lll}\text { Figure } 19 & \text { Explicit Values: Patterns of Responses } & 108\end{array}$

\section{List of Tables}

Table 1 Relevant Events in Education 26

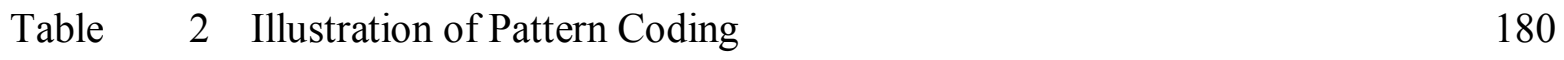

$\begin{array}{lll}\text { Table } 3 \text { Example of Coding Process } & 181\end{array}$

Table $\quad 4$ Sampling of Coded Representative Statements (p. 1) 182

Table 5 Sampling of Coded Representative Statements (p. 2) 183 


\section{Chapter One: Collaborative Dynamics}

In 2001, I accepted a request by the county board of education to be a part of a select group that would focus on the concept of creating an opportunity to implement Universal Preschool programs to 4-year old children. At the time, my oldest child was four; I was an elementary school teacher, and my husband worked Monday through Friday from 9:00 am to 5:00 pm. A free, quality, preschool program would be an economic advantage for our middle class family. I remember my first thought was "What a wonderful option for children with working parents." The project would include an approved preschool curriculum provided in an academic setting with a certified teacher. This was clearly an advantage for the children in my community, and indeed my own family. In this initial year, my designated role on this committee was as parent representative. I had no idea of the magnitude that this small committee of one childcare representative, one county official, one head start representative, one member of West Virginia DHHR, and me would lay the foundation of Universal Preschool in our county.

\section{Background of the Study}

In 1983, West Virginia provided public funding to local counties to provide preschool programs for three and four-year-old children. According to Bushouse, as cited in Ackerman, Barnett, Hawkinson, Brown, \& McGonigle (2009) in a Preschool Policy Brief published by the National Institute for Early Education Research (NIEER):

Declining K-12 enrollment in West Virginia played a role in promoting expanded access in that state as well. Targeted public school preschool had been available in the state since 1986. However, the school aid funding formula was based on K-12 enrollment. To compensate for declining enrollments in the late 1990s and early 2000s, some school 
districts began enrolling 4-year-olds in kindergarten. There was a growing awareness of the number of children who were eligible for free and reduced-price lunch and were also starting school behind their higher-income peers. (Ackerman et al., 2009, p. 5) Consequently, former West Virginia State Senator Lloyd Jackson sponsored an education reform bill in 2002 to increase education funding by $4.8 \%$ to $\$ 2.9$ billion (SREB, 2002). The passage of Senate Bill 247 mandated that each county provide Universal access to all 4-year-olds by 2012-2013 school year.

Policy 2525, Universal Access to a Quality Early Education System (WVDE, 2010), requires meaningful involvement from county collaborative team members. Each county’s collaborative core team must consist of representation from

- $\quad$ the county school system preschool program;

- $\quad$ the county school system preschool special needs program;

- a licensed community child care program in that county not operated by the county school system;

- $\quad$ the Head Start program in that county;

- the local department of health and human resources; and

- a parent/guardian of a preschool child.

Even though the State of West Virginia mandates that all fifty-five counties adhere to West Virginia's Board of Education Policy 2525 (WVDE, 2010), the extent of each county's collaborative varies. Each collaborative agency contributes to meeting the many needs of a child, and offers a different aspect of childcare.

Head Start is a federally funded, nationwide program that promotes school readiness by enhancing the social and cognitive development of children through the provision of educational, 
health, nutritional, social, and other services to enrolled children and families (U.S. Department of Health and Human Services, n.d.). The primary goal of childcare services is to provide early learning, social and nutritional experiences to children, which will foster their healthy development while enabling their parents to participate in work or educational activities. The local school system is the administrative entity for the Local Education Agency (LEA). The LEA is responsible for fiscal management, the actual implementation of policy, and ensuring regulatory compliance. In order to meet the needs of all 4-year-olds and designated 3-year-olds (those with an IEP), Head Start, licensed childcare providers, and LEA, combined to create the Universal Pre-K program as mandated by federal law. The goal of this research is to describe how the collaborators of multiple agencies referred to in Policy 2525 describe the experience of collaboration mandated by Policy 2525 (WVDE, 2010). Universal access, as defined in Policy 2525 requires that "every eligible child in the county has access to a high quality WV Pre-k classroom that meets or exceeds all of the requirements of this policy." However, the lens of this study will focus specifically on the requirement of collaboration.

The successful implementation of West Virginia's Universal Access to a Quality Early Education System, West Virginia Policy 2525 (WVDE, 2010), relies heavily on the collaborative efforts of each counties' collaborative team. West Virginia Policy 2525 (WVDE, 2010) mandates that collaborative partners such as locally licensed childcare providers and Head Start provide at least $50 \%$ of the preschool classrooms. A county earns the designation of universal when it complies with West Virginia Policy 2525. Section 16.4 of Policy 2525 states When a county has fully implemented their county collaborative plan and all eligible children in that county have access to a WV Pre-k classroom that meets all of the quality requirements as outlined in this policy, the county board of education is required to 
annually submit a report that includes: verification of the annual submission of the ECERS-R results, a summary of the WV Pre-k services provided in the county, the number of WV Pre-k children with identified special education needs, the staff development opportunities provided through the county collaborative plan and the number of staff who participated in those staff development opportunities, and number of children who transitioned into kindergarten and other information as required by the WVDE to the WVDE Assistant Director of Early Learning and Literacy by August 1.

(WVDE, 2010)

Local agencies must maximize services, resources, and funds by optimizing collaborative efforts to help children and their families. The successful execution of this policy relies heavily on the interactions of the key stakeholders. State policy mandated compulsory collaboration in Policy 2525. This forced collaboration created new concerns and duties for various preschool providers.

\section{Problem Statement}

Educating school-age children (five-year olds and older), has traditionally been the sole responsibility of the school system. Beginning in 2003, West Virginia began an initiative to lower the entrance age from five to four. Head Start officials, as well as childcare operators, were concerned that this movement would contribute to a loss of funding to support their respective programs. During the 2001-2002 West Virginia Legislative Sessions, the Senate Finance Committee created an advisory board to evaluate the effectiveness of existing licensed early childcare programs. Their intent was to coordinate efforts among childcare programs while increasing opportunities for children. This process established a basis for collaboration among 
county school systems, childcare providers, and Head Start programs, in order to create an environment in which all three entities vied for the most prominent political position.

West Virginia established, within the West Virginia state aid formula (WVDE, 2010), a method for funding the requirements. One constant remained however; low- income families continued to be a high priority in Head Start programs. These programs provided services primarily to children of families that met low-income federal guidelines. On the other hand, privately operated childcare programs relied heavily on tuition. West Virginia Policy 2525 (WVDE, 2010) mandated that West Virginia Pre-K classrooms would provide services to eligible children at no cost to the parents/guardians of the children. This intrinsic component of policy created many opportunities for children; however, it created controversy and conflict among and between agencies. The no-cost clause in state policy disrupted the day-to-day operations of outside daycare agencies. Negativity from some Head Start programs and childcare agencies overshadowed the benefits of Universal Preschool. This forced Head Start programs, as well as licensed childcare agencies to become collaborative partners so that they could be eligible for funding attributed to West Virginia Policy 2525 (WVDE, 2010). To maintain stability of outside agencies, the policy required that contractual agreements with community partners provide no less than $50 \%$ of the classrooms for eligible children. West Virginia Policy 2525 (2010) specifically required collaboration as a component of the county plan.

Collaborative planning, regular meeting times, distribution of responsibilities, and specific and compulsory key stakeholder memberships are a few of the mandates listed in the policy. The State of West Virginia incorporated these components to ensure that all parties follow a team approach in order to implement (WVDE, 2010). Collaborative members must 
maximize resources, funds, staff, and services. These specific guidelines make cooperation feasible for collaborative partners to follow. The phenomenon of collaboration between and among these entities is enigmatic. This study closely examined detailed descriptions of collaboration of those compulsory efforts in counties designated as Universal in West Virginia through first hand observations, county visits and interviews, because researchers know little regarding the extent of the effectiveness of the collaboration.

This study is important because it analyzed the dynamics of Universal Pre-K collaborative partnerships. Although there are no set guidelines on how to create an environment conducive to collaboration, common traits, and practices surfaced. Yin (2009) stated that "a report should indicate: the extent of replication logic and why researchers predicted certain cases to have certain results, whereas other cases, if any, were predicted to have contrasting results" ( p. 56). This particular study closely examined universal counties in West Virginia to garner a deeper and richer understanding of how they have successfully collaborated. The State of West Virginia designated certain counties as "Universal" based on their compliance with West Virginia Policy 2525. The State of West Virginia awards this designation to counties who successfully implement policy 2525 .

\section{Purpose of the Study}

The purpose of this study was to give a rich description of how Universal preschool stakeholders describe their participation in compulsory collaboration. The study answered the following question: How do Universal preschool stakeholders describe the experience of compulsory collaboration?

According to Patton, the process of the study may expose additional questions to be pursued. In Qualitative Research and Evaluation Methods (2002), Patton advises the researcher 
that emerging themes may require "openness to adapting inquiry as understanding deepens and /or situation to change; the researcher avoids getting locked into rigid designs that eliminate responsiveness and pursues a path of discovery as they emerge." Patton calls this "Emergent design Flexibility" (2002, p. 40).

In Designing Qualitative Research, Marshall and Rossman (1999) emphasized the “confusing, messy, intensely frustrating, and fundamentally nonlinear nature of real research" (1999, p. 21). They remind the would be researcher that

Because of the interrelatedness of the sections and because confusing, messy, intensely frustrating, and fundamentally nonlinear nature of real research writing is a developmental, recursive task, the writer may find it necessary to rewrite the research questions or problem statement after reviewing the literature or to refocus the significance after the research design s developed. Bargar and Duncan's (1982) description of "extensive recycling of concepts and perspectives (p .2) quoted earlier, captures this dialectic process. Our advice is that the writer be sensitive to the need for change and flexibility and not rush to closure too soon. Sound ideas or research may come in a moment of inspiration, but the hard work comes next as the idea, the intellectual traditions that surround the idea, and the methods for exploring it are developed, refined, and polished. (1999, p. 24)

The outcome of the research has four potential applications. The first application is policy. Policy makers have a need to understand how Universal Preschool programs actually work because their decisions affect the financial resources that support the programs. The second application will inform county superintendents through rich descriptions of how Universal programs actually work. Superintendents have the power to channel funding directly toward 
Universal Preschool programs. The third application will inform Universal Preschool program stakeholders. Head Start coordinators, LEA coordinators, parents, West Virginia Department of Health and Human Services, preschool special needs groups will be informed about the trials, tribulations, and triumphs of the described models. The fourth and final application will inform providers with details of implementation, successes and difficulties or roadblocks that will impede stakeholders groups. This will provide them with the opportunity to use the information to strengthen their current collaborative teams.

\section{Overview of the Method}

This descriptive qualitative case study investigated one universal county in West Virginia. This study investigated how compulsory collaboration has affected West Virginia preschool. West Virginia Policy 2525 requires that $50 \%$ of West Virginia Pre-K classrooms operate in a collaborative setting with Head Start, childcare, private centers, and LEA. A strong component of this policy is the ability to interact in a collaborative atmosphere.

As a case study researcher, I interviewed collaborative team members from one universal county. Evaluation of the data from that initial site provided multiple perspectives of collaborative models. The information from this initial site determined further universal site investigation and analysis.

Yin (2009) delineates five levels of questions in the case study.

Level 1: questions asked of specific interviewees.

Level 2: questions asked of the individual case (these are the questions in the case study protocol to be answered by the investigator during a single case, even when the single case is part of a larger, multiple-case study)

Level 3: questions asked of the pattern of findings across multiple cases 
Level 4: questions asked of an entire study-for example, calling on information beyond the case study evidence and including either literature or published data that may have been reviewed

Level 5: normative questions about policy recommendations and conclusions going beyond the narrow scope of the study. (2009, p. 87)

I investigated the results of the first site using Yin's first two levels of questioning (Yin, 2009). As more sites were investigated, results were analyzed using Yin's five levels of questioning.

\section{Limitations of the Study}

The concept of collaborating among Head Start, childcare and the school system to create a Universal Pre-K program in West Virginia was a novel idea. True collaboration lacks clearly defined roles, the execution of responsibilities, and the functions are still works in progress. These factors posed limitations to this study. Although policy 2525 (WVDE, 2010) addresses the parties involved in the county plan, it does not specify the extent or the role of each participant. A collaborative team must have the organizational culture to work together with a sense of respect and trust for one another. Covey (1989) addressed the importance of trust. He stated that "without trust, the best we can do is compromise; without trust, we lack the credibility for open, mutual learning, communication and real creativity" (p. 220). Personalities, turf issues, internal commitment, and group dynamics are subjectively based on the composition of the collaborative team. A shift in culture must take place if the collaborative partners are no longer separate entities, but one collective force to meet the needs of all eligible children. Dufour, Dufour, Eaker, and Many (2006) wrote, “...collaboration does not lead to improved results unless 
people are focused on the right issues. Collaboration is a means to an end, not the end itself' (2006, p. 3).

There are fifty-five counties supporting Universal Pre-K programs in West Virginia. The West Virginia Department of Education to date has designated only fifteen counties as Universal Preschool counties (2010-2011). This was a possible limitation to the study. The emergent themes from this study can be used to assist in designing collaborative models and future professional development sessions to enhance current county core teams. The descriptive nature of how people experience the collaborative model yielded rich information about what participants think and feel. This study analyzed participants in a universal Pre-k county.

The state may be able to utilize the common themes in this study to assist in designing collaborative models and future professional development sessions to enhance the effectiveness of collaboration of current and future county core teams.

\section{Definitions of Key Terms}

West Virginia Policy 2525 defined the following key terms (WVDE, 2010):

Approved West Virginia Pre-K. Programs including public school preschool, including preschool special education, and any community provider that contracts with the LEA including, but not limited to, childcare, private preschool, Head Start, and community-based programs that meet or exceed all of the requirements of West Virginia Policy 2525 and are a part of a county's collaborative plan. The school aid funding formula provides funding for children participating in approved West Virginia Pre-K programs. Participating programs are eligible to receive funds through the process of contractual agreements with the county school system. 
Collaborative setting. A classroom of West Virginia Pre-K children operated by a community program (with resource support from the state through the LEA), or a classroom operated jointly by a community program and LEA is considered a collaborative setting.

Contracted community program. Any provider of early childhood services that meets all of the requirements of West Virginia Policy 2525 and has a contractual agreement with the county school system to operate a West Virginia Pre-K classroom is a contracted community program.

County collaborative plan. Each county school board, in cooperation with the county collaborative team, is required to submit an annual plan. The plan must include the following:

- an analysis of facility and personnel needs;

- an analysis of demographics of the county related to the early childhood program implementation;

- financial requirements for implementation;

- potential sources of funding to assist implementation;

- details of how the county board will cooperate and collaborate with other early childhood programs;

- $\quad$ specific timelines for implementation; and - $\quad$ any other requirements of West Virginia Policy 2525. (WVDE, 2010)

Eligible child. An eligible child is any child, regardless of ability, who is four-years old prior to September 1 of the year he/she is to enroll. Three-year-old children with an Individualized Education Program (IEP) may enroll in the West Virginia Pre-K System. Threeyear-olds without IEPs may attend a collaborative classroom if they qualify under the community program's enrollment guidelines, but the state will not provide funding. 
Local Education Agency (LEA). The county school system is the administrative entity for each county.

Universal access. Every eligible child in the county has access to a high quality West Virginia Pre-K classroom that meets or exceeds all of the requirements of West Virginia Policy 2525.

\section{Organization of the Dissertation}

Chapter Two is a review of the key definitions. In this chapter, I review literature that is relevant to preschool. The first section gives an overview of early education. The second section highlights how preschool education has been transformed in the United States. The third section focuses on West Virginia Policy 2525 key terms. Fourth, a section details the effects on Universal Preschool because of collaboration. The fifth section introduces the reader to a framework of organizational culture.

Chapter Three explains my methodological choices. I detail my choice of qualitative research design and case study method, and include an explanation of my biases, and worldview. Sampling methods are detailed, as well as an explanation of the criteria used to select the counties studied. I provide a description of the interview process, and the observation guide.

Chapter Four provides an overview of the method and explains the organization of the data analysis. It presents the descriptive characteristics of universal counties, followed by my impressions of the sites visited. Coding procedures are explained and findings are outlined. In addition, emerging themes identified

The first section of chapter five presents the emerging themes of the research. The second section presents the discussion, includes a brief history of collaboration to illustrate the importance of collaboration, and discusses remarks of interested parties, as well researchers and 
participants of collaborative efforts. The third section consists of my reflections. The fourth section presents an outline of an application of the research. The last section presents recommendations for future research. 


\section{Chapter Two: Early Childhood Education}

In this chapter, I reviewed literature that is relevant to preschool programs in general terms. The first section gives a view of childhood education including important theorists and theories. The second section details the Classical era to relevant events in West Virginia in regards to education. The third section surveys various important historical events that affected education. The fourth section discusses collaboration. The final section reviews two case studies relevant to early childhood education and collaboration.

\section{Early Childhood Education}

"Early childhood education refers to group settings deliberately intended to affect developmental changes in children from birth to the age of entering first grade" (Gorden \& Browne, 2004, p. 23). Early childhood education has evolved from ancient Greek and Roman times to the current preschool programs. In Classical and Hellenic Greece, and in Ancient Rome, wealthy families had the opportunity to have their male children educated at an early age. In Western culture, education, limited to the upper classes, was primarily for male children. Females of the upper classes received instruction focused on homemaking (Ancient Greece, 2004).

Many trace the emergence of the field of early education to the work of Martin Luther (Altenbaugh, 1999). Eventually, philosophers including John Locke, Jacques Rousseau, and Johann Heinrich Pestalozzi devoted their time and effort to the study of the emotional, social, and intellectual aspects of the child.

A listing of some of the many theorists and theories that have contributed to the field of what we now call early childhood education follows. 


\section{Important Theorists and Theories}

John Amos Comenius, AKA Komenský (1592-1670). Comenius advocated for Universal education. Comenius published Janua linguarum reserata in 1631, and this Latin Grammar became popular in his day. He followed up his success with the first picture book for children, Orbis Pictus (The World Illustrated). These books were popular for over one hundred years, and were translated into every major European language (Comenius, 2010).

John Locke (1632 - 1704). Locke believed that the child's mind was a blank slate, or Tabula Rasa. The environment creates knowledge and fills the slate (Darragh, 2010). For this reason, Locke believed that education must begin at an early age (Tabula Rasa, 2010).

Jean Jacques Rousseau (1712 - 1778). Rousseau maintained that children's development unfolds naturally; that the teacher is responsible for designing the environment and providing experiences that complement the child's natural needs (Darragh,, 2010, p. 206). He popularized the myth of The Noble Savage (Pedagogy, 2010).

Johann Pestalozzi (1746 - 1827). Pestalozzi advocated for a child's right to an education following his or her own unique developmental path. According to Pestalozzi, the most important teacher to a child is the mother. He also believed that formal school fostered growth socially, academically, and vocationally. Children have a right to an education that follows their own developmental path; Formal school is needed to integrate knowledge from home life, vocational education, reading, and writing. The role of the teacher has evolved from tyrant of the classroom to facilitator. The teacher designs classrooms to foster engaging activities and problem solving experiences (Darragh, 2010, p. 205-206). This paradigm shift is supported by the work of Jean Jacque Rousseau. 
Jean Marc Gaspard Itard (1775 - 1838). Itard is considered a constructivist. He educated and treated deaf people. He is sometimes referred to as the Patriarch of special education. He was the first of a systematic attempt at specialized education based on individual needs of the child. He maintained that development could be enhanced based on environment stimuli (Darragh, 2010, p. 208). Piaget later supported Itard's theories.

Edouard Sequin (1812 - 1880). Sequin, a student of Itard, opened the first school dedicated to children with intellectual disabilities (Darragh, 2010, p, 208).

Friedrich Froebel (1782-1852). Froebel believed that readiness is central to children's successful learning and development. Readiness is supported through play. Early childhood curriculum currently centers on the concept of engaging in activities that support learning through play. Sometimes called the "Father of Kindergarten" for his extensive work with early education, he made relevant contributions to the development of early childhood programs according to Gordon \& Browne (2008, p. 12). Contemporaries of Froebel's time did not recognize his genius. Von Marenholtz-Bülow (2007) recognizing this; wrote, "This man is called an 'old fool' by these people; perhaps he is one of those men who are ridiculed or stoned by contemporaries, and to whom future generations build monuments" (p. 1). Froebel believed that children could learn through concrete experiences and should play with toys. Froebel designed educational toys for children to engage with during their playtime. According to Froebel, this play developed self-esteem and self-confidence. He also believed that teacher training was important to allow teachers to understand the development of the child (Gordon, and Browne, 2008, p. 12). The sustainability of Froebel's ideals is evident throughout history. 
Arnold Lucius Gesell (1880 - 1961). Gesell viewed a teacher's first responsibility as respecting and supporting children's internal drives as they interact with the environment. Curriculum should be based on the child's interests and needs. He maintained readiness is critical in designing effective educational experiences. “One of Gesell's largest contributions to the field was advancing the idea that Pre-Kindergarten education should represent a 'downward extension' of primary grade education" (Darragh, 2010, p. 206). This was later supported by Vygotsky's zones of proximal development.

G. Stanley Hall (1844 - 1924). Hall was the founder and leader of the American Psychological Association believed that children should be educated in natural environments. "He founded the child study movement" (Darragh, 2010, p. 206). Hall coined the phrase "Storm and Stress" with reference to adolescence, taken from the German Sturm und Drang movement. Its three key aspects are: conflict with parents, mood disruptions, and risky behavior" (Arnett, 1999, p. 317). Fancher (1998) related that Hall invited Freud to present a series of lectures at a conference celebration the $20^{\text {th }}$ anniversary celebration of Clark University, and Freud convinced Hall to invite Jung to the conference. Freud's lectures, despite being delivered in German, were a hit with the conference attendees. Hall sought and received permission to have the lectures translated into English and published. Freud agreed and the lectures were published as The Origin and Development of Psychoanalysis in the American Journal of Psychology in April of 1910 (1998, para. 1-2).

Sigmund Freud (1856-1939). The Father of Psychoanalytic Theory affected Western Culture so widely that his influence can barely be catalogued. The Encyclopedia Britannica (2010) attempts to sum up his influence: "Despite repeated criticisms, attempted refutations and qualifications of Freud's work, its spell remained powerful well after his death and in fields far 
removed from psychology as it is narrowly defined." (Freud Sigmund, 2010, para. 1). Freud's iconic status is a result of not only his publications, but also his legacy. His students included, Adler, Anna Freud, Reich, and Horney (Kheper, n.d., para. 7). Some of his students made their reputations by disagreeing with their mentor. From The Interpretation of Dreams, to his overarching concept of the unconscious, to his theories on infantile sexuality his ideas radically altered the Western conception of itself. (Freud Sigmund, 2010). Regardless of the debate about theoretical viewpoints of Freud, from the psychoanalytical aspect, Freud's theory of development influenced the educational theorists who followed him because of his focus on early childhood development. The debate over Freud's ideas rages on. While some of his ideas now form the canon of the Western thought, others appear as quaint ideas of his times. Only Darwin's influence on our view of ourselves rivals Freud's influence. As Darragh noted, “Some of the main applications of the psychoanalytic theory have provided a founding rationale for the importance of the early childhood years and the need for community and society to invest in high-quality services" (Darragh, 2010 p. 203). Watson accepted Freud's concept of development, but he rejected the concept of the unconscious.

John Watson (1878-1958). The theories of childhood development currently include Watson's concept of Cultural Transmission, and he maintains that social interaction precedes development. According to Riling (2000), "John Watson was fascinated by the discoveries of psychoanalysis, but he rejected Freud's central concept of the unconscious as incompatible with behaviorism" [abstract]. Children grow based on their environment Watson (2009) stated:

Give me a dozen healthy infants, well-formed, and my own specified world to bring them up in and I'll guarantee to take any one at random and train him to become any type of specialist I might select - doctor, lawyer, artist, merchant-chief and, yes, even beggar- 
man and thief, regardless of his talents, penchants, tendencies, abilities, vocations, and the race of his ancestors. I am going beyond my facts and I admit it, but so have the advocates of the contrary and they have been doing it for any thousands of years. Please note that when this experiment is made, I am to be allowed to specify the way the children are to be brought up and the type of world they have to live in. (p. 82)

In the ongoing debate of Nature vs. Nurture, Watson falls clearly on the side of nurture.

Lev Vygotsky (1896 - 1934). Vygotsky maintained that children's learning development is a socially mediated process. Children learn through societal expectations and gather knowledge through interactions with adults and other more experienced peers. Relationships are the center of children's development and learning (Darragh, 2010, p. 211). We can see a trend developing as more theorists focus on the concept of child development, readiness and the importance of social development.

Jean Piaget (1896 - 1937). He developed a stage-based theory of children's learning and development, which resulted in his being called "The Father of Constructivism." Children develop based on interactions between the child's own internal drives and surrounding environment. His four-stage theory of cognitive development shaped High/Scope Curriculum and the Kamii-DeVries Approach (Darragh, 2010, p. 208). Piaget shared with Dewey the concept that learning is a lifelong process based on experiences.

John Dewey (1859 - 1952). Dewey considered that the most effective education occurs within in interactive social context. He advocated for problem solving as a valuable learning opportunity. He is known as the "Father of Pragmatism" (Darragh, 2010, p. 211). Dewey’s ideas would shape the American educational system with a focus on experiential learning and recognition of the importance of teacher training. 
Maria Montessori (1870 - 1952). Montessori held that education as a catalyst in individual and social development. She devoted her life to developing an effective method for the education of all children, and saw children as the center of learning, and child centered curriculum as essential. She viewed the environment as a third teacher (Darragh, 2010, p. 210).Like Dewey and Piaget she believed that learning takes place in a child-centered environment with a facilitator instead of a teacher.

Erik Erikson (1902-1994). According to Davis and Clifton, Erik Erikson, the Father of Psychosocial Theory accepted some of Freud's theories but disagreed with his emphasis on sexuality, and the formation of the personality. Erikson's maintains that development continues through adulthood (Davis and Clifton 1995, para. 1).

Steven Pinker (1954). Pinker is a psychologist and linguist. He is the Johnstone Family Professor in the Department of Psychology at Harvard University. At MIT, he was a faculty member in the Department of Brain and Cognitive Sciences. His early research focused on the acquisition of language. Pinker's book The Blank Slate: The Modern Denial of Human Nature became a best seller and was a finalist for the Pulitzer Prize. Pinker's evolutionary approach to cognition has created controversy in academia as well as the popular press. Pinker insists that his focus on the determinist role of genes does not imply unequal treatment of individuals. Prior to publication, Pinker provided colleagues with the manuscript for The Blank Slate for their feedback and comments. In a lecture videotaped by TED (TED Talks, 2003) he listed some of the comments he received.

- " Better get a security camera for your house."

- "Don't expect to get any more awards, job offers, or positions in scholarly societies."

- " "Tell your publisher not to list your hometown in your author bio." 
• "Do you have tenure?" (2003, minute 22, text of lecture)

Classical Greece to the fall of Rome (480 BCE-476 CE). "Plato (427 B.C.), Aristotle

(384-323 B.C.), Cicero (143-106 B.C.), and Polybius (222 - 204 B.C.) founded schools with the model of small-group tutoring, teaching wealthy boys thinking skills, governing, military strategy, and managing commerce" (Gordon, and Browne, 2008, p. 8). Although the concept of education being available to the male children of the upper classes continued to the Reformation, early childhood education deteriorated due to the fall of the Roman Empire and the changing economic role of the child. Thomas Cahill, in Mysteries of the Middle Ages pointed out:

The collapse of the Roman Empire in the West had devastated European learning, and in the process literacy itself had become endangered. The enormous loss of books in the early Middle Ages (through catastrophes large and small, connected to the fall of Rome and the barbarian invasions) meant that centuries had to pass for basic texts to be rediscovered, recopied and distributed widely and for libraries to be built up again. (Cahill, 2006, p. 195)

In addition, the changing economic role of the child altered as children took on adult responsibilities and duties including hard labor, childcare and assisting in the family's fight for survival.

From Classical Greece to the Renaissance, literacy separated the haves from the havenots. Those few, those happy few, who could read, lived in a different world than the masses. However, access to education in most cultures remained limited to the males of the upper classes. Westfall Thompson wrote in The Literacy of the Laity in the Middle Ages.

The increasing poverty of creative imagination is reflected alike in the decay of literature and the loss of vigor in education. Education slowly ceased to be a discipline and 
became a rhetorical art. Grammarians degenerated into mere antiquarians; thought became repetitious and added nothing to the ancient store of knowledge. The splendid endeavor of cultivated pagan nobles, as Symmachus in the Theodosia epoch, who gathered together kindred spirits in Rome and strove to keep the candle of vision alight, failed to relieve the growing intellectual darkness. Finally, the triumph of Christianity had divorced almost all men from fellowship with the classical tradition. (Thompson, 1963, p. 2)

Ruby Payne stated, in A Framework for Understanding Poverty (1996).

For those living in poverty education is valued and revered as abstract but not as a reality. To the middle class, education is crucial for climbing success ladder and making money. To the wealthy, education is a necessary tradition for making and maintaining connections (1996, Chart, p. 59).

Maslow's Hierarchy of needs would support Payne's supposition (Learning Theories, n.d.) According to the University of Calgary's tutorial: The End of Europe's Middle Age, Language and Literature in Europe during the middle ages, "literacy" meant acquiring another language, as Latin remained the language of government, education and religion until the $16^{\text {th }}$ Century (University of Calgary, n.d., para. 1).

Renaissance to Reformation (1400 CE- $1600 \mathrm{CE})$. The European Renaissance saw the invention of the printing press, which allowed mass production of texts. This revolution allowed access to the Bible, and other texts to the rising middle classes (Jones, 2000 a, para. 1). Education remained focused on sons of the upper and middle classes until the Reformation. Luther's emphasis on direct interpretation of the Bible caused a revolution in education (Jones $2000 \mathrm{~b}$, para. 1). In order to read the Bible all classes needed to learn how to read, and schools 
were created for the poor and working class family. Martin Luther (1482-1546) established a foundation focusing on reading and developing skills applicable to people's lives. John Calvin championed Universal education and Calvinist Synods decreed that free public schools should be created. John Knox also attempted to set up schools but met with less success (Education, 2010). People began to invest time and effort into child rearing because of spiritual needs, and their potential to contribute economically to the welfare of the family.

Universal education. In the seventeenth century, Comenius advocated for Universal education (Froebel Web, n.d).

Not the children of the rich or of the powerful only, but of all alike, boys and girls, both noble and ignoble, rich and poor, in all cities and towns, villages and hamlets, should be sent to school.

Education is indeed necessary for all, and this is evident if we consider the different degrees of ability. No one doubts that those who are stupid need instruction, which they may shake off their natural dullness. But in reality those who are clever need it far more, since an active mind, if not occupied with useful things, will busy itself with what is useless, curious, and pernicious (quotes from John Amos Comenius, The Great Didactic, written 1628-32; published 1649; translated by M. W. Keatinge 1896), (The Froebel Web. n.d, para. 1).

A search of Amazon.com shows that both of these texts are currently available in paperback, editions, hardcover editions and KINDLE editions. His Didactical Magna, "The Great Didactic" claimed that learning is natural, and understanding is more important than memorization (Comenius, 2010).

As time progressed, philosophers including John Locke, Jacques Rousseau, and Johann 
Heinrich Pestalozzi devoted their time and effort to the emotional, social, and intellectual aspects of the child.

Compulsory education in Colonial America. The Old Deluder Act (1647). The brave, hardworking founders of the Massachusetts Bay Colony approached religion and civic duty with equal ardor. In order to read the Bible, the people would need to know how to read. In order to be a good citizen, a man had to be literate. (The American Colonist's Library, n.d.) From Records of the Governor and Company of the Massachusetts Bay in New England (1853), II: 203

It being one chief project of that old deluder, Satan, to keep men from the knowledge of the Scriptures, as in former times by keeping them in an unknown tongue, so in these latter times by persuading from the use of tongues, that so that at least the true sense and meaning of the original might be clouded and corrupted with false glosses of saintseeming deceivers; and to the end that learning may not be buried in the grave of our forefathers, in church and commonwealth, the Lord assisting our endeavors. It is therefore ordered that every township in this jurisdiction, after the Lord hath increased them to fifty households shall forthwith appoint one within their town to teach all such children as shall resort to him to write and read, whose wages shall be paid either by the parents or masters of such children, or by the inhabitants in general, by way of supply, as the major part of those that order the prudentials of the town shall appoint; provided those that send their children be not oppressed by paying much more than they can have them taught for in other towns.

And it is further ordered, that when any town shall increase to the number of one hundred families or householders, they shall set up a grammar school, the master thereof being 
able to instruct youth so far as they may be fitted for the university, provided that if any town neglect the performance hereof above one year that every such town shall pay 5 pounds to the next school till they shall perform this order. (The American Colonist's Library, n.d, para. 1)

The Massachusetts Bay Company was determined to have its members read the Bible in English, without interference of papist priests. Even the puritanical fear of taxes was not enough to stop the establishment of schools and the imposition of taxes to pay for them. For the first the first time in the American colonies, families are held responsible for educating their children. Early childhood education has been a challenge to public school systems in the United States since its conception in the early 1900s (see Table 1.0). Beatty (1995) recapitulated that Lillian Wald and Florence Kelley garnered federal attention due to their high status in regards to establishing a children's bureau, a federal agency for children, which started in 1912. According to Beatty (1995), the main purpose of the bureau was research and dissemination of information. Many school system officials were eliminating programs including kindergarten, art, music, and physical education due to limited funding, while others were beginning to experiment with creating innovative programs for children between the ages two to 4-year olds old. Beatty (1995) found that women's clubs in both the Chicago area and the Winnetka area sponsored nursery school experiments in public schools, because funding was limited, private sponsorship and/or tuition funded the programs. Beatty continues, "In a letter to the Chicago Day Nursery Association in 1925, Rose H. Alschuler spoke of the need to introduce higher standards and an educational program" (Beatty, 1995, p. 174). In many circumstances, Beatty (1995) found that limited funding excluded children with disabilities until they were of school age. 
Table $\quad 1.1$

Relevant Events in Education

\begin{tabular}{|c|c|c|}
\hline Date & Person, Place, or Issuing Agency & Event \\
\hline 1690 & John Locke, England ${ }^{\mathrm{i}}$ & An Essay Concerning Human Understanding \\
\hline 1762 & France: Jean Jacques Rousseau ${ }^{\mathrm{ii}}$ & The Social Contract. Immediately banned in Paris \\
\hline 1740 & South Carolina Act of 1740 iii & Prohibits teaching slaves how to read. \\
\hline 1801 & Jean Marc Gaspard Itard, France ${ }^{\text {iv }}$ & $\begin{array}{l}\text { Reports on the Savage of Aveyron } \\
\text { Provided education for the deaf }\end{array}$ \\
\hline 1805 & $\begin{array}{l}\text { Johann Heinrich Pestalozzi, } \\
\text { Switzerland }^{\mathrm{V}}\end{array}$ & $\begin{array}{l}\text { How Gertrude Teaches Her Children.(1801) } \\
\text { Establishes the Pestalozzi Method }\end{array}$ \\
\hline 1837 & Friedrich Froebel, Germany: ${ }^{\text {vi }}$ & Founds Kindergarten \\
\hline 1840 & Edouard Seguin, France ${ }^{\mathrm{vii}}$ & $\begin{array}{l}\text { The Moral Treatment, Hygiene, and Education of } \\
\text { Idiots and Other Backward Children (1846) } \\
\text { Established the first school for the mentally } \\
\text { handicapped. }\end{array}$ \\
\hline 1859 & Charles Darwin, England ${ }^{\text {viii }}$ & On The Origin of Species \\
\hline 1867 & $\begin{array}{l}\text { Department of Education } \\
\text { Established }^{\text {ix }}\end{array}$ & To collect information on school and learning \\
\hline 1889 & Chicago, Illinois ${ }^{x}$ & Jane Addams establishes Hull House \\
\hline 1890 & Second Morrill Act ${ }^{\mathrm{xi}}$ & Land -Grant Colleges and Universities \\
\hline 1899 & John Dewey, University of Chicago ${ }^{x i i}$ & $\begin{array}{l}\text { School and Society (1899), The Child and the Curriculum } \\
\text { (1902), and Democracy and Education (1916). } \\
\text { His progressive philosophy influenced American } \\
\text { education and teacher training. }\end{array}$ \\
\hline
\end{tabular}

Notes. U.S. Government information appears in boldface type.

Information from the State of West Virginia is italicized. 
Table 1.2

Relevant Events in Education

\begin{tabular}{|c|c|c|}
\hline Date & Person, Place, or Issuing Agency & Event \\
\hline 1905 & Sigmund Freud, Germany ${ }^{\text {xii }}$ & $\begin{array}{l}\text { Three Essays on the Theory of Sexuality } \\
\text { Psychoanalytic Theory }\end{array}$ \\
\hline 1912 & Maria Montessori $^{\text {xiv }}$ & $\begin{array}{l}\text { 1st Montessori School in the U.S. Emphasis on } \\
\text { child's self-direction }\end{array}$ \\
\hline 1916 & Lewis Terman, Stanford University ${ }^{\mathrm{xv}}$ & Stanford-Binet IQ test published \\
\hline 1917 & Smith-Hughes Act ${ }^{\mathrm{xvi}}$ & $\begin{array}{l}\text { Agricultural, Industrial, home economics in high- } \\
\text { schools }\end{array}$ \\
\hline WWII & $\begin{array}{l}\text { Federal Government sponsors } \\
\text { daycare }^{\text {xvii }}\end{array}$ & to over 400,000 preschool children \\
\hline 1942 & $\begin{array}{l}\text { Congress of Racial Equality } \\
\text { (CORE) }^{\text {viii }}\end{array}$ & Founded by James Farmer \\
\hline 1943 & Abraham Maslow ${ }^{\mathrm{xix}}$ & $\begin{array}{l}\text { A Theory of Human Motivation Theory of Self- } \\
\text { Actualization. }\end{array}$ \\
\hline 1943 & Arnold Geselle, Yale University ${ }^{\mathrm{xx}}$ & $\begin{array}{l}\text { Infant and Child in the Culture of Today } \\
\text { Infancy and Human Growth (1928) } \\
\text { Emphasized the importance of normal infant } \\
\text { development. }\end{array}$ \\
\hline 1944 & "GI BILL" Authorized ${ }^{\mathrm{xxi}}$ & $\begin{array}{l}\text { Postsecondary Educational Assistance to } 8 \text { million } \\
\text { WWII Vets }\end{array}$ \\
\hline Post War & The Federal Government ${ }^{\mathrm{xxii}}$ & Withdraws all support for daycare. \\
\hline 1946 & George Barden Act ${ }^{\text {xiii }}$ & $\begin{array}{l}\text { Agricultural, Industrial, home economics in high- } \\
\text { schools }\end{array}$ \\
\hline 1950 & Impact Aid Law ${ }^{\mathrm{xxiv}}$ & $\begin{array}{l}\text { Federal Government Subsidies Military and } \\
\text { Federal Installations }\end{array}$ \\
\hline
\end{tabular}
Notes. U.S. Government information appears in boldface type. Information from the State of West Virginia is italicized.


Table 1.3

Relevant Events in Education

\begin{tabular}{|c|c|c|}
\hline Date & Person, Place, or Issuing Agency & Event \\
\hline 1950 & Erik Erikson $^{\mathrm{xxv}}$ & $\begin{array}{l}\text { Childhood and Society } \\
\text { Maintained that development continued to }\end{array}$ \\
\hline 1960 & $\begin{array}{l}\text { Student Non-violent Coordination } \\
\text { Committee }\end{array}$ & established at Shaw University \\
\hline 1960 & Freedom Riders ${ }^{\mathrm{xxvii}}$ & $\begin{array}{l}\text { SNCC (Student Non-Violent Coordinating } \\
\text { Committee) and Congress of Racial Equality } \\
\text { (CORE) }\end{array}$ \\
\hline 1960 & $\begin{array}{l}\text { Jerome Bruner, Duke, Harvard, Oxford, } \\
\text { NYU xxviii }\end{array}$ & $\begin{array}{l}\text { Expanded Piaget's concepts and The Process of } \\
\text { Education (1960) affected curriculum reform. }\end{array}$ \\
\hline 1962 & Lev Vygotsky ${ }^{x x i x}$ & $\begin{array}{l}\text { Thought and Language English Translation } \\
\text { published in U.S. (originally published 1934) }\end{array}$ \\
\hline 1962 & $\begin{array}{l}\text { Federal Government orders } \\
\text { desegregation }^{\mathrm{xxx}} \\
\text { at the University of Mississippi }\end{array}$ & $\begin{array}{l}\text { Governor Ross Barnett denies Federal Orders } \\
\text { Six thousand Troops, hundreds injured, two } \\
\text { hundred arrests } \\
\text { Thirty- Five U.S. Marshals shot. }\end{array}$ \\
\hline 1964 & Title VI of the Civil Rights Act ${ }^{\mathrm{xxxi}}$ & $\begin{array}{l}\text { Prohibits discrimination based on race, color, } \\
\text { and national origin. }\end{array}$ \\
\hline 1968 & $\begin{array}{l}\text { Head Start Program }{ }^{x x x i i} \\
\text { The Elementary and Secondary Education }\end{array}$ & $\begin{array}{l}\text { Announced by President Johnson } \\
\text { Launched a comprehensive set of programs }\end{array}$ \\
\hline 1965 & Act $^{\mathrm{xxxiii}}$ & aimed at urban and rural poverty. \\
\hline $\begin{array}{l}1965 \\
1965\end{array}$ & $\begin{array}{l}\text { Title I }{ }^{\mathrm{xxxiv}} \\
\text { The Higher Education Act }{ }^{\mathrm{xxx}}\end{array}$ & $\begin{array}{l}\text { Federal aid to disadvantaged children } \\
\text { Authorized assistance for postsecondary } \\
\text { education }\end{array}$ \\
\hline 1968 & Kent State ${ }^{\mathrm{xxxvi}}$ & $\begin{array}{l}\text { The Ohio National Guard fires on unarmed } \\
\text { college students } \\
\text { Four dead, nine wounded. }\end{array}$ \\
\hline Notes. & $\begin{array}{l}\text { U.S. Government information appears in } \\
\text { boldface type. } \\
\text { Information from the State of West } \\
\text { Virginia is italicized. }\end{array}$ & \\
\hline
\end{tabular}


Table 1.4

Relevant Events in Education

\begin{tabular}{|c|c|c|}
\hline Date & Person, Place, or Issuing Agency & Event \\
\hline 1969 & Sesame Street ${ }^{\mathrm{xxxvii}}$ & appears on PBS stations \\
\hline 1973 & $\begin{array}{l}\text { T. B. Brazelton, Princeton, } \\
\text { Columbia xxxviii }\end{array}$ & Neonatal Behavioral Assessment Scale \\
\hline 1974 & $\begin{array}{l}\text { US District Court Judge W. } \\
\text { Arthur Garrity, Jr. }{ }^{\text {xxix }}\end{array}$ & $\begin{array}{l}\text { finds the city of Boston guilty of } \\
\text { unconstitutional } \\
\text { and intentional segregation in its schools. } \\
\text { Court ordered desegregation results in violence } \\
\text { and boycotts }\end{array}$ \\
\hline 1983 & $\begin{array}{l}\text { West Virginia provides funding to } \\
\text { counties }^{\text {xlxli }}\end{array}$ & $\begin{array}{l}\text { To provide preschool to } \\
\text { three and four year old children. }\end{array}$ \\
\hline 1983 & $\begin{array}{l}\text { West Virginia provides funding to } \\
\text { counties }\end{array}$ & $\begin{array}{l}\text { To provide preschool to } \\
\text { three and four year old children. }\end{array}$ \\
\hline 1983 & $\begin{array}{l}\text { Frames of Mind, The Theory of } \\
\text { Multiple xliii Intelligences }\end{array}$ & Howard Gardner \\
\hline 1988 & $\begin{array}{l}\text { First ADA Act introduced in } \\
\text { Congress }^{\text {xliv }}\end{array}$ & Disability Civil Rights \\
\hline 1990 & ADA Law Signed ${ }^{\text {xlv }}$ & Disability Civil Rights \\
\hline $1990 s$ & $\begin{array}{l}\text { West Virginia faces declining } \\
\text { enrollment }\end{array}$ & begins enrolling four year olds in kindergarten \\
\hline $\begin{array}{l}2001 \\
2002\end{array}$ & West Virginia Senate Session ${ }^{x l v i i}$ & $\begin{array}{l}\text { Senate Finance Committee creates advisory } \\
\text { board } \\
\text { to evaluate existing licensed early care programs }\end{array}$ \\
\hline Notes. & $\begin{array}{l}\text { U.S. Government information } \\
\text { appears in boldface type. } \\
\text { Information from the State of } \\
\text { West Virginia is italicized. }\end{array}$ & \\
\hline
\end{tabular}


Table 1.5

Relevant Events in Education

Date

Person, Place, or Issuing Agency Event

2002

Senate Bill $247^{x \text { viii }}$

Increases funding by $4.8 \%$ to $\$ 2.9$ billion

Sets ten year goal for

Universal Preschool

State Senator Lloyd Jackson

West Virginia Policy

Ensures that very four year old has access to high

2002

2525 passed $^{\text {plix }}$ quality Pre-K

by $2012-2013$

2009

West Virginia's Universal

Access to Requires collaboration of stakeholders

a Quality Educational System ${ }^{l}$

Notes. U.S. Government

information appears in

boldface type.

Information from the State

of West Virginia is

italicized. 
Footnotes: Table 1. 0, p. 1

${ }^{i}$ Locke, John. (2010). In Encyclopcedia Britannica. Retrieved July 10, 2010, from Encyclopædia Britannica Online: http://search.eb.com/eb/article-9108465

ii education. (2010). In Encyclopaedia Britannica. Retrieved July 10, 2010, from Encyclopædia Britannica Online:

http://search.eb.com/eb/article-47574

iii Slavery and the Making of America. The Slave Experience. Retrieved July 10, 2010 from http://www.pbs.org/wnet/slavery/experience/education/docs1.html

${ }^{\text {iv }}$ Itard, Jean-Marc-Gaspard. (2010). In Encyclopcedia Britannica. Retrieved July 10, 2010, from Encyclopædia Britannica Online: http://search.eb.com/eb/article-9043037

${ }^{v}$ Pestalozzi, Johann Heinrich. (2010). In Encyclopcedia Britannica. Retrieved July 10, 2010, from Encyclopædia Britannica Online: http://search.eb.com/eb/article-9059406

${ }^{\mathrm{vi}}$ Froebel, Friedrich. (2010). In Encyclopcedia Britannica. Retrieved July 10, 2010, from

Encyclopædia Britannica Online: http://search.eb.com/eb/article-9035478

viieducation. (2010). In Encyclopcedia Britannica. Retrieved July 10, 2010, from Encyclopædia

Britannica Online:

http://search.eb.com/eb/article-47609

viii Darwin, Charles. (2010). In Encyclopcedia Britannica. Retrieved July 10, 2010, from

Encyclopædia Britannica Online: http://search.eb.com/eb/article-9109642

${ }^{\text {ix }}$ U.S. Department of Education. Overview: The Federal role in education. Retrieved July 6, 2010, from http://www2.ed.gov/about/overview/fed/role.html

${ }^{\mathrm{x}}$ Hull House. (2010). In Encyclopædia Britannica. Retrieved July 9, 2010, from Encyclopædia Britannica Online:

http://search.eb.com/eb/article-9041459

${ }^{x i}$ U.S. Department of Education. Overview: The Federal role in education. Retrieved July 6, 2010, from http://www2.ed.gov/about/overview/fed/role.html

xii education. (2010). In Encyclopcedia Britannica. Retrieved July 10, 2010, from Encyclopædia Britannica Online:

Footnotes: Table 1. 0, p. 2

http://search.eb.com/eb/article-281679

xiii Freud, Sigmund. (2010). In Encyclopcedia Britannica. Retrieved July 10, 2010, from

Encyclopædia Britannica Online: http://search.eb.com/eb/article-22604

${ }^{\text {xiv }}$ Montessori, Maria. (2010). In Encyclopædia Britannica. Retrieved July 9, 2010, from

Encyclopædia Britannica Online: http://search.eb.com/eb/article-9053523

${ }^{\mathrm{xv}}$ Terman, Lewis Madison. (2010). In Encyclopcedia Britannica. Retrieved July 10, 2010, from Encyclopædia Britannica Online: http://search.eb.com/eb/article-9071762

${ }^{x v i}$ U.S. Department of Education. Overview: The Federal role in education. Retrieved from Retrieved July 6, 2010, http://www2.ed.gov/about/overview/fed/role.html

${ }^{x v i i}$ U.S. Department of Education. Overview: The Federal role in education. Retrieved from http://www2.ed.gov/about/overview/fed/role.html

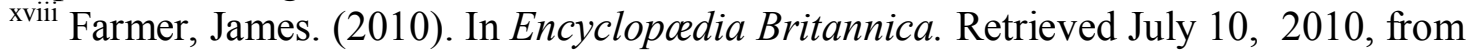

Encyclopædia Britannica Online: http://search.eb.com/eb/article-9399802 
${ }^{\text {xix }}$ Maslow, Abraham H.. (2010). In Encyclopcedia Britannica. Retrieved July 10, 2010, from Encyclopædia Britannica Online: http://search.eb.com/eb/article-9051264

${ }^{\mathrm{xx}}$ Gesell, Arnold. (2010). In Encyclopcedia Britannica. Retrieved July 10, 2010, from Encyclopædia Britannica Online: http://search.eb.com/eb/article-9036614 ${ }^{x x i}$ U.S. Department of Education. Overview: The Federal role in education. Retrieved July 6, 2010, from http://www2.ed.gov/about/overview/fed/role.html

${ }^{x x i i}$ U.S. Department of Education. Overview: The Federal role in education. Retrieved July 6, 2010, from http:/www2.ed.gov/about/overview/fed/role.html

${ }^{x i i i}$ U.S. Department of Education. Overview: The Federal role in education. Retrieved July 6, 2010, from http://www2.ed.gov/about/overview/fed/role.html

${ }^{x x i v}$ U.S. Department of Education. Overview: The Federal role in education. Retrieved July 6, 2010, from http://www2.ed.gov/about/overview/fed/role.html

\section{Footnotes: Table 1.0, p. 3}

${ }^{\mathrm{xxv}}$ Erikson, Erik H.. (2010). In Encyclopcedia Britannica. Retrieved July 19, 2010, from Encyclopædia Britannica Online: http://search.eb.com/eb/article-9032912

xxvi Student Nonviolent Coordinating Committee. (2010). In Encyclopcedia Britannica.

Retrieved July 10, 2010, from Encyclopædia Britannica Online: http://search.eb.com/eb/article9399806

${ }^{x x v i i}$ Freedom Rides. (2010). In Encyclopcedia Britannica. Retrieved July 10, 2010, from

Encyclopædia Britannica Online: http://search.eb.com/eb/article-939976

${ }^{x x v i i i}$ Bruner, Jerome S.. (2010). In Encyclopaedia Britannica. Retrieved July 10, 2010, from

Encyclopædia Britannica Online: http://search.eb.com/eb/article-9016778

xxix Vygotsky, L(ev) S(emyonovich). (2010). In Encyclopcedia Britannica. Retrieved July 9, 2010, from Encyclopædia Britannica Online: http://search.eb.com/eb/article-9473583

${ }^{\mathrm{xxx}}$ U.S. Department of Education. Overview: The Federal role in education. Retrieved July 6 , 2010, from http://www2.ed.gov/about/overview/fed/role.html

${ }^{x x x i}$ U.S. Department of Education. Overview: The Federal role in education. Retrieved July 6, 2010, from http://www2.ed.gov/about/overview/fed/role.html

${ }^{x x x i i}$ U.S. Department of Education. Overview: The Federal role in education. Retrieved July 6, 2010, from http://www2.ed.gov/about/overview/fed/role.html

${ }^{x x x i i i}$ U.S. Department of Education. Overview: The Federal role in education. Retrieved July 6 , 2010, from http://www2.ed.gov/about/overview/fed/role.html

${ }^{\text {xxxiv }}$ U.S. Department of Education. Overview: The Federal role in education. Retrieved July 6, 2010, from http://www2.ed.gov/about/overview/fed/role.html

${ }^{\mathrm{xxxv}}$ U.S. Department of Education. Overview: The Federal role in education. Retrieved July 6, 2010, from http://www2.ed.gov/about/overview/fed/role.html

${ }^{\text {xxxvi }}$ Kent State University. (2010). In Encyclopaedia Britannica. Retrieved July 10, 2010, from Encyclopædia Britannica Online: http://search.eb.com/eb/article-9001987

xxxvii Sesame Street. (2010). In Encyclopcedia Britannica. Retrieved July 10, 2010, from

Encyclopædia Britannica Online: http://search.eb.com/eb/article-9438949 


\section{Footnotes: Table 1, p. 4}

xxxviii Psychology Encyclopedia. T. Berry Brazelton. Retrieved July 10. 2010 from http://psychology.jrank.org/pages/94/T-Berry-Brazelton.html ${ }^{x x x i x}$ U.S. Department of Education. Overview: The Federal role in education. Retrieved July 6 , 2010, from http://www2.ed.gov/about/overview/fed/role.html

${ }^{\mathrm{xl}}$ West Virginia Department of Education, (2010). Policy 2525. Retrieved from WVDE Web county: http://www.k12.wv.us/policies

${ }^{x l i}$ West Virginia Department of Education, (2010). Policy 2525. Retrieved from WVDE Web county: http://www.k12.wv.us/policies

xlii West Virginia Department of Education, (2010). Policy 2525. Retrieved from WVDE Web county: http://www.k12.West Virginia.us/policies

xliii intelligence, human. (2010). In Encyclopcedia Britannica. Retrieved July 9, 2010, from Encyclopædia Britannica Online: http://search.eb.com/eb/article-

${ }^{x l i v}$ U.S. Department of Education. Overview: The Federal role in education. Retrieved July 6, 2010, from http://www2.ed.gov/about/overview/fed/role.html http://www.k12.wv.us/policies ${ }^{x l v}$ U.S. Department of Education. Overview: The Federal role in education. Retrieved July 6, 2010, from http://www2.ed.gov/about/overview/fed/role.html

${ }^{x l v i}$ West Virginia Department of Education, (2010). Policy 2525. Retrieved from WVDE Web county: http://www.k12.wv.us/policies

${ }^{x l v i i}$ U.S. Department of Education. Overview: The Federal role in education. Retrieved July 6, 2010, from http://www2.ed.gov/about/overview/fed/role.html

\section{Footnotes: Table 1, p. 5}

${ }^{x l v i i i}$ West Virginia Department of Education, (2010). Policy 2525. Retrieved from WVDE Web county: http://www.k12.West Virginia.us/policies

${ }^{x l i x}$ West Virginia Department of Education, (2010). Policy 2525. Retrieved from WVDE Web county: http://www.k12.West Virginia.us/policies 


\section{Collaboration}

Collaboration has been a historical phenomenon that has a significant impact on education. Collaboration has evolved and has created innovative practices and ideas that have influenced early childhood education. From Cicero's collaboration with Atticus, his friend and publisher (Halsall, 2006) to today's collaboration in West Virginia among Head Start, West Virginia Department of Health and Human Resources, the LEA and private licensed childcare, collaboration is ever evolving. Henry Ford stated, "Coming together is a beginning. Keeping together is process. Working together is success" (Henry Ford Quotes, n.d., para. 1).

West Virginia policy 2525 (WVDE, 2010) requires collaboration among various licensed childcare providers and agencies. This research will provide a lens through which the collaborative efforts of the participants may be studied. Using interviews, county visits, and observations, I will obtain four perspectives of Universal Pre-K programs. My notes from the West Virginia Universal Pre-k 2010 Summer Leadership Institute, June 21-22 Embassy Suites, Charleston, West Virginia:

At the West Virginia Universal Pre-K Conference held at the Embassy Suites in Charleston, West Virginia on June 23, 2010, Senator Robert Plymale addressed a statewide group of key stakeholders. He eloquently spoke of the vision of Senator Lloyd Jackson's goal to implement quality Universal access to all 4-year old children. He indicated that due to his rural residence, his child was unable to receive quality preschool programming. This served as the impetus of SB 247. Senator Plymale stated, "It is rare in the legislature being able to implement policy and see it through. It's easy to implement a policy, tougher to carry it through...” He continued, “...in 2002 the legislature passed SB 247 as an ambitious goal for early childhood care for all 4 year olds. This would improve overall readiness, decrease 
problems with behavior, attendance, repeating grades and special education placement." $\mathrm{He}$ indicated that the benchmark moment occurred when policy included the mandate of counties to ensure the $50 \%$ collaboration. The intention of the collaboration was to blend funding, resources and services to improve outcomes for children.

A shared mission guides the West Virginia Universal Pre-K collaborative partners through unknown territories when interagency groups work together. Successful collaboration occurs when common goals are established, communications opened, tasks are assigned and completed, concerns are immediately addressed, and remedies are discussed openly as a group. Common goals guide a collaborative team to make collective decisions that will prove to be beneficial for the child.

"Building support for early childhood education requires collaboration, involvement, and a vision of the outcomes. The product of collaboration should be the synergy that occurs where the full complement of stakeholders are involved in the initiative" (Kostelnik \& Grady, 2009, p. 66). Policy 2525 (WVDE, 2010) mandates that collaboration exists in every county in West Virginia. Collaborative teams make concerted efforts to work jointly to achieve the ultimate goal of Universality.

Historically...the term "collaboration" in government has been pejorative, implying consorting with the enemy. It is now better understood as a way of improving services to children and their families in the community. Collaborative efforts...yield greater results and save money long-term. The whole "is more than the sum of its parts." (Cooper as cited by Kostelnik \& Grady, 2009. p. 66)

According to Vodicka (2006), "Research and experience indicate that trust maybe among the most essential elements in developing a true learning community...Consistency, compassion, 
communication, and competence are the key factors in establishing a trusting school climate." (2006, p. 1)

Per conversation with West Virginia State Superintendent, Steven Paine, and "Pre-K may very well be the most important investment we can make in the lives of our economically disadvantaged young children. The preponderance of evidence from research is clear. For every dollar invested at least seven-fold is consistently returned. It is my hope and dream that all eligible children in West Virginia will participate in these life transforming early education programs."

Legislation SB 247 (West Virginia DHHR, 2009) requires each county board of education to establish a voluntary early-education program for 4-year-olds before the 2012-2013 school years. Each school district is expected to submit an annual implementation plan to the Department of Health and Human Services and the state Board of Education, beginning in 2003 2004. Each district must coordinate its plans with existing programs, such as Head Start and private childcare providers, and those existing programs can be counted toward fulfilling the requirements of the legislation. The bill also requires local districts to provide K-12 students with at least 180 instructional days, provides teachers with pay raises and calls for a study of the student-to-teacher ratios in the elementary and middle grades (2009).

General funds for higher education in 2002-2003 will remain nearly the same at $\$ 377.1$ million. The budget includes $\$ 4.3$ million to reduce budget cuts to institutions from 3 percent to about 1.5 percent and $\$ 4.5$ million to help colleges and universities remain competitive with peer institutions in the South. The $\$ 41.4$ million allocated from the lottery includes $\$ 18$ million (no change) for need-based financial aid to full-time students and $\$ 3$ million (up 50 percent) for need-based aid to part-time students. In addition to the $\$ 41.4$ million allocation, lottery funds of 
\$10 million (up from \$5.5 million) will support merit-based PROMISE Scholarships. College and university boards will determine pay raises for faculty.

House bill 4319 calls for a standards-based system to hold schools accountable for their students' academic performance and improvement. It creates the Council to Monitor Student Performance, which comprises members of the Legislative Oversight Commission on Education Accountability, the governor and the chancellor of the Higher Education Policy Commission to track students' academic performance and progress. The bill clarifies the role of the Office of Education Performance Audits, which was created in 1998 legislation to provide independent reviews of schools and school districts. The office will focus on student performance so as not to duplicate other state agencies reviews. The bill also clarifies the Regional Education Service Agencies role of assisting low-performing schools and providing high-quality professional development.

Innovative programs revolve around current professional learning communities (PLCs) to foster collaboration in the educational realm. Confucius observed more than 2,500 years ago, "I hear and I forget, I see and I remember, I do and I understand.” (Dufour, Dufour, Eaker, and Many, 2006) stated, "Most educators acknowledge that our deepest insights and understandings come from action, followed by reflection and search for improvement...collaboration is a means to an end, not the end itself" (p. 1).

Collaboration focusing on children's services has been under the researcher's lens for a long time. Regular educators and special educators have collaborated for a long period. 


\section{Organizational Culture: A Framework}

Edgar Schein. "One of the most prominent theorists of organizational culture"

(Symphony Orchestra Institute, n.d.) defines organizational culture as:

A pattern of assumptions -invented, discovered, or developed by a given group as it learns to cope with its problems of external adaptation and internal integration-that has worked well enough to be considered valid and therefore, to be taught to new members as the correct way to perceive, think and feel in relation to those problems. (Schein, 1985, p. 9)

According to Schein (Shafitz, Ott, and Jang, 2005) in Defining Organizational Culture, culture refers to those elements of a group or organization that are most stale and least malleable. "Culture is the result of a complex group learning process that is only partially influenced by leader behavior" (2005, p.361).

Figure 1 illustrates Schein's three levels of organizational culture. 


\section{Uncovering the Levels of Culture}

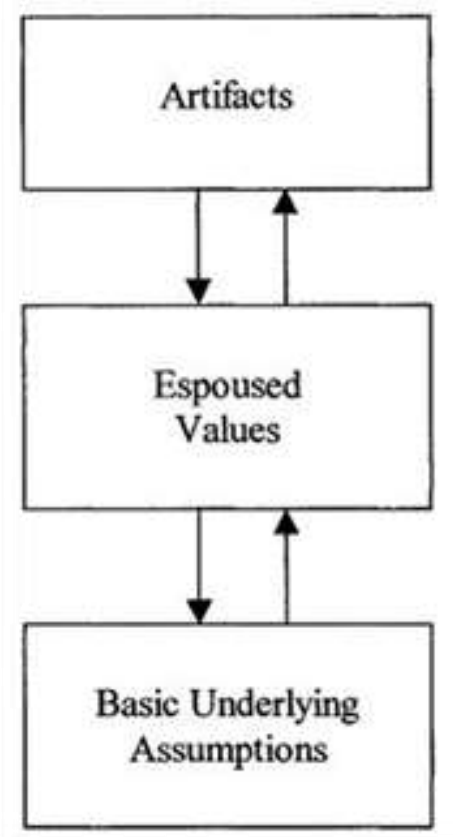

Visible organizational structures and
processes

(hard to decipher)

Strategies, goals, philosophies

(espoused justifications)

Unconscious, taken-for-granted beliefs, perceptions, thoughts, and feelings (ultimate source of values and action)

Figure 1. Schein's Three Levels of Organizational Culture

Retrieved from http://www.fsc.yorku.ca/york/istheory/wiki/index.php/Image:OCT.jpg\#file

Argyris and Schon. According to Argyris and Schon (as cited in Schein, 1985), explicit values may not be identical to "espoused values" (Schein, p.17). Schein stated, "Consensus through social validation is possible" and that "Many values remain conscious and are explicitly articulated because they serve the normative or moral function of situations" $(1985, \mathrm{p} .17)$.

In Argyris and Schon Some Elements of their Models, Dick and Dalmau (2000) explained that Argyris and Schön divide theories of action into two types, "Espoused Theories and Theories in Use. Espoused theories are those, which we know about: which we espouse to ourselves. Theories-in-use are the theories of action implied by our behaviour; they are more likely to be unknown to us." 
Senge. Smith (2001) summarized the key points of Senge's Disciplines.

In his book, The Fifth Discipline: The Art and Practice of the Learning Organization (1990) Peter Senge identifies five disciplines of the learning organization.

Systems thinking

Personal mastery

Mental models

Building shared vision

Team learning

According to Peter Senge (1990: p. 3) learning organizations are:

...organizations where people continually expand their capacity to create the results they truly desire, where new and expansive patterns of thinking are nurtured, where collective aspiration is set free, and where people are continually learning to see the whole together.

Howard Gardner. In Multiple Lenses on the Mind (2005) a paper presented in Bogota, Columbia Gardner clarified his theory of multiple intelligences. Concerning his sixth and seventh intelligence: interpersonal and intrapersonal intelligences, he noted:

The next two intelligences have to do with the world of human beings.

6. Interpersonal intelligence involves the understanding of other persons- - how to interact with them, how to motivate them, how to understand their personalities, etc. This skill is obviously important for people in business, teachers, clinicians, and those involved in politics or religion. 
7. Intrapersonal intelligence is the capacity to understand oneself—one's strengths, weaknesses, desires, fears. Access to one's emotional life is important for intrapersonal intelligence.

Whether or not you have heard of multiple intelligence theory, you have certainly heard of emotional intelligence. What Daniel Goleman means by emotional intelligence is similar to what I mean by the personal intelligences.

\section{Case Study: Uchida}

Uchida (2005) conducted an in-depth study of the process of collaboration between general and special education teachers in an inclusive early childhood education program. This qualitative study was "grounded in cultural-historical perspectives" Uchida (2005, p. 51-52). Uchida describes a vision of the general and special education model of the Educational Center for Young Children and Families (ECYCF) as establishing a collaborative model with a focus on "providing high-quality education to children with and without special needs from diverse families." The mission statement of the ECYCF is:

To enhance the quality of life for children, their families, and the community by providing collaborative and comprehensive services that are inclusive, affordable, and accessible. (p. 2)

The author clearly delineated the development of collaboration among partners. Common goals include sharing a mission including key players, and being aware of the influences involved in a collaborative culture. Blending of resources, funding, and services are at the apex of the collaborative model. As with all successful collaborative models, time is an essential piece of the puzzle. The author values the importance of cultural-historical perspectives (Cole, 1998; Moll, 2000 as cited by Uchida), and stated, "The practice in ECYCF reflects the 
social and historical context in the field" (p. 11). Vygotsky's studies supported this perspective, as he believed the central role to culture and social interaction is the development of complex thinking.

For this study, Uchida examined multi-level collaboration in one classroom located in the ECYCF building. A partnership between the Mental Retardation and Developmental Disabilities (MHDD), Metro Head Start, Council Head Start, the Urban Public School (UPS), and YWCA childcare operate the building. This classroom serviced children from birth to the age of eight. Uchida served as a participant at the ECYCF for four years. The author chose this target classroom after a year of observations and suggestions from the directors. This classroom received blended services from Head Start and MRDD.

Data collection began in February 2004 and ended in June 2005. The author observed a classroom of sixteen children and four teachers. Ten children and two teachers were affiliated with Head Start, while six children with special needs and two teachers were with MRDD. The building was located near a fast growing Midwestern city with a population of approximately 1,000,000. Each teacher had a diverse background ranging from a high school graduate to a Master's Degree in Early Education. The teachers ranged in age from late twenties to early fifties. This study focused attention on the classroom culture and obstacles related to the phenomenon of collaboration.

Uchida defined collaboration as "a relationship between individuals, groups, and organizations in which they work together toward shared goals" (Uchida, 2005, p. 27). According to John-Steiner (as cited in Uchida, 2005), "Collaboration is an intellectual dynamic of joint efforts and themes of connection, fusion, transformation, conflict, and separation that energize joint connections" (p. 27). In order to gain an in-depth understanding of the 
collaboration among the collaborative key players, Uchida triangulated the data to garner a multi-level perspective of the collaborative interactions with the community, the overall building, and the chosen classroom. This qualitative experience allowed the author to garner a rich understanding of the inter-agency dynamics and culture.

Throughout Uchida's four years of participation with the ECYCF, she had the opportunity to witness the inner-dynamics of the adults throughout the building. She was a participant in meetings, activities, and events. Uchida chose to study a diverse classroom at the suggestion of the directors. Uchida (2005) wrote that the purpose of the study is to "analyze some of the complexities and to understand the context and document elements that affected the ECYCF collaboration and to live in a class and understand the collaboration process in implementation" (p. 10). According to Yin (1984), a case study must be conducted "with existing people, not in the controlled confines of a laboratory" (Vol. 5, p. 67). The combination of Uchida's 4-year participation with ECYCF and her understanding of the collaboration provided her with the time and opportunity to collect data without time constraints.

Uchida (2005) conducted both semi-structured interviews and formal interviews with ECYCF key players and members. The semi-structured interviews began in 2002 when the author participated in a research group. During the four months of participation in the research group, semi-structured interviews were recorded. Uchida explained her strategy:

Classroom observations and topics at different meetings were always compared and contrasted in the analysis to relate to the discussions at the meeting to the actual practice. Formal and informal interviews were done for key events to obtain "emic" (Pelto \& Pelto, 1978), or insider perspectives. This process is also considered member check. In addition, data corpus at the leadership and administrative level were included in the data 
analysis of the practice level to compare and contrast the themes and patterns in different layers and contexts within the building.

The author observed the teachers in their classroom environment and attended on-going staff meetings to gain an understanding of the collaborative culture. Teachers were interviewed both individually and collectively to garner an understanding of their personal stories and collaborative responses.

The study conducted by Uchida provides a common connection to (WVDE, 2010). Existing agencies are blending resources, funds, children, and services to develop programs for the best interest of the child. Both entities, policy 2525 (WVDE, 2010) and ECYCF experience challenges from the complexities of the varying collaborative partners and policy. Both entities have established rich and historical programs. The collaboration or joining of programs provides children with an opportunity to receive services from multiple agencies. Throughout the inception of each respective program, relationships have developed, services have been provided, and family needs have been met. Uchida sums it up perfectly, "Leaders came together for the greater good of young children and their families in order to provide seamless service" (Uchida, 2005, p. 142).

\section{Case Study: Grandinetti}

Grandinetti (1998) conducted an in-depth study of the process of collaboration between the Figsboro Elementary School Study Committee and agencies that serve children and families. Developing Collaboration Between the Figsboro Elementary School Child Study Committee and Agencies that Serve Children and Families, her doctoral dissertation for the Virginia Polytechnic Institute and State University is relevant because of its on focus on collaboration among early childhood providers and a local school system. 
Grandinetti (1998) wrote, “A keen interest in collaboration began to develop when investigations were made to identify and make contact with other agencies who could serve or were serving children and families" (1998, p. 1). She wanted to discover "why Figsboro Elementary School was working independently of agencies that serve children and families" (1998, p. 2).

Grandinetti (1998) identified the problem as an existing collaborative situation that she described as "fragmented. (p. 3)." She continued, "As a result of this fragmentation, children at Figsboro Elementary School were not receiving the appropriate assistance needed to ensure success in school" (p. 3).

Grandinetti (1998) identified the purpose for the study.

...to describe the building of effective linkages between the Figsboro Elementary School Child Study Committee and agencies that serve children and families and to reflect on the use of action research by the researcher as a vehicle to create systemic change for the Figsboro Elementary School Child Study Committee. (1998, p. 3)

Her research questions (Grandinetti, 1998. p. 4) focused on "current linkages," and the "barriers" that are "inhibiting collaboration," and the "strategies ... identified or used to minimize the impact of barriers to collaboration." As an action researcher, she also asked (Grandinetti, 1998. p. 4), "What new linkages would be created? in addition, "What skills were acquired by" the participants "in order to implement action research?"

She discovered that the Figsboro Elementary School Study Committee lacked several components that she identified as components of systemic change.

- Leadership

- Action research

- Teams 
- Team effectiveness

- Team building

In addition, during the process of her study, "Criterion problems to define group effectiveness emerged..."

Grandinetti (1998) reviewed the state regulations of the State of Virginia that "requires that a Child Study Committee be established in each public school to assist students who are experiencing academic/developmental, behavioral, or social/emotional problems in the school setting. (Commonwealth of Virginia, 1993, p. vi) (p. 2). She reviewed the history of the policy and mentioned that funding for the policy was created when "Former Governor Douglas Wilder and the 1991 General Assembly appropriated more than \$2.4 million for the fiscal year 19911992 to start dealing with issues of family intervention reviewed and escalating costs (p. 7).

Grandinetti (1998, p. 4) reviewed Mattessich \& Monsey's (1992) research, which identified nineteen factors that influenced the success of collaboration by human service, government, and other nonprofit agencies.

- History of collaboration or cooperation in the community;

- Collaborative group seen as a leader in the community;

- Political/social climate favorable;

- Mutual respect, understanding, and trust between group members;

- Appropriate cross-section of members;

- Members see collaboration as in their self-interest;

- Ability to compromise;

- Members share a stake in both process and outcome;

- Multiple layers of decision-making;

- Flexibility;

- Development of clear roles and policy guidelines;

- Adaptability;

- Open and frequent communication;

- Established informal and formal communication links;

- Concrete, attainable goals and objectives;

- Shared vision;

- Unique purpose; 
- Sufficient funds; and

- Skilled convener (Mattessich \& Monsey, 1992, pp. 12-14).

Grandinetti (1998) provided a theoretical foundation and framework for using action research as a means to create change and to discuss case study in her literature review (p. 7- 19). She cited Merriam (1998), and Maykut \& Morehouse (1996) concerning the natural setting of a study (p. 29).

Grandinetti's research (1998) is relevant to my study because it uses the qualitative method in a case study. I will be investigating participants in their natural settings and "keenly observing what is happening between people and relying on emerging research design" (p. 29). Grandinetti recognized that "themes emerged as barriers but later became strengths for the committee" (p. 60). I will be interested to find out if similar barriers emerge in my study. Grandinetti concluded that her study illustrated the Figsboro Elementary School Child Study Committee moving from an uninformed committee to the status of an informed committee ( $p$. $61)$. 


\section{Chapter Three: Method}

The purpose of this study was to gain an understanding of how collaborative members of West Virginia Universal Preschool Programs described the experience of collaboration. The study answered the following question: How do Universal preschool stakeholders describe their experience of compulsory collaboration?

The outcome of the research has four potential applications. First, policy makers have a need to understand how Universal Preschool programs actually work because their decisions affect the financial resources that support the programs. Second, rich descriptions of how Universal programs actually work will inform superintendents and stakeholder groups. Third, superintendents who have the influence to channel funding directly toward Universal Preschool programs will gain a better understanding of collaboration. The fourth and final application will inform stakeholders of the details of implementation, and the success and challenges facing participants of collaborative groups. Collaborative teams will have the opportunity to use the information to strengthen their alliances.

\section{Qualitative Research Design}

According to Miles and Huberman (1994), as cited by Neill (2007, p.1), in his Research: Key Points in a Classic Debate, Donald Campbell is quoted: "All research ultimately has a qualitative grounding” (1994, p.40). Neill places Campbell's quote side by side with a quote from Fred Kerlinger: "There's no such thing as qualitative data. Everything is either 1 or 0" (1994, p 40). These two quotes capture the soul of the debate between the qualitative and quantitative researchers.

The qualitative researcher is like the student in the Buddhist proverb: "When the student is ready, the teacher will appear." When the themes emerge, the qualitative researcher will bow 
and follow the path. Qualitative researchers have faith that "If we are facing in the right direction, all we have to do is keep on walking."

The quantitative researcher has a GPS system installed on his Landover, a laser equipped sniper rifle, and topological maps of the area he will study, measure and objectify. The quantitative researcher has science. He has binary code. He has a theory to nullify. To design qualitative research the researcher is forced to design a system for a process that is cyclic and open-ended. As Maxwell (2005) pointed out in Qualitative Research Design:

Such models usually resemble a flowchart, with a clear starting point, goal, and a specified order for performing the intermediate tasks. Such sequential models are not a good fit for qualitative research, in which any component of the design may need to be reconsidered or modified during the study in response to new developments or to changes in some other component. In a qualitative study, "research design should be a reflexive process operating through every stage of a project" (Hammersley \& Atkinson, 1995, p. 24). The activities of collecting and analyzing data, developing and modifying theory, elaborating or refocusing the research questions, and identifying and addressing validity threats are usually all going on more or less simultaneously, each influencing all of the others. This process is not adequately represented by a linear model, even one that allows multiple cycles, because in qualitative research there isn't an unvarying order in which the different tasks alternatively, components must be arranged. (p. 2) I have used questions from Maxwell's Model for Qualitative Research Design (2005) 
Before I conducted my research, I answered 12 of Maxwell's questions to assist me in mapping out a plan.

\section{Why is your study worth doing?}

To learn how universal counties collaborate effectively.

2. What issues do you want it to clarify, and what practices and policies do you want it to influence?

The first application is policy. Policy makers have a need to understand how Universal Preschool programs actually work because their decisions affect the financial resources that support the programs. The second application will inform county superintendents through rich descriptions of how Universal programs actually work. Superintendents have the power to channel funding directly toward Universal Preschool programs. The third application will inform Universal Preschool program stakeholders. Head Start coordinators, LEA coordinators, parents, West Virginia Department of Health and Human Services, preschool special needs groups will be informed about the trials, tribulations, and triumphs of the described models. The fourth and final application will inform providers with details of implementation, successes and difficulties or roadblocks that will impede stakeholders groups. This will provide them with the opportunity to use the information to strengthen their current collaborative teams.

\section{Why do you want to conduct this study, and why should we care about the results?} If themes emerge, they will be useful to counties not yet designated as universal. Preschool is the foundation of our educational system.

\section{What do you think is going on with the issues, settings, or people you plan to} study? 
Compulsory collaboration presents challenges as well as opportunities. My study will investigate the issues of onsite collaboration among the providers to see what issues emerge.

5. What theories, beliefs, and prior research findings will guide or inform your research and what literature, preliminary studies, and personal experiences will you draw on for understanding the people or issues you are studying?

Research in the area of compulsory collaboration in West Virginia Universal Pre-k Counties is scant. My personal experience, as both a parent representative, and currently as the county administrator of Pre $\mathrm{K}$ will guide me in understanding the people or issues.

6. What, specifically, do you want to understand by doing this study? How collaborators describe the experience of collaboration.

7. What do you not know about the phenomena you are studying that you want to learn?

I do not know how the process of collaboration works in other universal Pre-k counties. I do not know how they share information and resources to improve services.

8. What questions will your research attempt to answer, and how are these questions related to one another?

How do Universal preschool stakeholders describe the experience of compulsory collaboration?

9. What will you actually do in conducting this study? What approaches and techniques will you use to collect and analyze your data? 
I will visit a site: observe, interview and collect artifacts relevant the process of collaboration.

\section{How might your results and conclusions be wrong?}

Since I will be using emerging themes, the coding process must be carefully designed. I do not know what I do not know.

11. How can the data that you have, or that you could potentially collect, support or challenge your ideas about what is going on?

I support the concept of collaboration and I could discover that individual collaborators are uneven in their participation of the process.

\section{Why should we believe your results?}

- Education and Experience

As a researcher, my credibility rests on my experience, knowledge, and education. I have nine years of experience as an administrator in a county school system. I hold a Bachelor of Arts in Elementary Education with a specialization in Early Childhood, a Master's degree in Elementary Education, and I am a parent of three children. I have two children who have gone through this system and one more that will go through it.

- Data Collection

In Conducting Research Literature Reviews, Fink (2005) noted, "Data collection is the soul of a study. The validity or 'truth' of all research depends on accurate data" (2005, p. 106). The "truth" of the study will stand on the data collected.

- Truth Value

In a section titled Truth Value, Ryan-Nicholls \& Will (2009) noted in Rigour in Qualitative Research: Mechanisms for Control that "According to Guba and Lincoln 
(1989), determination of a given inquiry's 'truth value' is based on the extent to which it establishes how things really are and really work (2009, p. 76). My data will come directly from the participants. I will analyze the descriptions of collaboration provided by the collaborative partners. The "truth value" of my research relied on the quality of my data collection and analysis.

Ryan-Nicholls \& Will continue:

In contrast Sandelowski (1986) posits that the search for truth is much more elusive in qualitative research. In this type of inquiry, truth value is subject-oriented rather than defined by the researcher. Truth is found in the discovery of human phenomena or experiences as they are lived and perceived by subjects as opposed to the verification of a priori conceptions of such experiences (p. 76). The "truth" of my research will be defined by the subjective descriptions provided by the collaborative partners.

\section{Qualitative Research}

In Qualitative, Quantitative, and Mixed Methods Approaches, Creswell (2009)

emphasized the definition of qualitative research.

Qualitative research is a means for exploring and understanding the meaning individuals or groups ascribe to a social or human problem. The process of research involves emerging questions and procedures, data typically collected in the participant's setting, data analysis inductively building from particulars to general themes, and the researcher making interpretations of the meaning of the data. The final written report has a flexible structure. Those who engage in this form of inquiry support a way of looking at research that honors an inductive style, a focus on individual meaning, and the importance of rendering the complexity of a situation (adapted from Creswell, 2007) (2009, p. 3). 


\section{Case Study Research}

In Case Study Research Design and Methods, Robert K. Yin prescribes the case study method when the researcher is asking "how" or "why" questions.

To summarize, the first and most important condition for differentiating among the various research methods is to classify the type of research question being asked. In general, "what" questions may either be exploratory (in which case, any of the methods could be used) or about prevalence (in which surveys or the analysis of archival records would be favored). "How" and "why" questions are likely to favor the use of case studies, experiments, or histories (p. 9).

I chose a qualitative research design to unveil emerging themes among the criterion-based counties.

\section{World View}

Creswell (2009) described the social constructivist worldview in Research Design Qualitative, Quantitative, and Mixed Methods Approaches:

Social constructivists hold assumptions that individuals seek understanding of the world in which they live and work. Individuals develop subjective meanings of their experiences - meanings directed toward certain objects or things. These meanings are varied and multiple, leading the researcher to look for the complexity of views rather than narrowing meanings into a few categories or ideas. The goal of the research is to rely as much as possible on the participants' views of the situation being studied. The questions become broad and general so that the participants can construct the meaning of a situation, typically forged in discussions or interactions with 
other persons. The more open-ended the questioning, the better, as the researcher listens carefully to what people say or do in their life settings. Often these subjective meanings are negotiated socially and historically. They are not simply imprinted on individuals but are formed through interaction with others (hence social constructivism) and through historical and cultural norms that operate in individuals' lives. Thus, constructivist researchers often address the processes of interaction among individuals. They also focus on the specific contexts in which people live and work, in order to understand the historical and cultural settings of the participants. Researchers recognize that their own backgrounds shape their interpretation, and they position themselves in the research to acknowledge how their interpretation flows from their personal, cultural, and historical experiences. The researcher's intent is to make sense of (or interpret) the meanings others have about the world.

Rather than starting with a theory (as in postpostivism), inquirers generate or inductively develop a theory or pattern of meaning. (2009, p. 7)

This research used the case study method with the lens of the social constructivist to establish differences and commonalities among the counties included in the study; their Universal Preschool services; and the experiences of collaboration of the stakeholders at each county. Yin (2009) stated that; "how' and 'why' questions are more explanatory and likely to lead to the use of case study, history, and experiments as the preferred research method" (2009, p. 9).

Figure 2, reprinted from Multiple Case Study Analysis by Stake (2006, p. 5), illustrates the process of case study design. 


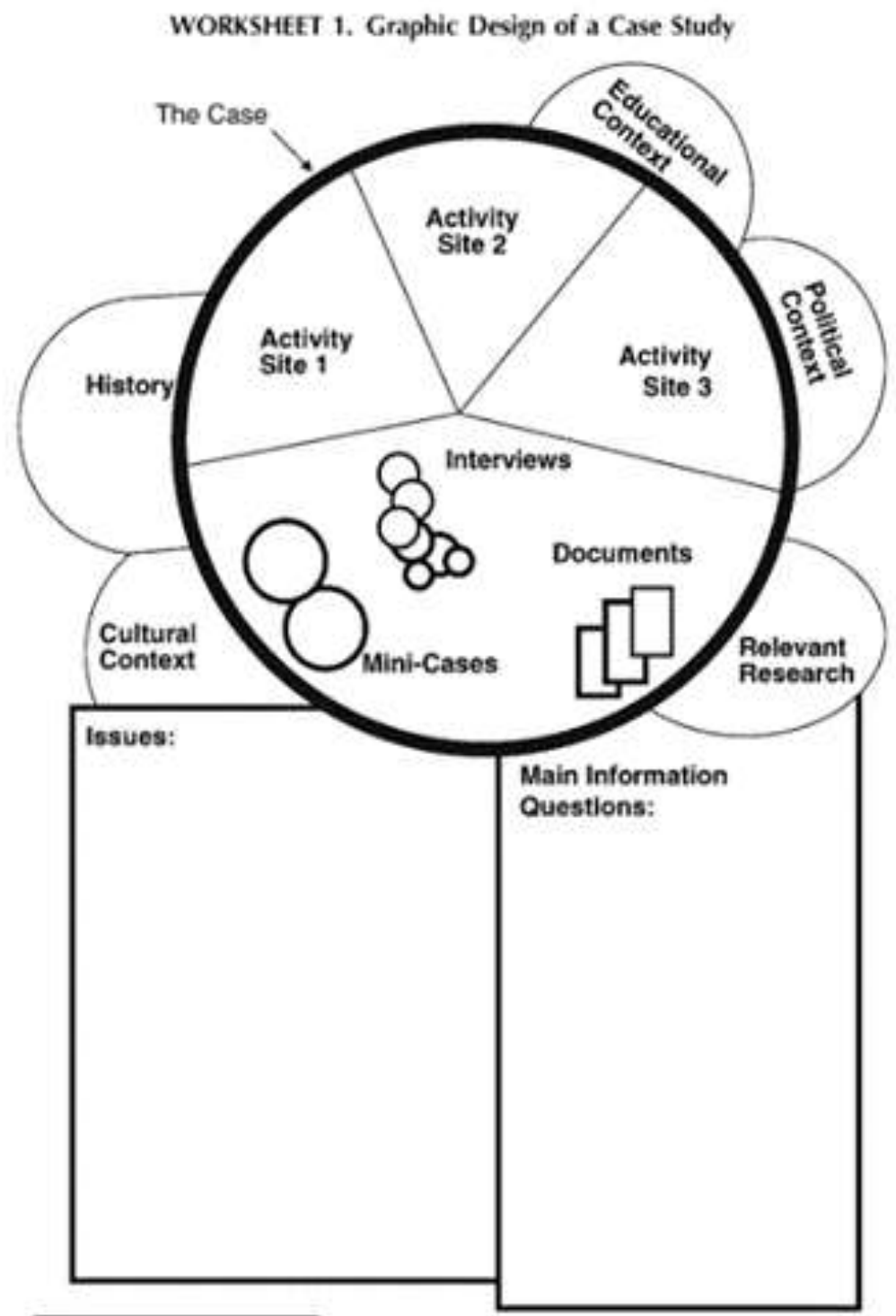

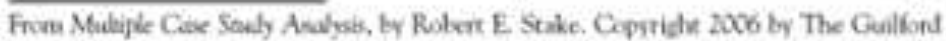
Pres. Permision to photicesy this worksher is granted to purchasers of thas bock for

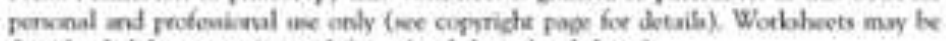

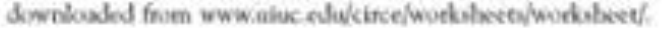

Figure 2. Graphic Design of a Case Study: Reprinted from Multiple Case Study Analysis by Robert E. Stake, p. 5: Copyright 2006 by the Guilford Press. Reprinted with permission. 
I decided to use a descriptive approach for this research. I described the course of events that led to successful collaboration in counties in West Virginia, and the counties and the participants.

Reus (2006) Customization in the Internet Economy explains Yin's (2003) three types of case studies: exploratory, explanatory and descriptive. In exploratory studies the research question or questions and hypothesis are "precisely defined." Descriptive research design requires a theory to guide the data collection, and as its name implies attempts to describe a phenomenon. Explanatory research tries to outline a chronology of events. (Reuss, 2006)

This is a descriptive qualitative case study. It is a descriptive study because I described through interviews real life participants in the ongoing process of collaboration. This qualitative study sought to describe "events at a higher level" (Yin 2009, p. 133). This study investigated how the collaboration has affected West Virginia preschools. West Virginia Policy 2525 requires that $50 \%$ of West Virginia Pre-K classrooms operate in a collaborative setting with Head Start, childcare, or private centers. A strong component of this policy is the ability to interact in a collaborative setting.

As an LEA County Contact, interviewing collaborative team members from Universal counties, my research obtained multiple perspectives of collaborative models. The information from this study lends itself to creating a framework of collaborative models for counties working toward the Universality designation. The state may be able to utilize the descriptions provided by this study to assist in designing collaborative models and future professional development sessions to enhance current county teams.

There are fifty-five counties supporting Universal Pre-K programs in West Virginia. The West Virginia Department of Education currently designated only fifteen counties as Universal Preschool counties (2009-2010 school year). Patton (2002) wrote that in a case study, "The 
researcher serves as the instrument that collects data through unbiased observations, and interviews" (2002, p. 51). I visited counties designated as universal.

\section{Researcher Bias}

In 2001 , I accepted a request by the county board of education to be a part of a select group that would focus on the concept of creating an opportunity to implement Universal Preschool programs to 4-year old children. At the time, my oldest child was four; I was an elementary school teacher, and my husband worked Monday through Friday from 9:00 am to 5:00 pm. A free, quality, preschool program would be an economic advantage for our middle class family. I remember my first thought was "what a wonderful option for children with working parents." The project would include an approved preschool curriculum provided in an academic setting with a certified teacher. This was clearly an advantage for the children in my community, and indeed my own family. In this initial year, my designated role on this committee was as parent representative. I had no idea of the magnitude that this small committee of one childcare representative, one county official, one head start representative, one member of West Virginia DHHR, and me would lay the foundation of Universal Preschool in our county.

The county official scheduled monthly meetings focusing on what the preschool would look like in an academic setting, while incorporating existing services of the Head Start and child-care programs. It was clear that everyone believed it would be impossible to join forces to provide services to children. Territory issues and funding questions loomed large at each meeting with the concept that this initiative would never come to fruition. This group agreed 
that one childcare program would become the county Universal Preschool and parents would partially fund the program. At the conclusion of the year, the initiative did not fade as just another innovative idea.

During the second year of the project, as a new administrator in the county office with a background in elementary education, specializing in preschool, I was chosen to be the county official responsible for preschool. The preschool trend flourished each year with rigorous guidelines and more outside agencies requesting to be collaborative partners. Over the next eight years, the Head Start participation and childcare representation grew to the current team of six licensed collaborative partners including the local Head Start agency. This concept was the beginning of a Universal Preschool that would develop into a program that today services nearly 300 children in sixteen free preschool settings. We became a team focused on designing programs that would prepare our youngest children for success in the classroom. The focus remained on the children, even though many feared that the issues of funding, a lack of child participation, and job security would hinder our efforts.

My experiences over the next eight years helped me to appreciate the power of collaboration. My role as the county official lent itself to involve the collaborative partners to utilize their expertise in various areas. Each partner contributed to the program to meet the needs of all 4-year-old children and 3-year old-old children with an IEP. Over the years, I learned that with respect and patience, the team would design a quality program that provides a solid foundation for every child wanting to partake in the program. My eight years of experience influenced how I view collaboration in a preschool setting. Over eight years, I gained hands on practice in collective problem solving, effective communication, careful listening, and team planning execution. Therefore, my study bias is as the preschool county official. 
I am biased regarding a pro-collaborative stance in this setting. As a participant on the committee that successfully created Universal Preschool; I am a participant who champions collaboration. I am a participant with a serious stake in the success of Universal Preschool. However, my research addressed, not the success of the program (which has already been determined by the State of West Virginia), but investigated the experiences of the Universal Preschool collaborative partners. This research sought to examine the process through which the collaborative members face the challenges of collaboration. Through the narratives of the members, I investigated the working relationships of the collaborative organizations, as well as the affective attitudes of the individual participants. As the instrument, my role was to frame a picture of the collaborative partners, but the members of the collaborative organization created the painting.

Maykut and Morehouse (1994) wrote that:

A posture can be defined as a state or condition taken by one person at a given time especially in relation to other persons or things. This is the meaning of the title of this chapter: A qualitative researcher assumes the posture of indwelling while engaging in qualitative research. This posture (indwelling) is very different from the posture of a quantitative researcher because each research orientation is based on different sets of postulates regarding the nature of the world and the implication of those postulates on the conducting of research. (1994, p. 23)

After reflecting on the concept of Indwelling, as explained by Maykut and Morehouse, I realized that my posture as the instrument was the key to creating authentic dialogue with the stakeholders I interview. I used the two different lenses of the insider and the outsider to focus on eliciting statements that will answer my research questions. 
Clayton Burch, Assistant Director of the Office of Instruction was asked to comment on the current state of West Virginia's Universal Pre-k system.

Collaboration in West Virginia's Universal Pre-k system has continued to grow and morph over the past several years. What was once a goal of $50 \%$ collaboration with community partners has become a new vision of collaboration in which services follow the child instead of the location. In $2010,69 \%$ of classrooms are collaborative with over half of the collaborative programs being with Head Start. What this tells us is that we are moving to a seamless early childhood system where children are being segregated by income less and less. The challenges of collaboration still linger, but the benefits for children drive us all in our 2013 goal for a truly universal pre-k system.

Burch (2010) compiled data of collaboration in each of the fifty-five counties in West Virginia. Figure 4 illustrates the extent of collaboration in all fifty-five counties. Figure 5 from the same source illustrates the collaboration per location for the 2009-2010 school years.

\section{Purposeful Sampling}

Purposeful sampling means a set of criteria written before hand to answer the questions for the research. For sampling techniques, I chose criterion-based purposeful sampling (see Kyungsoon Jeon (n.d.) cited Merriam, 1998, Creswell 1998 and Le Compte \& Preissle (1993) in her qualitative research work: A Teacher's Belief about the Nature of Mathematics and its Manifestation in Teaching Practice. Jeon (n.d., para. 4) concisely and clearly explained, 


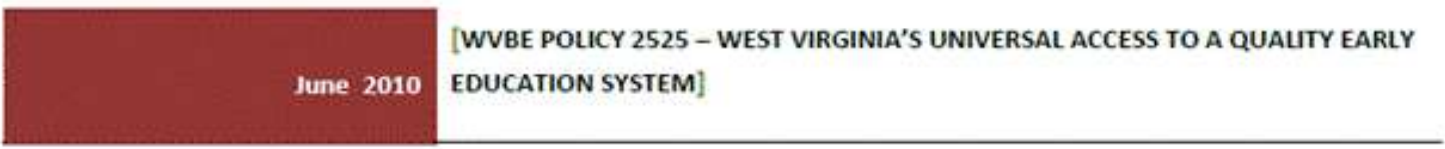

WV Pre-K - 2009-10
Collaboration Summary - from the 2009 County Plans
\begin{tabular}{cr}
\hline Collaboration & Classrooms/Sites \\
\hline CC & 164 \\
\hline Head Start & 487 \\
\hline LEA & 203 \\
\hline PSN & 90 \\
\hline Grand Total & 944 \\
\hline
\end{tabular}

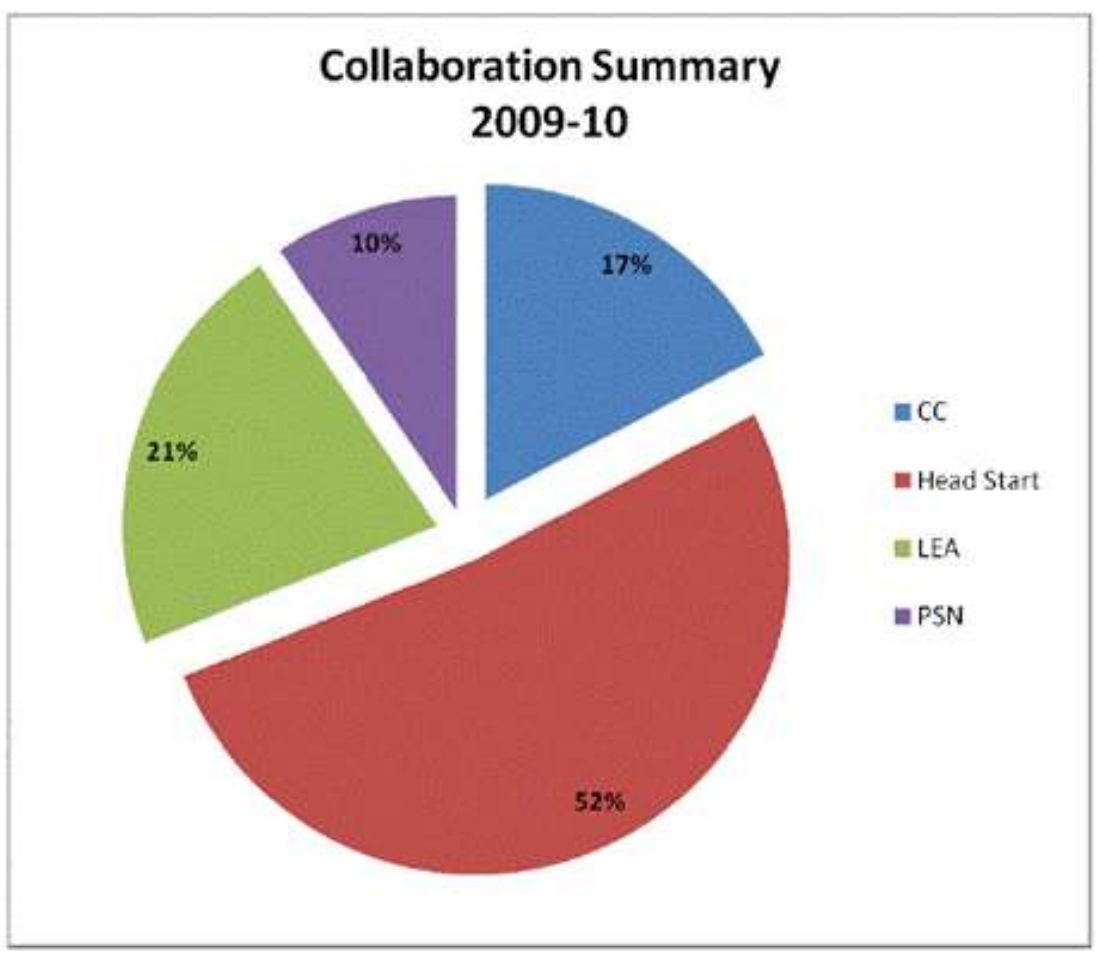

Figure 3. West Virginia's Universal Access to a Quality Early Education System, June 2010 Collaboration Summary (Burch 2010, p. 6) 


\section{Collaboration per Location Summary 2009-10}

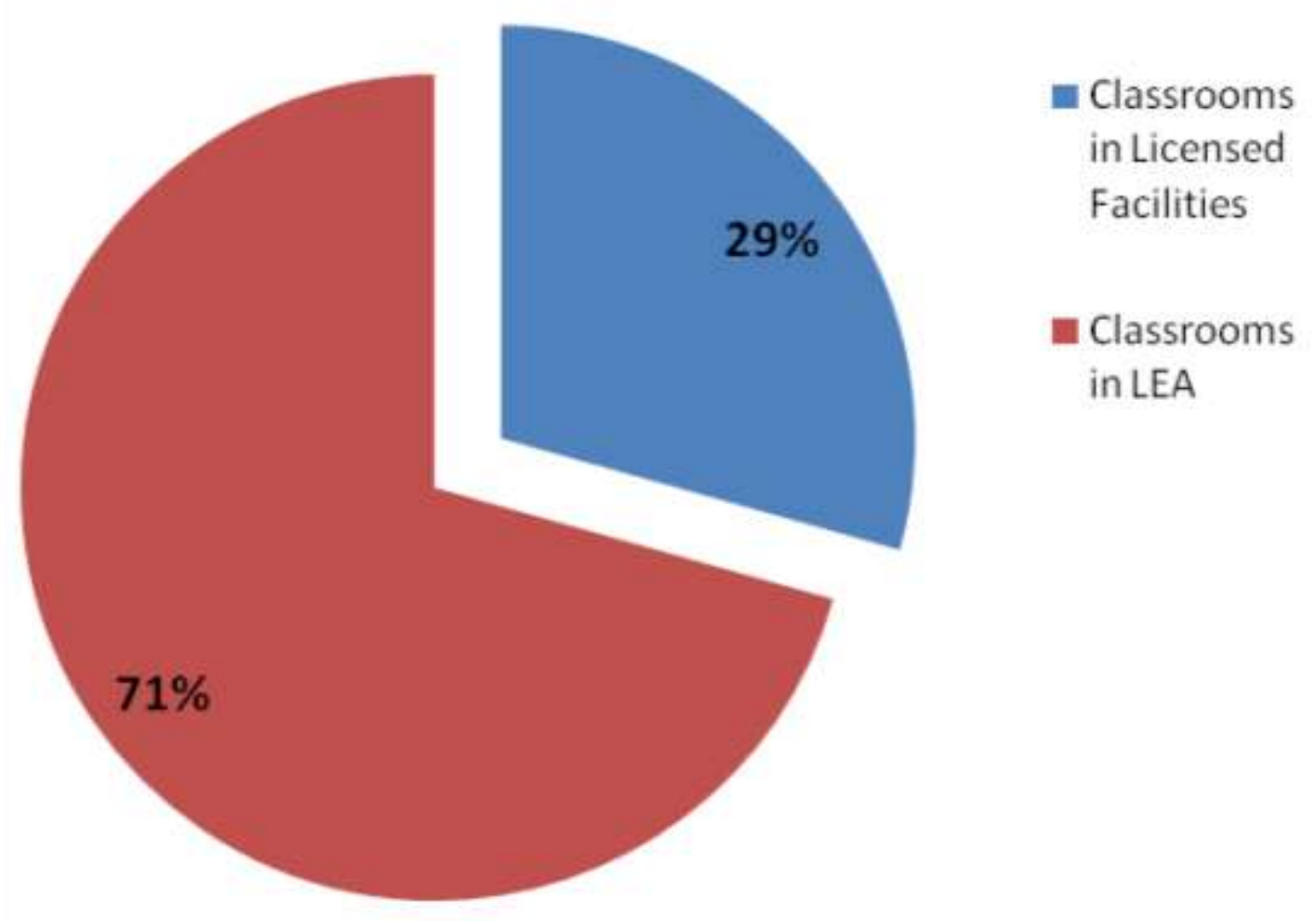

Figure 4. West Virginia's Universal Access to a Quality Early Education System. Collaboration per Location Summary (Burch 2010, p. 7) 
"Purposeful sampling is based on the assumption that the investigator wants to discover, understand, and gain insight and therefore must select a sample from which the most can be learned (p. 61).” In addition, criterion-based selection (LeCompte \& Preissle, 1993): In criterion-based selection you 'create a list of the attributes essential' to your study and then 'proceed to find or locate a unit matching the list.' (p. 70)

First, each county has been designated by the state of West Virginia as Universal (criteria).

Second, each county was purposeful because it provided information on collaboration. Third, I visited each county (convenience). Some universal designated counties had many partners, and some had few. The number of partners of a county was weighed when I made site selection decisions.

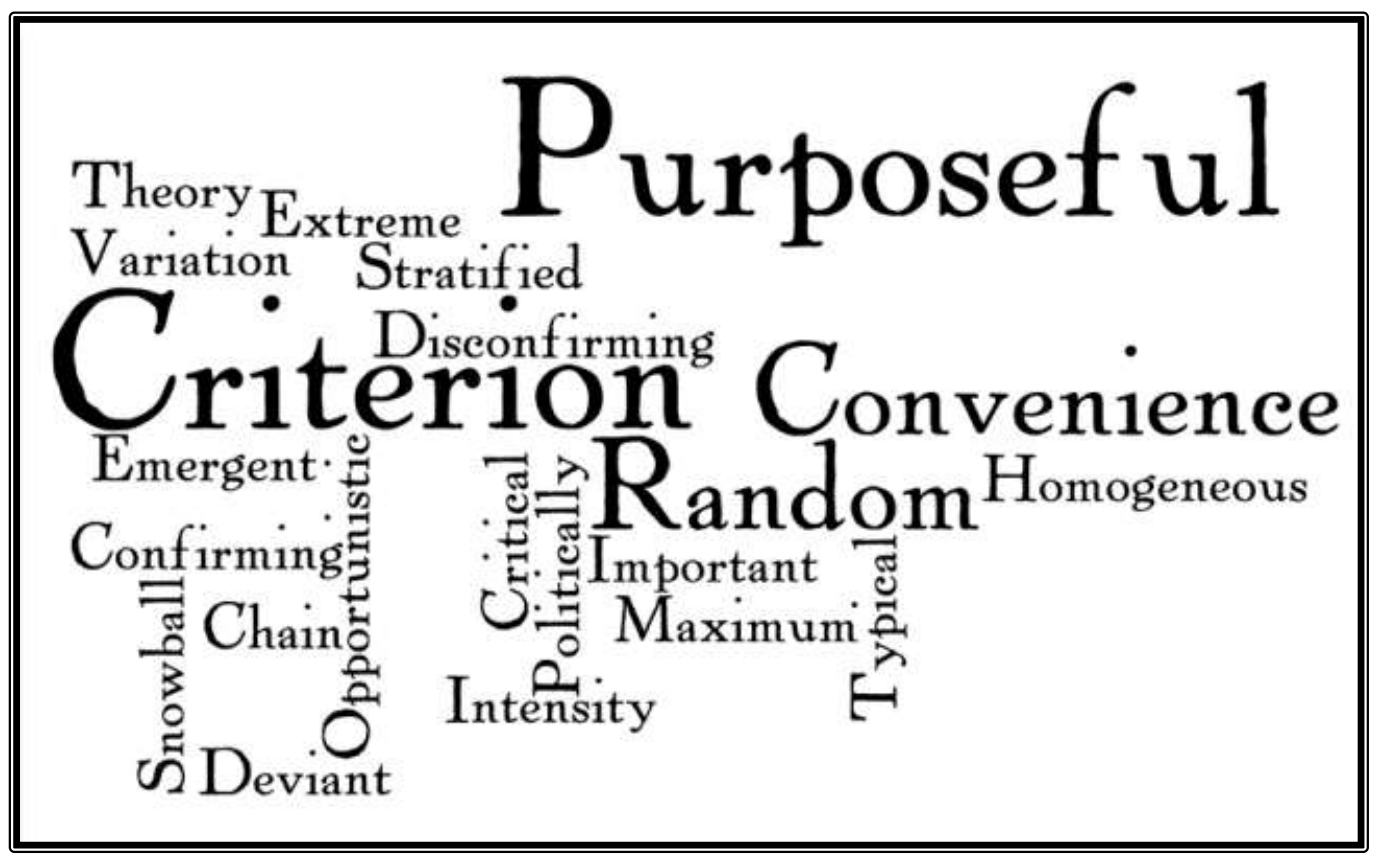

Figure 5. Sampling Diagram: Created by K.S. Miller (Wordle.net) from The Robert Wood Johnson Qualitative Research Guidelines Project, Sampling Page: http://www.qualres.org/HomeSamp-3702.html 


\section{County Selection Criterion}

Counties were designated as Universal Pre-K by the state of West Virginia (WVDE, 2010).

Criterion based. All counties were selected from north-central West Virginia. Each has been designated by the state of West Virginia as Universal (criteria), which requires that contractual agreements with community partners provide no less than $50 \%$ of the classrooms for eligible children. West Virginia Policy 2525 (2002) specifically addresses collaboration and the county plan. Collaborative planning, regular meeting times, responsibilities, and specific key stakeholder membership are mandates listed in policy. The State of West Virginia incorporated these components to assure all parties follow a team approach in order to implement policy 2525 (WVDE, 2010). Collaborative members must maximize resources, funds, staff, and services. These specific guidelines make cooperation feasible for collaborative partners to follow. As of the 2009-2010 school year, 15 counties have been designated as Universal by the State of West Virginia. My criterion-based selection studied a county designated as universal.

Purposeful. All counties were selected from north-central West Virginia. Each county has been designated by the state of West Virginia as Universal (criteria). Each county was purposeful because it provided information on collaboration.

The first county that I visited collaborates with Head Start for 23 classrooms and 6 other childcare centers. I chose this county because of the number of partners involved. The other counties that I chose had fewer partners. 
Convenience. Each county was in driving distance from my home.

\section{Research Participants}

Participants in this study included key stakeholders at each identified county. The stakeholders on each county's collaborative team are:

- the county school system preschool program coordinator,

- the county school system preschool special needs program coordinator,

- a licensed community child care program in the county not operated by the county school system,

- the Head Start program in that county,

- $\quad$ the local department of health and human resources; and

- $\quad$ a parent or guardian of a preschool child West Virginia Policy 2525 (WVDE 2010).

\section{Data Collection}

I visited each county, interviewed the stakeholders, and collected relevant documents. I used Patton's Evaluative Criteria focusing on rigorous techniques in methods for gathering high quality data. Patton recognizes that "issues of quality and credibility intersect with audience and intended research purposes" (1999, Part II, pp. 1189-1208.). Patton's criteria of good research include:

- credibility of the research,

- rigorous techniques and methods for gathering high quality data, carefully analyzed, with attention to issues of reliability, validity and

- credibility of the researchers (training and experience, track record, status and presentation of self), and 
- creative, yet methodical analysis.

Patton reiterates that sufficient detail should be reported to allow others to judge the quality of the resulting product.

\section{Interview Process}

According to Yin (1984), “... the questions are posed to the investigator, not to a respondent. The questions in essence are reminders to the investigator regarding the information that needs to be collected, and why" (1984, p. 70). I observed the interactions, meetings, and conversations of the key stakeholders, and I interacted with the participants.

In order to gain a rich and deep understanding of how the collaboration emerges, I began research in one county. Erikson, as cited by Glesne (2006) stated that through participant observation, you "seek to make the strange familiar and the familiar strange" (p. 50). Glesne continued, "in the end, your new understandings, achieved through your learner's stance, your flexibility, and your emphasis on making the strange familiar and the familiar strange, provide new vantage points with wider horizons, new ways of thinking about some aspect of social interaction" (2006, p. 52).

Yin (2009) delineates five levels of questions in the case study.

Level 1: questions asked of specific interviewees.

Level 2: questions asked of the individual case (these are the questions in the case study protocol to be answered by the investigator during a single case, even when the single case is part of a larger, multiple-case study)

Level 3: questions asked of the pattern of findings across multiple cases

Level 4: questions asked of an entire study-for example, calling on information beyond 
the case study evidence and including either literature or published data that may have been reviewed

Level 5: normative questions about policy recommendations and conclusions going beyond the narrow scope of the study. $(2009$, p. 87$)$

This research utilized Stanford University's Sample Interview Protocol from the NCPI Toolkit ${ }^{\text {i }}$ (complete text of the protocol is available in Appendix A).

\section{Observation Guide}

I developed various forms for observations and interviews, and they are included as Appendix F. These forms assisted me in the observation process. Any particular form was a compass, not a map. The forms were designed to assist me, not tie me down top particular details at all sites.

Rubin \& Rubin's (2005, p. 14) concept of “conversational partner" appeals to me as an interviewer because it mirrors my natural method of interpersonal communication. In addition, their term provides me with a posture that will allow me to try to put my "partner" at ease while I maintain my integrity as a researcher. Rubin \& Rubin (2005) stated that their term:

has the advantage of emphasizing the active role of the interviewee in shaping the discussion and in guiding what paths the research should take. Moreover, the term suggests a congenial and cooperative experience, as both interviewer and interviewee work together to achieve a shared understanding. Keeping in mind that the person being interviewed is a conversational partner reminds the researcher that the direction of the interview is shaped by both the researcher's and the interviewee's concerns.

\footnotetext{
i (Adapted from Stanford University, NCPI) http://www.stanford.edu/group/ncpi/unspecified/student_assess_toolkit/sampleInterviewProtocol $. h t m l)$
} 
The term conversational partner also emphasizes the uniqueness of each person with whom you talk, his or her distinct knowledge, and the different ways in which he or she interacts with you. Some conversational partners are self-revelatory, others more restrained and formalistic. Some need prodding to elaborate; others won't stop talking. Some have keen memories and provide lots of evidence, whereas others speak tentatively or are given to speculative conclusions (2005, p. 14).

The research question I have stated on page six of this document is "How do Universal preschool stakeholders describe the experience of compulsory collaboration?" This question was answered by asking many other types of questions to arrive at the core description of the experience; however, even these questions are not a checklist to be filled in but a "conversational guide" (Rubin \& Rubin, 2005, pp. 147-148) to lead me in the questioning process. After my initial interviews, I chose to amend my "conversational guides" (2005, p .147). Yin mentions this concept as well $(2009$, p. 87$)$.

Rubin \& Rubin (2005, pp. 4-5) use two dimensions to describe the process. They place questions whose goal is to "describe and portray specific events or processes" as having description as their "subject of focus" (p. 5). If the goal of the questions is "eliciting understandings or meanings" (p. 5). They define "meaning" (p. 5) as the subject of focus. The goal of my research is to determine how collaborators describe their experience, so clearly my questions have description as their "subject of focus." The second dimension that Rubin \& Rubin (2005) utilize is "breadth of focus" (p. 5). Rubin \& Rubin They define the "breadth of focus" as being either "narrow or broad" (p. 5). My questions will be "broad" as I try to elicit descriptions from my "conversational partners." 
Rubin \& Rubin (2005) also emphasize that “Overall, qualitative interviewing requires more intense listening than normal conversations, a respect for and curiosity about what people say, a willingness to acknowledge what is not understood, and the ability to ask about what is not yet known" (p. 14). I was aware of this, as I visited sites and scheduled interviews. I completed a number of interviews in one day due to logistics; however, I was prepared to return if necessary.

Rubin \& Rubin (2005) state that "Richness means that your interviews contain many ideas and different themes, often including those that you did not anticipate when you began the study. Richness allows depth interviewers to unravel the complexity of other people's worlds" (2005, p. 134). This posture allowed me to obtain depth and detail in my interviews, but allowed me to be open and alert to that which I had not anticipated.

I interviewed stakeholders in their natural setting at their site at a time convenient for them. I contacted the first local county's preschool chairperson and asked about the feasibility of onsite interviews. I asked if there was a meeting room that would accommodate the interview and provide a comfortable atmosphere. Since I did not know what I would encounter, I was prepared to return to the county to conduct follow- up interviews or seek alternative means of documentation. As the key tool, I was flexible in order to accommodate their needs.

In the ideal situation, I would meet with my conversational partner at a place and time that allowed them to feel comfortable and free to reflect on my conversational guides. I asked the partner directly if this was a good place or a good time, or if they would like to go offsite. I was aware that the partners may be severely limited with time and place, but I was willing to accommodate their needs. In my initial contact with the chairperson, I asked their cooperation and assistance in the timing and the environment of interviews, in the hopes that he or she would 
recommend that best dates, times, and place. I was prepared to encounter conversational partners who would be reticent in their answers, or who may have limited time to spend with me.

Introductory protocol. I prefaced my interviews with the following script:

To facilitate my note taking, under the supervision of Dr. Paul Chapman, I would like to audio tape our conversations today. Please sign the release form. For your information, only researchers on the project will be privy to the tapes, which will eventually be destroyed after they are transcribed. In addition, you must sign a form devised to meet our human subject requirements. Essentially, this document states that: (1) all information will be held confidential, (2) your participation is voluntary, and you may stop at any time if you feel uncomfortable, and (3) I do not intend to inflict any harm. Thank you for your agreeing to participate. I have planned this interview to last no longer than one hour. During this time, I have several questions that we would like to cover. If time begins to run short, it may be necessary to interrupt you in order to push ahead and complete this line of questioning.

Introduction. You have been selected to speak with me today because you have been identified as someone who has a great deal to share about Universal Pre-K in West Virginia. My research project as a whole focuses on the collaboration among partners in Universal Pre-K, with particular interest in understanding the experience, beliefs, ideas, and suggestions of those who participate in the collaboration. My study does not aim to evaluate you or your techniques or experiences. Rather, I am trying to learn more about collaboration among partners, in order to learn about Universal Pre-K.

Interviewee background. The following prompts were used to gather information about the interviewee's background. How long have you been in your present position? 
How long have you been a collaborative partner at this county?

Interesting background information on interviewee:

What is your highest degree?

What is your field of study?

1. Briefly describe your role (Headstart, LEA, childcare etc. as it relates to collaboration.).

Probes: How are you involved in collaboration, how did you get involved?

2. What motivates you to collaborate with partners in your county?

County perspective. The following prompts will be used to gather information about the interviewee's county perspective.

1. What is the strategy at this county for enhancing collaboration?

Probes: Is it working - why or why not?

Purpose, development, administration, recent initiatives

2. What resources are available to collaborative partners for improving relationships? techniques?

3. What rewards do collaborative partners receive for engaging in collaborative strategies?

Probe: Do you see a widening of the circle of participants here at this county?

4. What is changing about collaboration at this county?

Probe: What is being accomplished through county-based collaboration?

What kinds of networks do you see developing surrounding collaborative partners?

5. Have you or your colleagues encountered resistance from collaborative partners, outside agencies or parents to collaboration at this county? 
Department and discipline. This protocol will elicit information about the interviewees' department and discipline.

1. What are some of the major challenges your collaborative team has faced in maintaining Universal status?

Probes: How can barriers be overcome?

3. To what extent is teaching and assessment valued within your discipline.

Collaboration. This protocol will elicit information about the interviewee's experience of collaboration.

1. Describe how collaboration practices are improving at this county.

Probe: How do you know? (criteria, evidence)

2. Is collaboration a major focus of attention and discussion here?

Probe: why or why not? (reasons, influences)

3. What specific new collaborative practices have you implemented at your county?

4. Are there any particular characteristics that you associate with successful collaborative members?

5. What types of development opportunities do you see emerging at your county that focus on building collaborative strategies for the classroom?

Probes: What motivates you to participate in the development of the collaborative steering team at this county?

How frequently do you attend meetings?

How are items placed on the agenda for meetings?

Who designs the agenda?

Who runs the meeting? 
How often are they held?

How long are the meetings?

Where are the meetings held?

Do they feed you?

Are you reimbursed for the cost of attending the meeting? (mileage, lunch)

F. County Description

Post Interview Comments and/or Observations:

Confidentiality. I established the identity of the representative of the collaborative partner.

- Identified county by number.

- Identified collaborative partner by code.

- Identified interviewees with fictitious names to ensure confidentiality. Pre-K chairpersons' were referred to as Pat. Head Start partners were referred to as Harper. Child Care partners were called Chris. Other interviewees were referred to as Ophelia.

Additional counties were visited to meet the needs of the study and the same format was used.

\begin{tabular}{|c|c|c|c|c|}
\hline \multirow{2}{*}{ County } & \multicolumn{4}{|l|}{ Pre-K } \\
\hline & Chair & Head Start & Child Care Collaborative & Other \\
\hline 1 & Pat 1 & Harper 1 & Chris 1 & Ophelia 1 \\
\hline 2 & Pat 2 & Harper 2 & Chris 2 & Ophelia 2 \\
\hline 3 & Pat 3 & Harper 3 & Chris 3 & Ophelia 3 \\
\hline
\end{tabular}

\section{Summary}

This descriptive, qualitative case study investigated a county in West Virginia. Through the lens of case study methodology, I used interviews, direct participant observations and collected relevant documents. The findings were rendered as a highly descriptive picture of how these collaborative members experience their work. 


\section{Introduction}

\section{Chapter Four: Analysis of Data}

The purpose of this study was to give a rich description of how Universal Pre-School stakeholders describe their participation in compulsory collaboration. The study answered the following question: How do Universal Pre-School stakeholders describe the experience of compulsory collaboration?

According to Patton, the process of the study may expose additional questions to pursue. In Qualitative Research and Evaluation Methods (2002), Patton advised the researcher that emerging themes may require "openness to adapting inquiry as understanding deepens and /or situation to change; the researcher avoids getting locked into rigid designs that eliminate responsiveness and pursues a path of discovery as they emerge." Patton called this "Emergent Design Flexibility” (2002, p. 40).

In Designing Qualitative Research, Marshall and Rossman (1999) emphasized the “confusing, messy, intensely frustrating, and fundamentally nonlinear" nature of "real research" (p. 21). They reminded the would be researcher that ...the writer may find it necessary to rewrite the research questions or problem statement after reviewing the literature or to refocus on the significance of the research after its design is developed. Bargar and Duncan's (1982) description of "extensive recycling of concepts and perspectives" (p .2) captures this dialectical process. Our advice is that the writer be sensitive to the need for change and flexibility: Be prepared to rewrite sentences numerous times, not rush to closure too soon, and learn to love the word processor's functions. Sound ideas for research may come in a moment of inspiration, but the hard work is in developing, refining, and polishing the idea- that is, the pursuance of the 
intellectual traditions that surround the idea- and in the methods used for exploring it. (1999, p.24)

This qualitative process validates Marshall and Rossman's (1999) description of qualitative research as a complex and conceptual process $(1999$, p.22). Visiting each county provided me with the opportunity to explore how three West Virginia Universal counties describe their compulsory collaborative efforts. Although I prepared questions to guide my interviews, the complex experience of observing steering team meetings and interacting with key stakeholders framed my findings. My experience of traveling, scheduling, obtaining approvals, and eventually arriving at sites to interview collaborative members certainly confirmed Marshall and Rossman's (1999) description of qualitative research as "confusing, messy, intensely frustrating, and fundamentally nonlinear” (p. 21) experience. That was even before I sat down with pages of transcripts, documents, and files to design and implement the coding cycles. This allowed me to experience what Marshall and Rossman (1999) describe as "a developmental, recursive task "(p. 21).

\section{Overview of the Method}

Although the initial descriptive qualitative case study targeted one Universal county in West Virginia, I studied two additional Universal counties. I investigated how compulsory collaboration has affected West Virginia preschool. In those counties designated as Universal, a minimum of 50 percent of the Pre-K classrooms are required to operate in a collaborative setting with Head Start, childcare, private centers, and the local educational agency (LEA). A strong component of this policy is the ability to interact in a collaborative atmosphere.

As a case study researcher, I interviewed collaborative team members from one Universal county. Evaluation of the data from that initial county prompted me to visit two more 
collaborative models to obtain multiple perspectives of collaboration. Yin (2009) delineates five levels of questions in the case study.

Level 1: questions asked of specific interviewees.

Level 2: questions asked of the individual case (these are the questions in the case study protocol to be answered by the investigator during a single case, even when the single case is part of a larger, multiple-case study)

Level 3: questions asked of the pattern of findings across multiple cases

Level 4: questions asked of an entire study-for example, calling on information beyond the case study evidence and including either literature or published data that may have been reviewed

Level 5: normative questions about policy recommendations and conclusions going beyond the narrow scope of the study. (2009, p. 87)

The second section of this chapter investigated the findings of the three counties based on Yin's levels one, two and three (Yin, 2009). Yin's levels four and five will be addressed in Chapter 5.

In Multiple Case Study Analysis (2006), Stake presents a diagram of the case study method. Figure 6 illustrates Stake's worksheet. Stake suggests that the worksheet be adapted for each separate study. I used the worksheet to illustrate the process of the study. Stake describes the phenomenon studied as a quintain. In this case, collaboration is the quintain being studied and represented by Figure 7. 


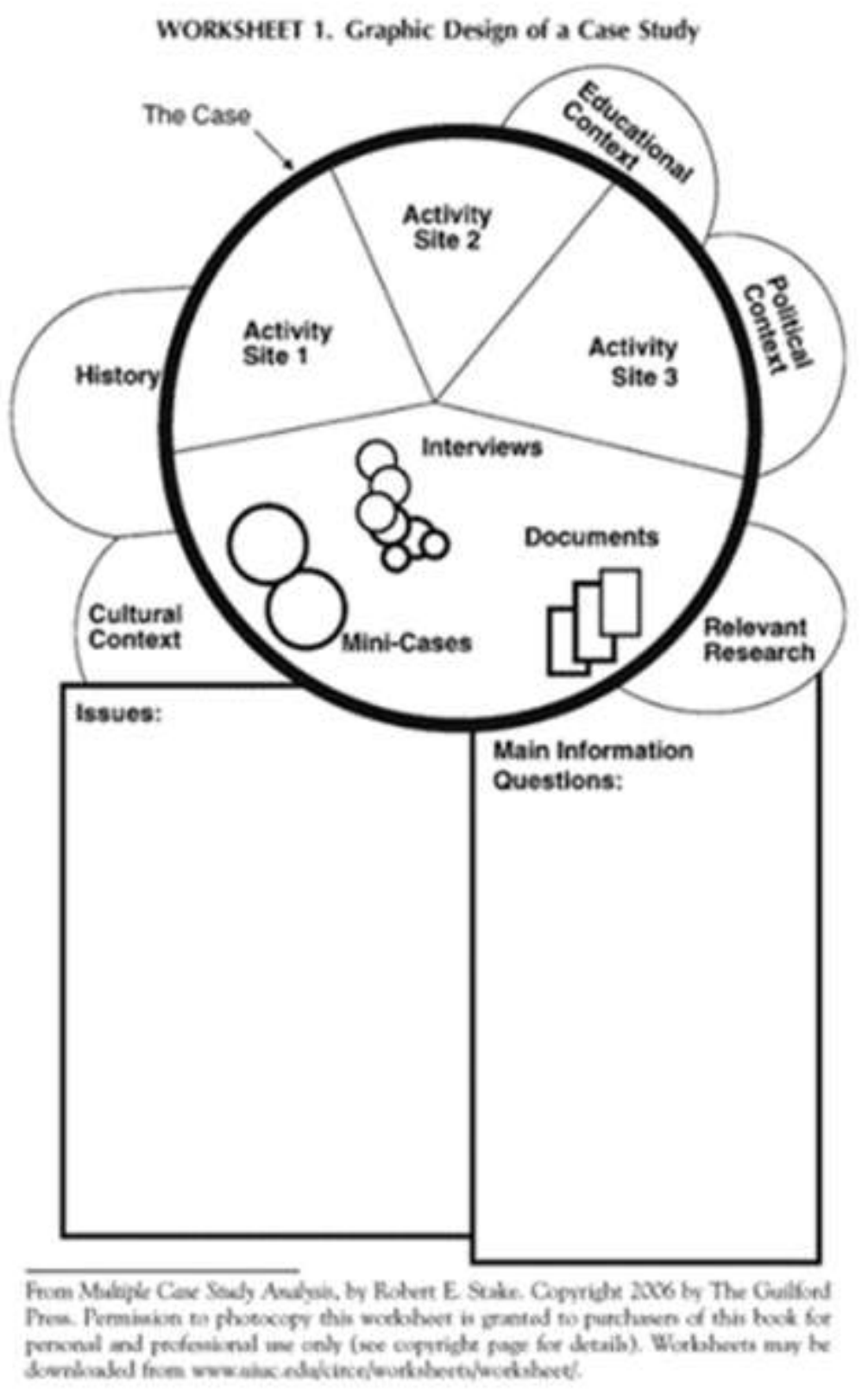

5

Figure 6. Graphic Design of a Case Study: Reprinted from Multiple Case Study Analysis by

Robert E. Stake, p. 5: Copyright 2006 by the Guilford Press. Reprinted with permission. 


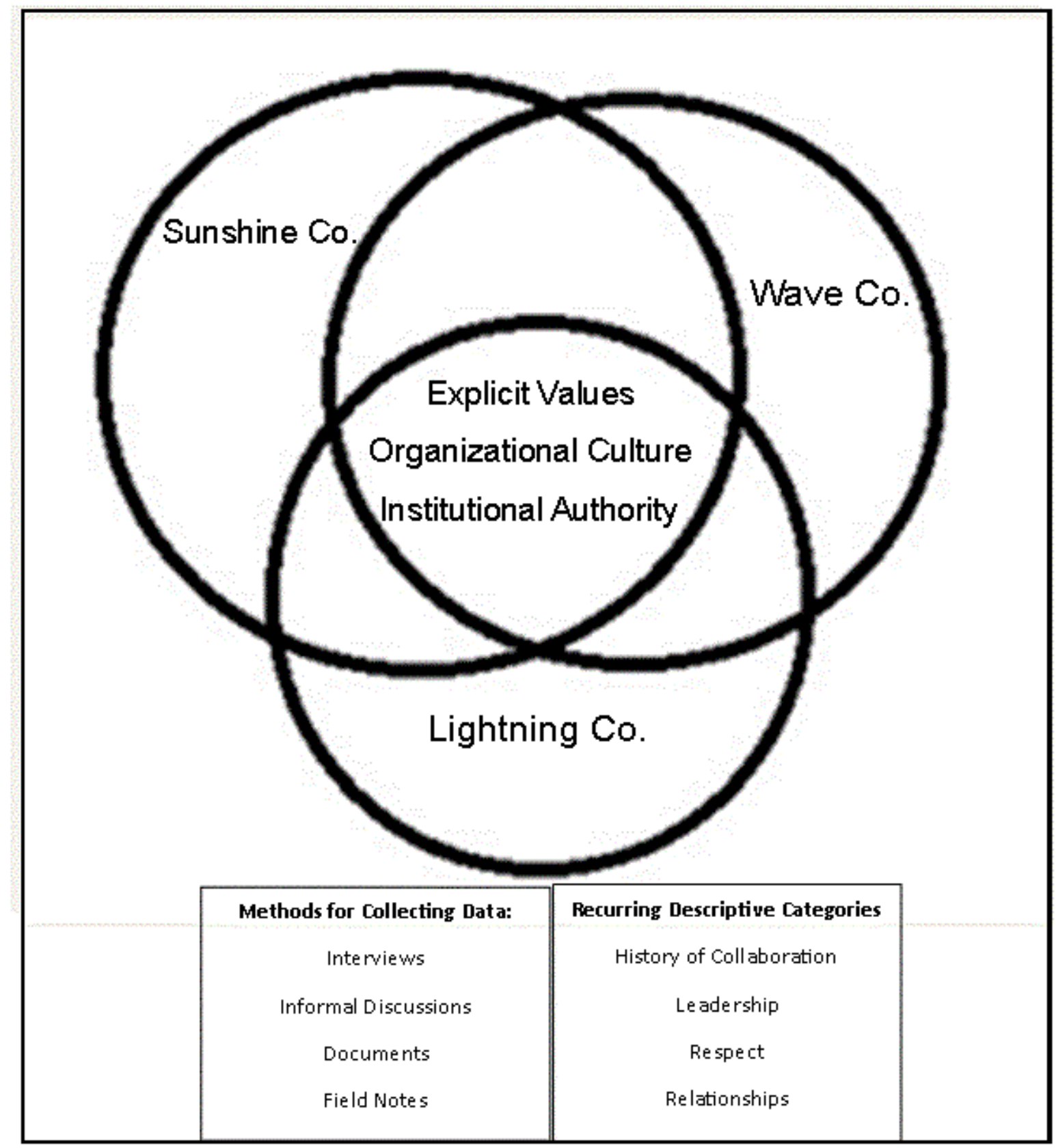

Figure 7. Thematic disposition of descriptions of compulsory collaboration from multiple stakeholders at three different West Virginia Universal Pre-School Counties. Adapted by K.S. Miller from "Multiple Case Study Analysis” by Stake, P.5 Copyright 2006 by the Guilford Press. 


\section{Organization of the Data Analysis}

The case study began with one Universal Pre-K county. The results prompted further investigation of two additional Universal counties that meet the eligibility standard of Universal as designated by the Board of Education of the State of West Virginia.

Each of the following sections presents the data by site name:

Site One: Lightning County

Site Two: Wave County

Site Three: Sunshine County

The first section of this chapter presents a demographic analysis of each county. The second section presents my impressions of the sites. The third section outlines the coding procedures, and the last section presents the findings.

The data has been organized utilizing 13 of Mattessich, Murta-Close, and Monsey’s 19 factors of successful collaboration (2001). While Mattessich, et al placed their factors into six categories, they state, "There is no research significance to the category groupings or to their names" (2001, p.67). I have placed 13 of the factors listed by Mattessich, et al factors into patterns that developed from descriptive categories. Pattern coding was applied to the descriptive coding of the interviews and meetings that were identified through "in vivo" coding. The patterns are by no means completely independent and freestanding. For example, statements identified as communication could fall into one, two, or three different patterns. Patterns were grouped according to themes. The patterns were tabulated by combining interviews and data from each site. Thematic results are presented in a pie chart for each site.

Quotes from the interview transcripts and steering-team meeting transcripts are used in this chapter to illustrate the themes that emerged from the findings, and fictional names were 
given to each county and steering team members. Findings in each county during the qualitative case study revealed commonalities among the three counties.

\section{Presentation of Descriptive Characteristics of Universal Counties}

The case study began with one Universal Pre-K County. The results prompted further investigation of two additional Universal Counties that meet the eligibility standard of Universal as designated by the Board of Education of the State of West Virginia.

Ethnic diversity. The counties are not ethnically diverse. West Virginia's population rate of $6 \%$ minority is larger than the researched sites minority population rates that range from 0.6 to $3.5 \%$ (Sullivan, 2006). Compared to the other 49 states, West Virginia is not ethnically diverse, and the three sites mirror this.

Rural component. All the counties contain large rural areas; only one county contains what could be called a city (population greater than 16,000). Among the three counties, there is one institution of higher learning (Sullivan, 2006).

Home values. A medium home value in the four Counties range from $\$ 61 \mathrm{~K}$ to- $\$ 67 \mathrm{~K}$ (Sullivan 2010), the average U.S. home value is \$167 K (Bloomberg, 2010).

Income. Income levels among the three counties are similar. The homeownership rates among the counties range from $73 \%$ to $83 \%$ (Sullivan, 2006) which is considerably higher than that of the average of $65 \%$ in the US (US Census Data, n.d.).

Age. The median age among the three counties ranges from 39 years to 40 years (Sullivan, 2010), slightly older than the US average of 35 years (U.S. Census Data, n.d.).

Collaborative systems. Lightning County has six collaborative partners. It is located in north-central West Virginia. It boasts numerous parks of scenic beauty and opportunities for outdoor recreation. Sunshine County has one collaborative partner, and boasts of holding recent 
events such as a getaway weekend at an upscale resort, and a culinary contest. Sunshine County also boasts areas of scenic beauty, golf courses, and fishing and hunting opportunities.

Wave County has one collaborative partner. Wave County provides information for relocation and lists 13 separate categories under churches. It advertises itself as "the heart of Appalachia, a community built on the American Dream" (citation not provided) ${ }^{\mathrm{ii}}$. It also boasts of its scenic beauty and recreational opportunities.

Children under the age of five. Figure 8 illustrates the percentage of children under the age of five by county.

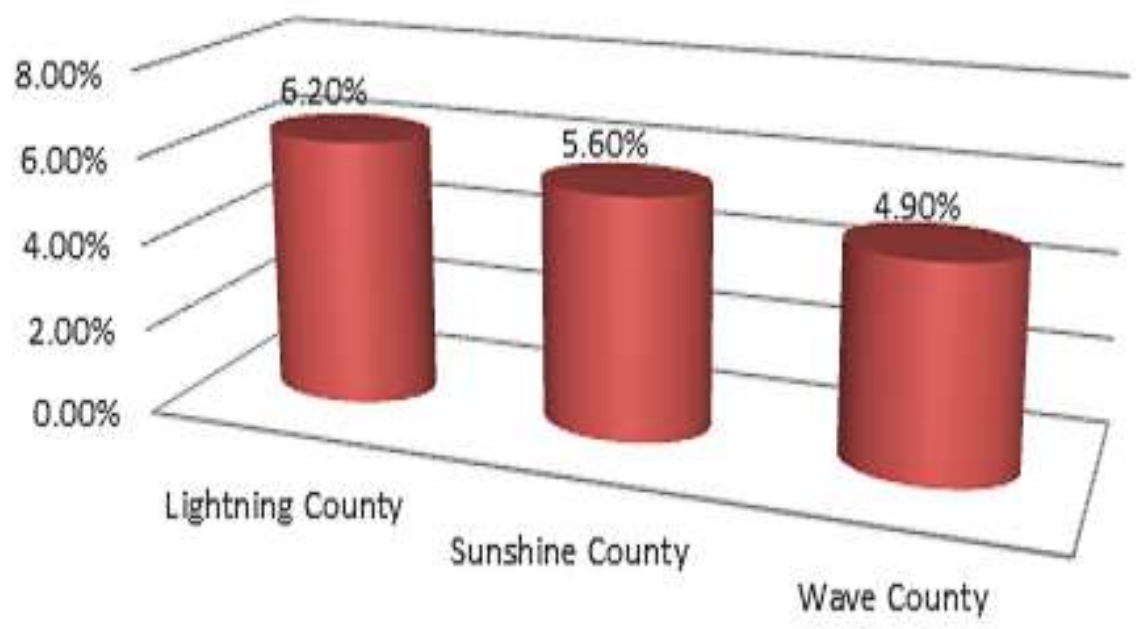

Persons under 5 years old, percent, 2008

Figure 8. Persons under 5 years old, percent, 2008

U.S. Census Bureau; generated by K.S. Miller; from data retrieved May 23, 2010 from http://quickfacts.census.gov/qfd/states/39000.html:

\footnotetext{
ii due to confidentiality issues
} 
Households. All three of the counties have experienced an increase in this percentage from 2002 to 2009 (Data for 2008 was not available).

Of the three counties researched Lightning County is vastly more populated, and has three times as many households as the other two counties, as illustrated in Figure 9.

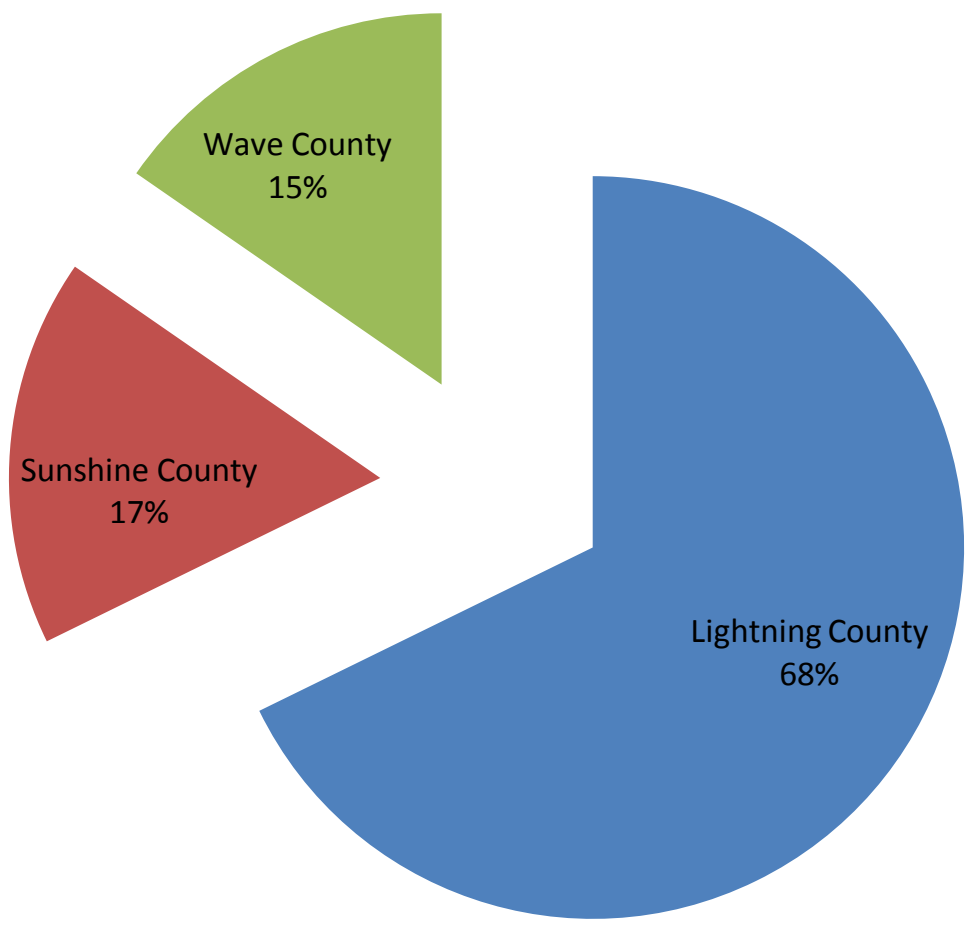

Figure 9. Percentage of Households by County (2000)

_Note: U.S. Census Bureau; generated by K.S. Miller; from data retrieved May 23, 2010 from http://quickfacts.census.gov/qfd/states/39000.html 
Participation rates. Lightning County has a participation rate of $70 \%$ with 39 Pre-K classrooms. Wave County has a participation rate of $63 \%$ with seven Pre-K classrooms. Sunshine County has a participation rate of $83 \%$ with 10 Pre-K classrooms (WVDE, n.d.).

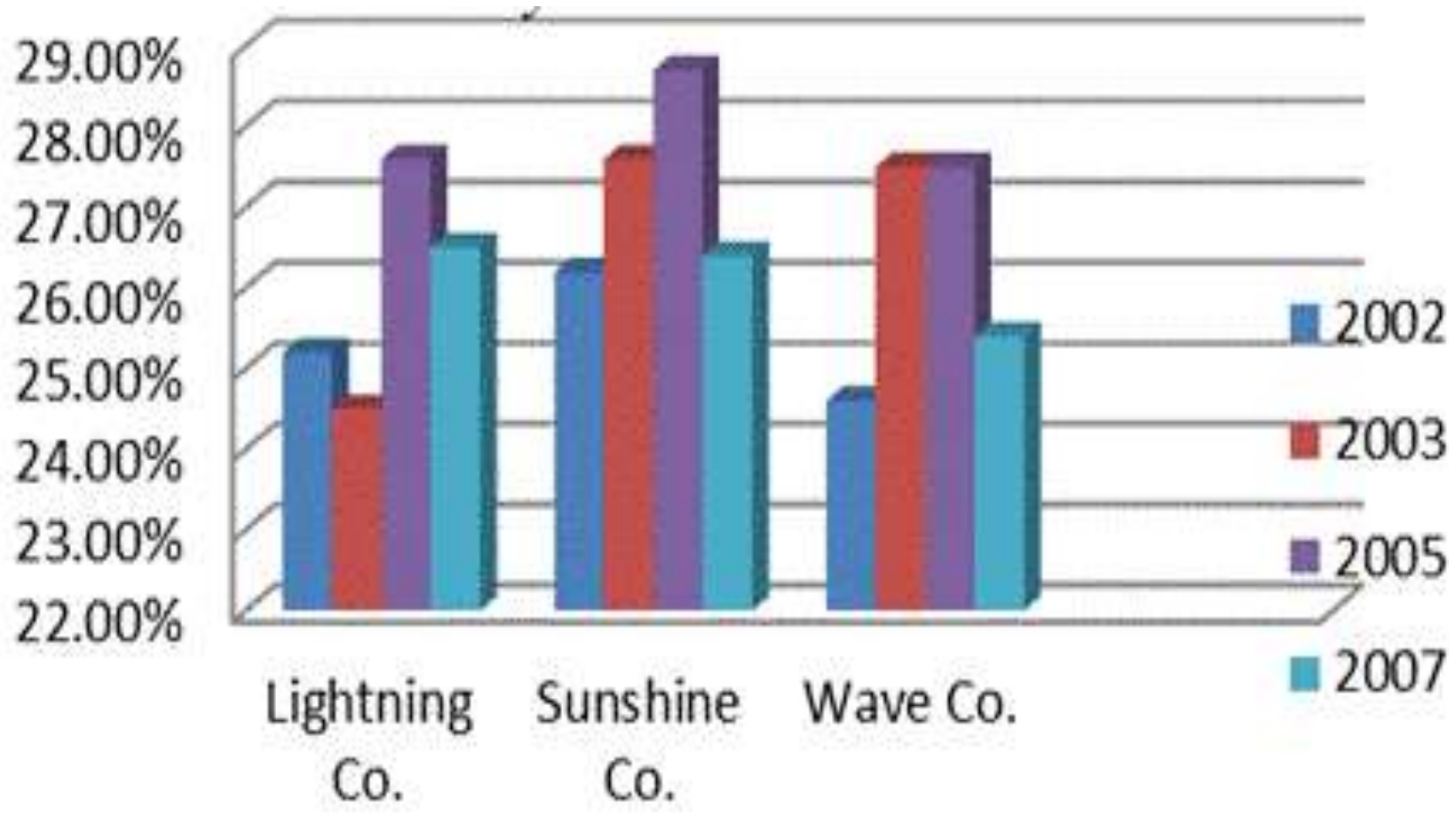

Figure 10. Participation Rates 
Figure 11 highlights the economic differences among the counties.

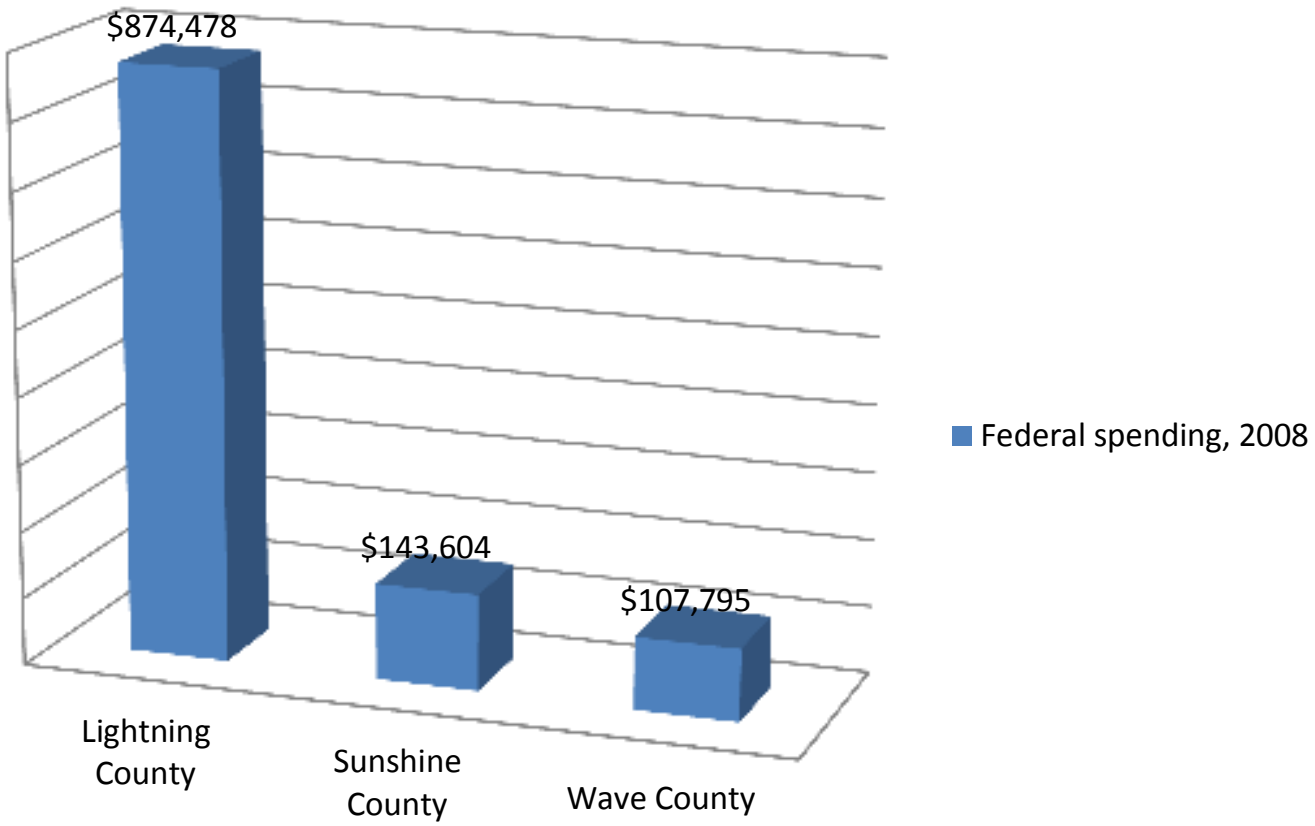

Figure 11: Federal-Spending Comparison (2008)

Data Source: (1990) U.S. Census Bureau. Census of Population and Housing, U.S. Census Bureau; generated by K.S. Miller; using American Fact Finder; $<$ http://factfinder.census.gov>; (16 August 2010).

\section{Researcher Impressions}

Lightning County. I was very nervous before the meeting - I came early and waited in the parking lot reviewing my notes about Lightning County and my target questions. I decided that business casual dress was best in order to talk to the steering team and blend with teachers, 
directors, and Head Start representatives. I started my day with an informal discussion with Pat 1 exchanging ideas and thoughts about Universal Pre-K in general. We then went into our oneon-one interview.

Pat-1 was very cooperative in arranging a time to talk before the meeting. She appeared as a knowledgeable, articulate, and well-educated woman with a great amount of early childhood experience. Her experience includes working in a Head Start Universal classroom. She taught general education and preschool special needs for 14 years in another county. She was very confident and organized. She clearly ran the meeting with a set agenda and working session to place children in Universal Pre-School classrooms for the next school year. She regularly asked for input from her collaborative partners and allowed time for comments and suggestions. Nineteen people attended the meeting and sat at table in a large room. The meeting was held at a neutral site, which was convenient for everyone with plenty of room and little distractions. Pat 1 was very instrumental in this statewide Universal initiative and served on various state committees. Her colleagues throughout the state valued her expertise.

After my interview with Pat-1, Harper-1 entered the room and immediately began to talk informally to Pat-1. She politely introduced herself, and we began our interview before the meeting.

Harper-1 was cooperative and willing to talk about the successful collaboration in Lightning County. It was obvious the positive relationship between her and Pat-1. They spoke informally about their personal lives before the meeting and during the interview restated the close relationship between them. Harper-1 also spoke intelligently about the collaboration and was very confident in her role with the Universal collaborative process. She spoke about the comfort level that had developed between the two collaborators. She stated that she felt free to 
call Pat -1 at any time concerning students or situations, sometimes in the late evening. Harper1 works in multiple counties and indicated that the collaboration in this county is excellent. She had a personal experience with her own child with special needs. Her child did not have the opportunities currently offered from this collaborative effort. Harper-1 was very child centered and was very proud of the outcomes of the Universal Pre-K programs and the mass number of children served due to teamwork. She was very complimentary to PAT-1 and referred to her as a great leader. She stated that the leader does not "sugar-coat" difficult issues.

After the interview with Harper-1many people began to enter the room - they all came into the room, signed in, picked up an agenda, and took their seats. PAT-1 had student folders prepared for each of the sites - it was placement day. They chatted amongst themselves waiting for the meeting to begin - on time. PAT-1 began the meeting, introduced me, and allowed me an opportunity to address the group. Each member was given the permission paper that would allow me to use them in my research and there were no questions. The meeting was well organized and PAT-1 clearly was in charge of the meeting. She allowed opportunities for others to comment. It was well run and very direct. The actual meeting concluded and a work session began to work on child folders for the upcoming year. After the meeting, I had the opportunity to talk to Child Care Director Chris-1.

I met with Chris-1, a Child Care Director of 37 years. She was very eager for someone to listen to her story and spoke of the collaboration as a program that has grown. She initially did not become a Universal site until the Senate Bill passed. She referred to her continual concerns with funding. I received the impression that prior to the current LEA Representative, Chris-1's relationship with the Universal team was not as strong as it has become under the new leadership. She found the blending of Head Start/school/child care to be a positive thing. She 
indicated that new childcare sites approach her for advice because of her longevity in childcare and her relationship with the Universal Pre-K. My impression was that she appreciated being a collaborative partner but had financial concerns and has had curriculum concerns. She made significant changes in her program to adhere to policy.

Wave County. What a day. It rained during the entire drive to the county. We planned to meet in a neutral site that was equipped for professional development training for teachers and set up for meetings. I was greeted by the receptionist and waited patiently because I was early. After the Harper 3 (the Head Start representative) came in, she led me to the conference room, and we began our interview. She maintained a formal posture, but was cooperative and forthcoming. She exhibited a positive attitude towards collaboration. At the conclusion of our interview, Pat-3 (the LEA Representative) entered the room; she appeared very open as well. They answered some questions jointly and they appeared to be on the same page. It was a very non-threatening environment and they complimented one another. Pat 3 (the LEA Representative) exhibited what I interpreted as intelligence, and explained that she was relatively new to her position. She relied on the expertise of other collaborative members. The LEA Representative (Pat-3) reports everything to the Board of Education. There were no Child Care Representatives on the steering team. At this particular meeting, there was one Head Start member and the LEA representative. The three women attacked issues jointly and seemed to work together. They had a set agenda and speak regularly. The Special Education Director was very articulate and interjected regularly. They appeared to work well together.

Sunshine County. Once again, I drove to a place not familiar to me. I relied on my GPS to find the location of a restaurant, which I found to be a little different. I entered the establishment, and I was greeted warmly by the LEA Representative (Pat-2). She was very 
happy to see me and asked me about my drive. I had driven for hours, and had not been sure where I was going, so I was relieved to arrive and was met by a welcoming LEA representative. A room was set up with a long table. Many people entered the establishment. They came in and talked to one another informally. It appeared to be a non-threating environment. This was the first county to have men in attendance, and I was eager to hear their input. The LEA director (Pat-2) thought it was best to hold a group interview following the meeting and I was looking forward to the interview. A group meeting was held with a sign-in sheet and a prepared agenda. The LEA Representative (Pat-2) ran the meeting, but allowed others to interject freely. She encouraged others to report to the group concerning policy pieces including ECERS-R (Early Childhood Environmental Rating Scale Revised, a policy-required instrument to assess the environment in the Universal Pre-K classroom).

The LEA Representative mentioned that this was her last meeting. The group applauded her for her dedication to the initiative. I sat off to myself trying to absorb as much information as possible. The dynamics appeared positive and everyone seemed willing to help each other.

Agenda items included playground grants and ECERS-R, the policy required assessment tool. This is a county with a great amount of collaborative history. They had jointly confronted and conquered issues (transportation), and have a history of problem solving. They each believed that their success is due to their collaborative efforts. They ate lunch, joked with one another, and talked about their plans. I did not observe any animosity among the members of the group.

The group interview was very positive and members complimented the LEA Representative (Pat-2) for her hard work. They met during lunch because it made people comfortable and more willing to attend. A member stated that more people attend because the 
meeting was conducted during lunch. I was most impressed with a board member who was an active steering team member with multiple views of the collaboration. He serves as a board member, but is also involved in the private sector of education. He stated that he was asked to be a steering team member and was surprised to see how well it worked. He also commended Pat-2 for her leadership. The group appeared friendly and unified. The dynamics indicated that longterm relationships had developed over the years.

\section{Coding Procedures}

I chose the Coding Manual for Qualitative Researchers by Johnny Saldana as my guide to coding procedures. Cooper, R. (2009) In Decoding Coding via The Coding Manual for Qualitative Researchers referred to Saldana as "the Dan Brown of qualitative research," for his succinct explanations of first and second cycle coding methods, and his focus (2009, p. 1). In chapter three (p. 48) of this document, under the heading Data Collection, I wrote, "Until I have completed my research, and compiled and coded my data, I will not be able to address this issue thoroughly."

In order to determine which coding methods I would use, I researched a number of books on the subject. I read reviews of the various coding manuals, and discovered a coding manual that received positive reviews for its clarity. The Coding Manual for Qualitative Researchers by Johnny Saldana received high reviews. I researched Mr. Saldana on the web, and at first, I thought there must be two different Johnny Saldanas with books published in academic areas. I finally determined that Saldana was a professor of film and theatre at the Herberger Institute for Design and the Arts at Arizona State University. I remained skeptical until I was able to spend some time reading Saldana's manual. 
After repeatedly reading various chapters of Saldana's coding manual I made lists of the coding methods I thought would be appropriate. I listed them in various sequences. Once I found the formula that I was sure would best provide a model for coding, I applied it to the data that had been inserted line by line into excel spread sheets. As I applied each level of coding to the data, it became clear that I had not found the winning combination of methods and sequencing. Only after the application of various methods in various orders, did I finally discover the sequencing and methods that I chose to employ. Eventually I decided on the following coding methods and sequences (Saldana, 2010).

First Cycle

1. In Vivo

2. Descriptive

Second Cycle

3. Pattern

4. Pattern

The coding process is illustrated in Figure 12 (p.91).

Recorded interviews and meetings were transcribed into text, and each line was numbered. The text was then inserted into an excel spreadsheet (one for each county). Columns to the right of the text were labeled: In Vivo / Descriptive Category/ Patterns A/ Theme A /Pattern B/ Theme B/ Pattern C/ Theme C. For more detailed information regarding coding please refer to Table 2, p.1 in Appendix G. 


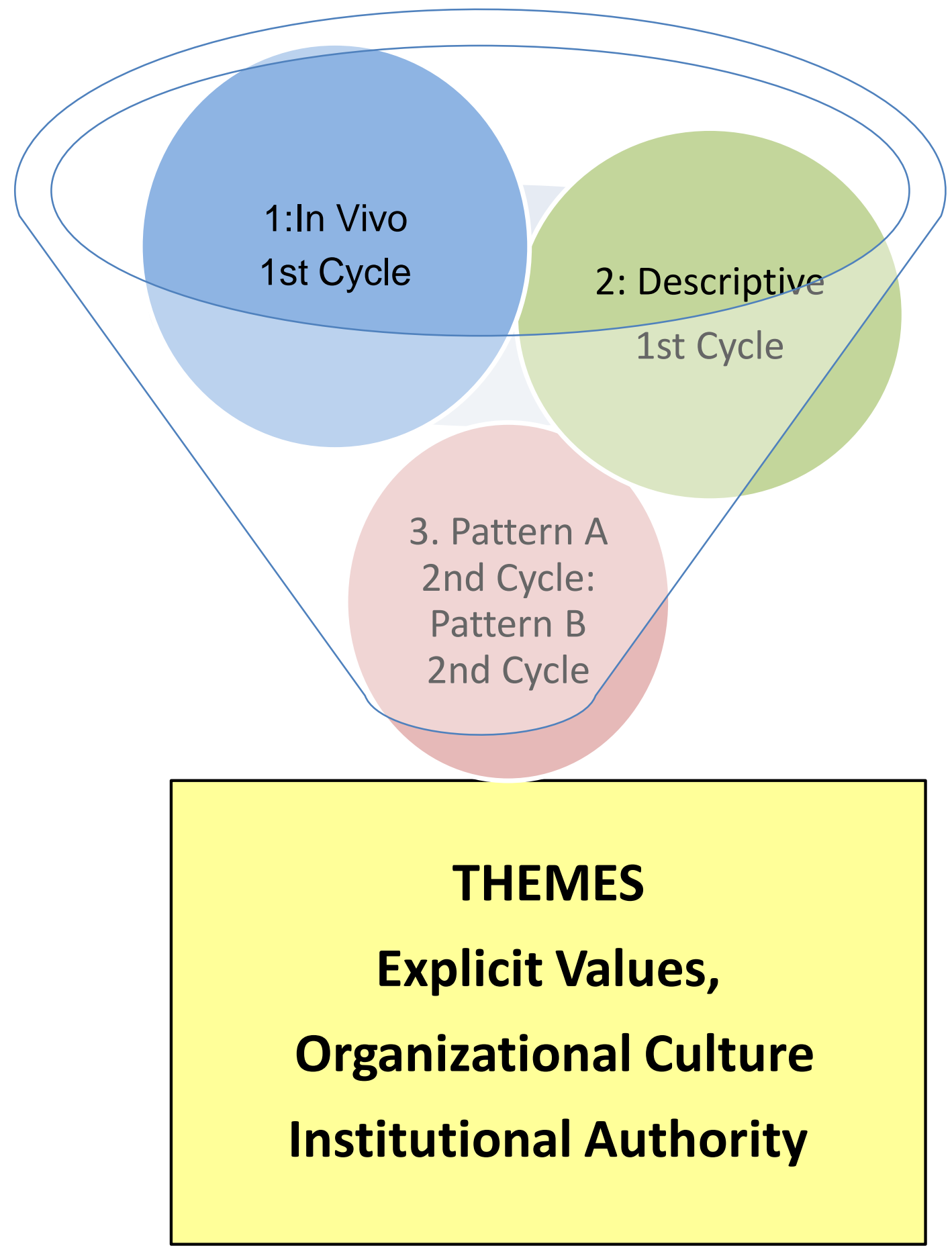

Figure 12. Coding Process: Themes and Patterns 
Theme: Explicit Values. Explicit Values refer to those responses that represent an individual's personal values.

Theme: Organizational Culture. Organizational Culture refers to those responses that represent values shared at that individual site.

Theme: Institutional Authority. Institutional Authority refers to those responses that are imposed by governmental entities.

Patterns: Explicit Values (personal).

1. Mutual Resources, Understanding and Trust

2. Ability to Communicate \& Compromise/Flexibility

3. Shared Vision

4. Open and Frequent Communication

Patterns: Organizational Culture (organization wide values).

1. History of Collaboration

2. Concrete/Attainable Goals \&Objectives

3. Collaboration in Self-interest

4. Open and Frequent Communication

5. Partners/Members

\section{Patterns: Institutional Authority (required by governmental agencies).}

1. Policies/Procedures/Guidelines

2. Open and Frequent Communication

3. Skilled Convener

4. Resources

The themes emerged from the pattern coding applied to the descriptive categories of the interviews and meetings that were identified through "in vivo" coding. The patterns were not completely independent and freestanding. For example, statements identified as communication could fall into one, two, or all three patterns. 
The themes were tabulated by combining interviews and data from each site. The results are presented in Figures 13, 14, and 15... An example of the coding process is provided in Appendix G (page 2).

\section{Findings: Emerging Themes}

Quotes from the interview transcripts and steering team meetings transcripts were used in this chapter to illustrate the themes that emerged from the findings. Fictional names were given to each county, and to steering team members. I changed any words in the quotes that might lead to identification of participants. Findings in each county during the qualitative case study revealed commonalities between three counties that have received the designation of Universal.

Sampling of representative statements from interviews. The sampling statements are listed as follows:

1. We work well together, there are no barriers, and success is going to be that the students are going to get the services they need.

2. There is a mutual respect on a professional level and on a personal level...it's not just a job, not just a paycheck, it's seeing that children get the services they need.

3. I see that we are stronger...I see the pluses of working as a team because everybody wins especially the children by working together instead of the child care is here, the board of education is over here and the Head Start is over here. We are all just LIGHTNING County.

4. The rewards of the collaboration is (sic) that we are servicing every four year old that wants service. That is a big reward.

5. It is all about that relationship building.

6. It just happens, it's just automatic. We are one committee. One team.

7. We don't really say "Oh we got to make sure that we are really collaborating with this, "we just do...it was built with the foundation of this program. It is not something new that we have to make sure we are collaborating.

8. Communication and rapport building are essential because at this point we have built such a relationship on a professional level I could call any of these people and ask them for something and it would happen. And on a personal level, I could call any of these people and say I need a favor can you help me out?

9. One reason we have moved along so smoothly is because we started Universal PreSchool as a collaborative program before we were told we had too. If you do it because you want to do it and it is the best things for kids, it is usually accepted a lot better just because we want to do it.

10. If we try to move forward in isolation, were just not going to get where we need to be, 
we are not going to be able to provide the services that we do.

11. When you are going to have success when you come together and stay together and I think that has been a key component in why, well one reason why, this particular county received Universality so early...we made a commitment to know we are going to make this work and we are going to get together.

A sampling of coded representative statements may be found in Appendix G (p.3-4).

\section{Emerging Themes by County}

Findings in each county during the qualitative case study revealed commonalities between the three counties. What follows is an account of the revealed commonalities.

It is important to note that in Sunshine County (Figure 13) a group interview was recorded and coded using the same procedure as the other two counties. However, since the group meeting comprised ten members, and participants introduced themselves, and stated for the record how long they had been involved in collaboration, the number of responses coded as history of collaboration (Organizational Culture) outnumbered all other coded responses.

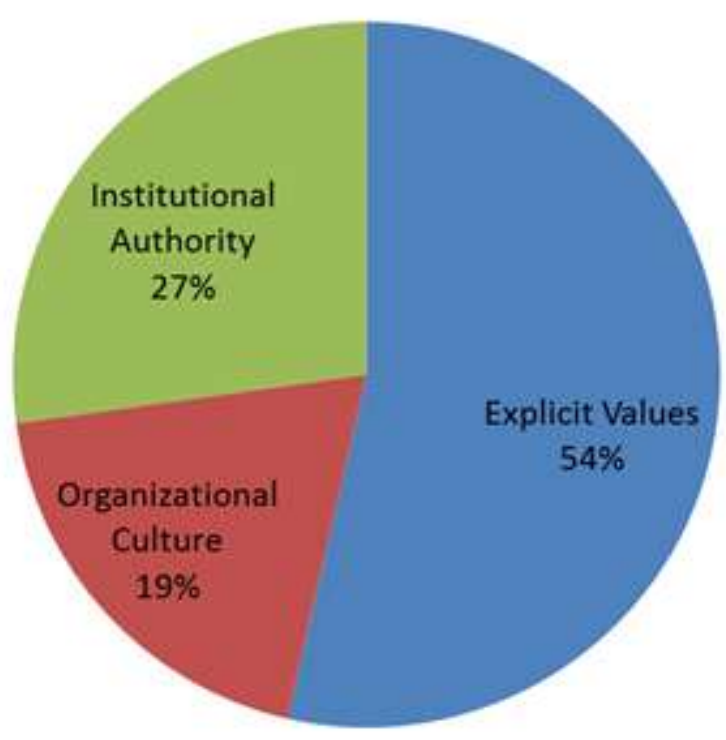

Figure 13. Lightening County, Percentages of Responses by Theme 


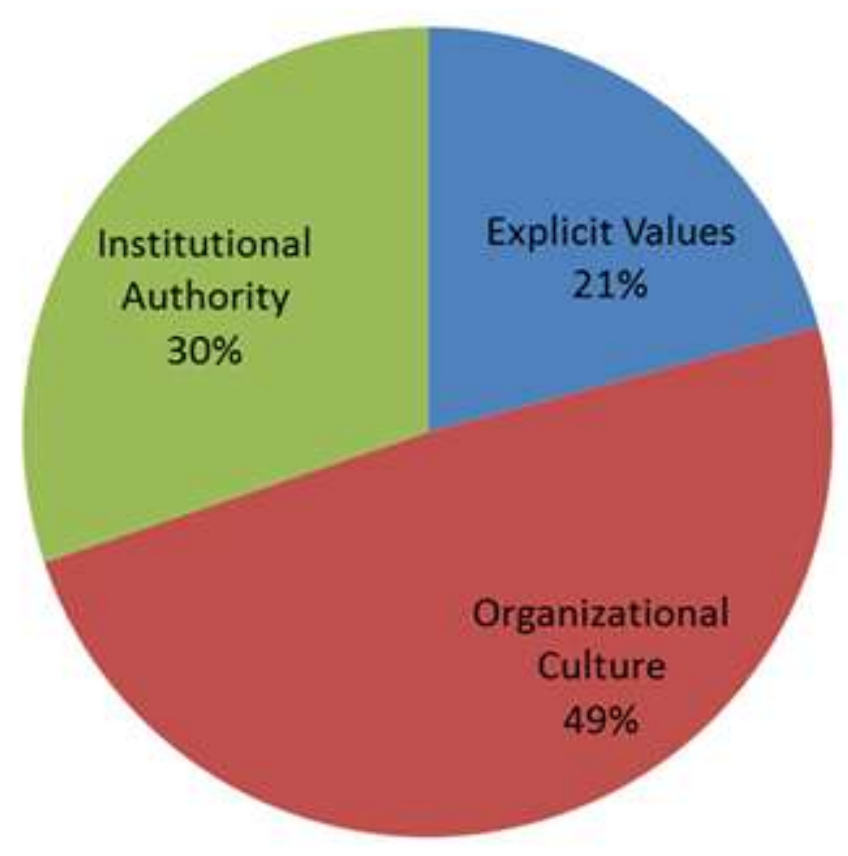

Figure 14. Sunshine County, Percentages of Responses by Theme

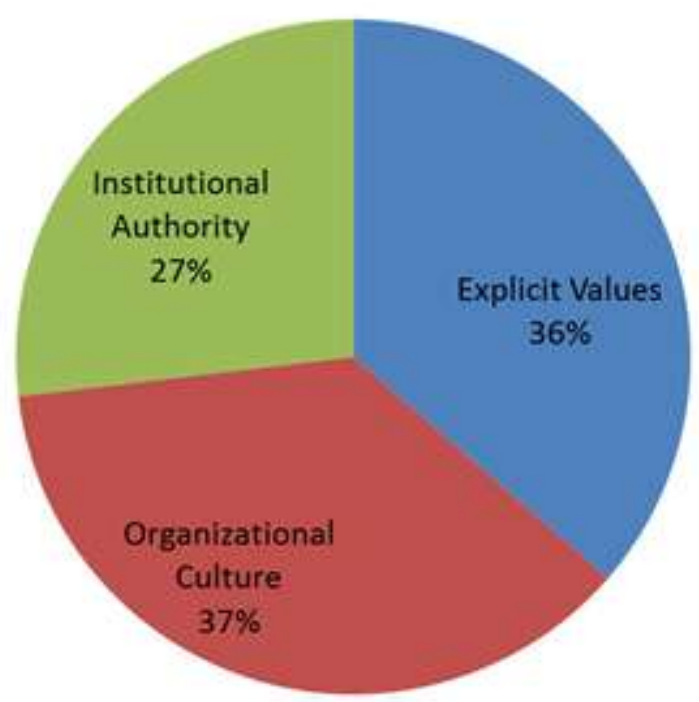

Figure 15: Wave County, Percentages of Responses by Theme 


\section{Summary}

The purpose of this study was to give a rich description of how Universal preschool stakeholders describe their participation in compulsory collaboration. The study answered the research question: How do Universal preschool stakeholders describe the experience of compulsory collaboration. Three West Virginia Universal Preschool counties were used in this case study.

The findings obtained during this case study revealed three emerging themes derived from multiple patterns, as described in this chapter. The major findings in these collaborative Universal counties were organized into three emerging themes.

1. Explicit Values

2. Organizational Culture

3. Institutional Authority

The major findings derived patterns in the second coding process. The coding patterns were a result of interviews, field notes, documents, and informal conversation. Thirteen patterns were distributed into the three emerging themes.

Explicit Values (personal)

a) Mutual Resources, Understanding and Trust

b) Ability to Communicate \& Compromise/Flexibility

c) Shared Vision

d) Open and Frequent Communication

Organizational Culture (organization wide values)

a) History of Collaboration

b) Concrete/Attainable Goals \&Objectives

c) Collaboration in Self-interest

d) Open and Frequent Communication

e) Partners/Members 
Institutional Authority (required by governmental agencies)
a) Policies/Procedures/Guidelines
b) Open and Frequent Communication
c) Skilled Convener
d) Resources

The related findings presented include quotes from interviewees and coding methods. This conveyed the interviewees' opinions and thoughts concerning collaboration. 


\section{Chapter Five: Summary, Discussion, and Conclusion}

The purpose of this study was to give a rich description of how Universal Pre-School stakeholders describe the experience of compulsory collaboration. The first section of chapter five presents the emerging themes of the research. The second section presents the discussion, includes a brief history of collaboration to illustrate the importance of collaboration, and discusses remarks of interested parties, as well researchers and participants of collaborative efforts. The third section consists of my reflections. The fourth section presents an outline of an application of the research. The last section presents recommendations for future research.

\section{Emerging Themes}

Based on observations and interviews of April 8, April 12, and May 2, 2011; documentation from three counties, interviews with 17 individuals over three counties, and numerous informal discussions, the themes that emerged were

Institutional Authority

Organizational Culture

Explicit Values.

These themes can be peeled back like the layers of an onion. Just as every layer of the onion has its place in the flavor of a recipe, all three themes had their place in the dynamics of collaboration in these three Universal Pre-K counties of West Virginia. The outer layer symbolized the institutional authority, which encased the organizational culture that grew from the core explicit values. The explicit values were the core that supported and allowed the organizational culture to flourish. See Figure 16. 


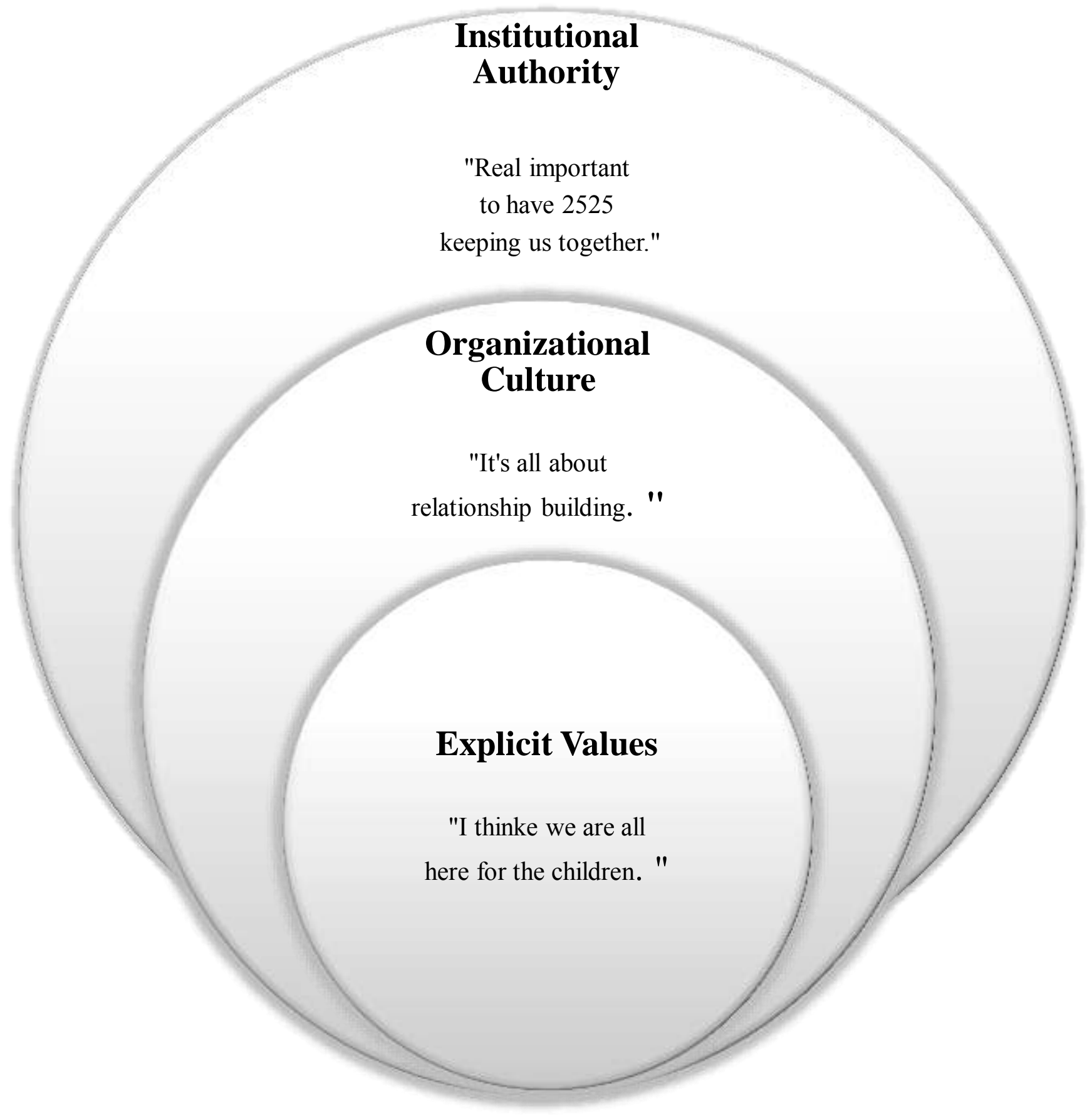

Figure 16. Thematic Layers of the Onion of Collaboration 
All themes were important in this research. The Institutional Authority served as the impetus of collaboration in each county. The Organizational Culture illustrated observable interactions and communication styles and included the overarching importance of relationships in building a successful collaboration. The Explicit Values were based on my observations and the remarks of the members. The dynamics of the three themes together provided a rich description of how universal pre-k stakeholders described collaboration. The following implications were based on the research findings presented in chapter four. The patterns were categorized into three emerging themes.

Institutional authority. Institutional Authority was the emerging theme to investigate first; without it, without policy 2525 collaboration would not be required. Without the requirement, it would not be necessary to study the process or to provide information to others. This theme included responses of the participants in the study that referred to guidelines, policies, or laws that govern their work.

What were the patterns that created the emerging theme of Institutional Authority? Patterns: Institutional Authority (required by governmental agencies).

- Policies/Procedures/Guidelines

- Open and Frequent Communication

- Skilled Convener

- Resources

- Members and Partners

I have placed five of Mattessich, Murta-Close, and Monsey’s (2001) factors into the theme of Institutional Authority. We see from figure 17 (p.101) that the overriding concerns of collaborative participants focus on policy, colleagues, and resources. Since these members were working with each other and sharing resources because of policy, their remarks reflected the requirements of policy in open and frequent communication and blending of resources. 
Open and frequent communication allowed collaborative members to interpret and implement policy, procedures, and guidelines with one voice. Efficient blending of resources must occur if participants were to reach their goal of serving children. Policy 2525 mandates specific members/partners to participate on the collaborative steering team.

The research discovered that among successful collaborative members certain practices, behaviors, and attitudes held by the individuals allowed a specific type of organizational culture to emerge. That organizational culture reflected the values and attitudes of the individual. The organizational culture that emerged because of compulsory collaboration allowed the members to execute policy requirements. Figure 17 illustrates the patterns of responses categorized as organizational culture.

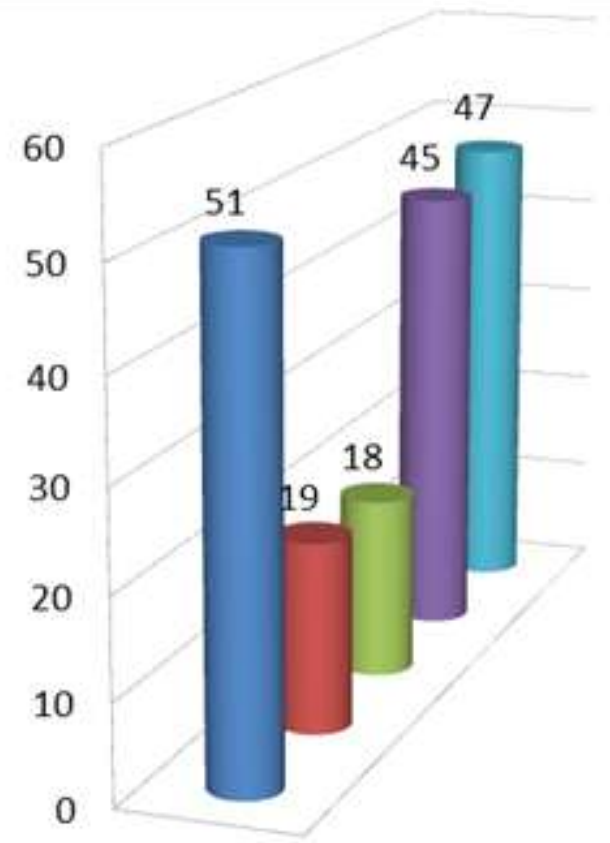

1

\author{
Institutional Authority-1 \\ Policies/Procedures/Guid \\ elines \\ Institutional Authority-2 \\ Open and Frequent \\ Communication \\ Institutional Authority-3 \\ Skilled Convener \\ Institutional Authority-4 \\ Resources \\ Institutional Authority-5 \\ Members/Partners
}

Figure 17. Institutional Authority- Patterns of Responses 
Organizational culture. What is organizational culture? Edgar Schein (Schein, 1985), "one of the most prominent theorists of organizational culture" (Symphony Orchestra Institute, N.D) defined organizational culture as:

A pattern of assumptions -invented, discovered, or developed by a given group as it learns to cope with its problems of external adaptation and internal integration-that has worked well enough to be considered valid and therefore, to be taught to new members as the correct way to perceive, think and feel in relation to those problems. $(1985$, p. 9$)$ Throughout the interviews I held with collaborative participants, I discovered that the participants spoke freely of the process that allowed them to collaborate successfully. They frequently referenced their former mindset as individualistic service providers and compared that mindset to their current collaborative attitudes and behaviors. One collaborative partner described her experience.

I think as we have had new people come on after they have gotten the hang of what we are talking about and how things have worked in the past and you know, everything is a trial and error when you change things. And we have changed a few things so that the collaboration I think is stronger now than it has been in prior years just simply because we know each other better.

Cook and Yanow (Shafritz, Ott, \& Jang, 2005) explained in Culture and Organizational

\section{Learning:}

Organizations commonly acquire new members. As we noted above, such occasions present an opportunity for an organization to learn, where that learning can be understood to constitute the maintenance or preservation of the know-how associated with an organization's activities and abilities. There is a need for a fuller understanding of how 
the group and the individual come to hold the shared intersubjective meanings that constitute organizational cultures, as well as of processes by which both 'agree to disagree.' (2005, p 378)

Another collaborative participant stated:

I think it took us ... you know me coming in new from another county, our first year, our meetings were attended by every principal, by every person in head start that you could imagine just because there was no trust there. There was no rapport, nobody knew what to expect. By our second year, we occasionally will have a principal attend and not so many outside agencies are coming because they kind of know what to expect and we have built that rapport and relationship and if they are not here that we are going to call if we have a question or they call if they have a question or need something. So it is really all about that relationship building.

This member clearly exhibited the "Multiple Intelligence" that Gardner defined as "Interpersonal Intelligence." "Interpersonal intelligence is concerned with the capacity to understand the intentions, motivations, and desires of other people. It allows people to work effectively with others. Educators, salespeople, religious and political leaders and counselors all need a welldeveloped interpersonal intelligence" (Smith, 2002, 2008).

The participants who had a history within their sites were clear on the process that allowed them to make the jump to collaboration. For employees arriving after the collaborative process is in place will arrive in a culture that already supports collaboration.

I have placed five of Mattessich, Murta-Close and Monsey's factors (2001) into the theme of Organizational Culture. The most prominent of these factors is "History of Collaboration." 
Patterns: Organizational Culture (organization wide values).

- History of Collaboration

- Concrete/Attainable Goals \&Objectives

- Collaboration in Self-interest

- Open and Frequent Communication

- Partners/Members

These patterns contained the responses of the participants that referred to how their collaborative team communicated, worked together, and solved problems. Each participant was asked, "How long have you been involved in collaboration?" The response to that question was one of the coded patterns of Organization Culture-One; however, participants repeatedly referred to their experience of collaboration, and to the experience of their colleagues.

The research discovered that among successful collaborative members certain practices, behaviors, and attitudes held by the individuals allowed a specific type of organizational culture to emerge. That organizational culture reflected the values and attitudes of the individual. The organizational culture that emerged because of compulsory collaboration allowed the members to execute policy requirements. The research discovered evidence based on personal interviews, organizational agendas, field notes, and my observations. The evidence portrayed an atmosphere conducive to collaboration. Some collaborative partners stated they collaborated before the compulsory collaboration was implemented. One partner stated, “it has gotten to the point that we evolve into a real good collaborative which we hadn't in the first couple to three years... it took us a while to get there, and now we are working with Head Start, the BOE, and child care centers and we really now have molded well together." 
All partners interviewed spoke of their relationship with one another. One partner spoke of her ability to call another partner "any time of day" because of his or her collaborative partnership.

The second most common response among participants in factors categorized as Organizational Culture was open and frequent communication. Policy 2525 requires "regular meetings" but does not state the frequency. Some sites had regular monthly meetings, others met when they had something to discuss; however, all participants agreed that open and frequent communication allowed them to work collaboratively.

The third most common response in the interviews occurred when participants referred to their collaborative partners. The frequency of this response indicated how intertwined the process of collaboration and the problem solving skills have become among the members. Development of these skills relied heavily on the members' capacity to work together. See figure 18 .
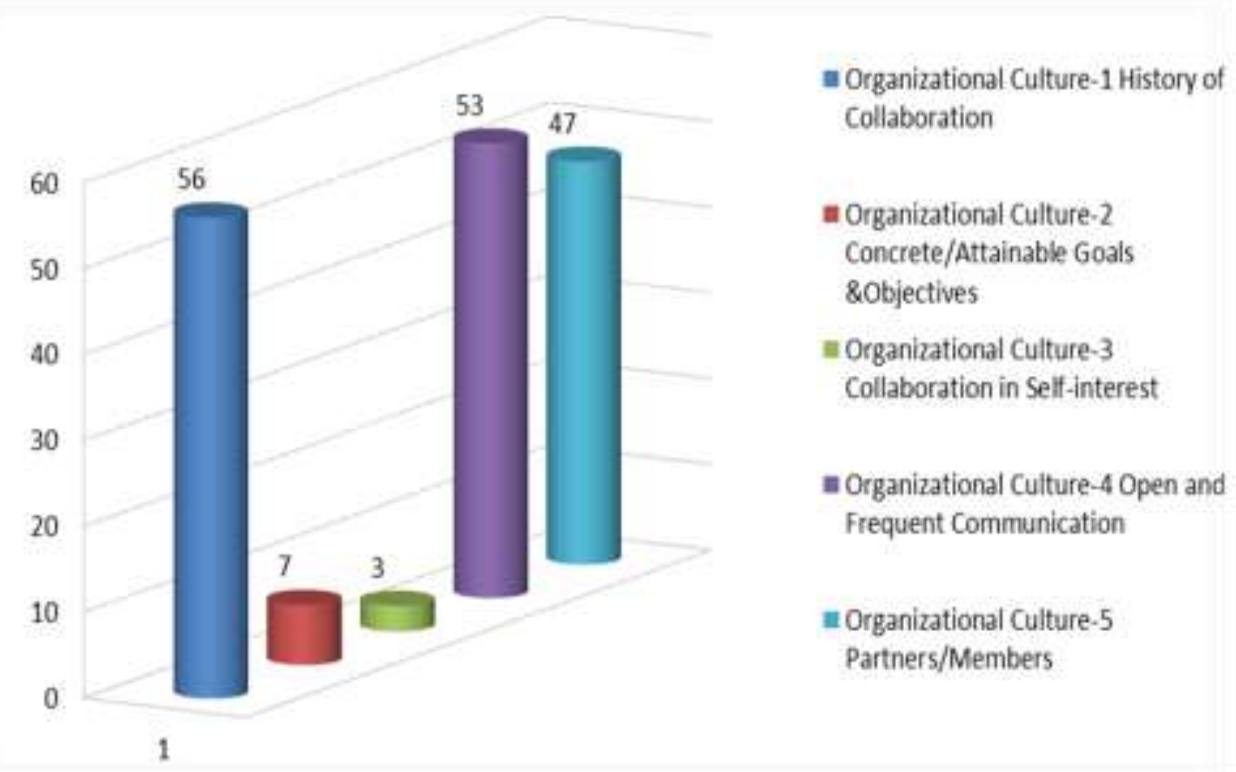

Figure 18. Organizational Culture: patterns of responses 
Explicit values. For this study, explicit values referred to the personal values of participants that were directly mentioned in the interviews; values that they openly espoused. According to Argyris and Schon (as cited in Schein, 1985), explicit values may not be identical to "espoused values" (Schein, p. 17); however, for purposes of coding the research data, we assumed that they were congruent. Investigating any supposed differences was beyond the goal of this research. Schein stated, "Consensus through social validation is possible" and that "Many values remain conscious and are explicitly articulated because they serve the normative or moral function of situations" (1985, p.17). Schein defined social validation.

By social validation, I mean that values about how people should relate to each other, exercise power, define what is beautiful, and so on, can be validated by the experience that they produce uncertainty and anxiety. A group can learn that the holding of certain beliefs and assumptions is necessary as a basis for maintaining the group.

The factors (Mattessich, et al, 2011) that detail the explicit values of the interviewed collaborative partners are categorized as follows:

Patterns: Explicit Values.

- Mutual Resources, Understanding, and Trust

- Ability to Communicate \& Compromise/Flexibility

- Shared Vision

- Open and Frequent Communication

Figure 19 details the patterns of the responses. It was clear from the pattern of responses that the abilities to communicate, compromise, and be flexible were the values most frequently mentioned by the respondents. These values were followed by a shared vision, and open and frequent communication, as illustrated in Figure 19. 


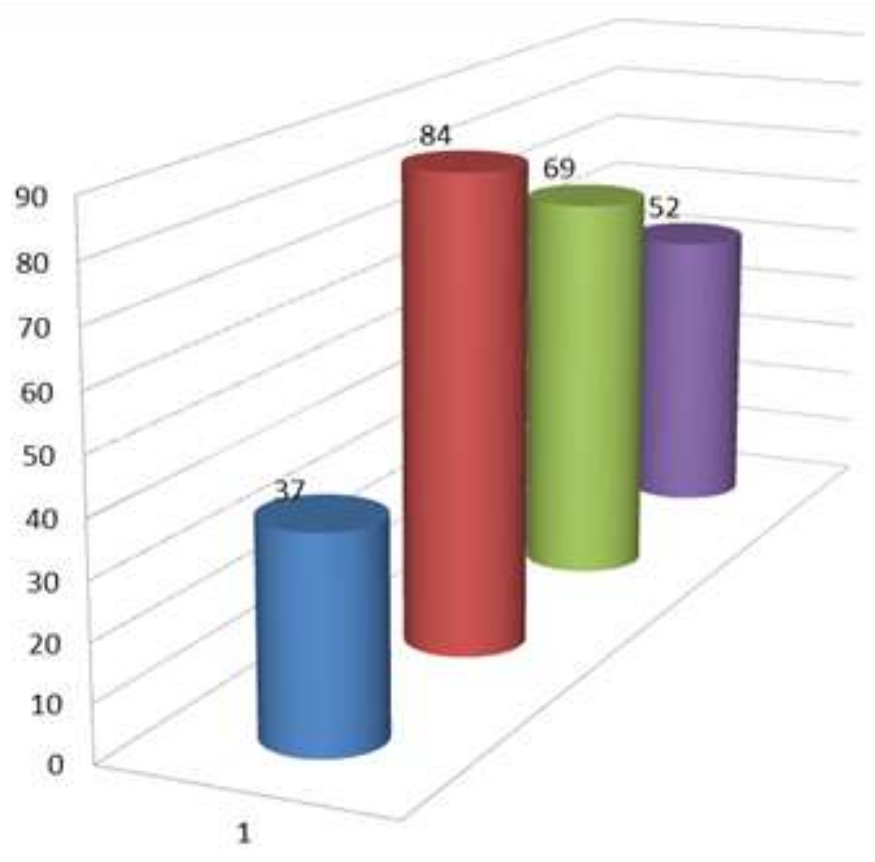

Explicit Values-1 Mutual Resources, Understanding and Trust

Explicit Values-2 Ability to Communicate \& Compromise/Flexibility

= Explicit Values-3 Shared Vision

m Explicit Values-4 Open and Frequent Communication

Figure 19. Explicit Values: Patterns of Responses

The explicit values appeared to come from the various individuals concepts of "service" or "providing services."

Interviewees referenced the concept in a sense larger than the bureaucratic concept.

-...I would say that it has a lot to do with the community in itself that we know that if we try to move forward in isolation were just not going to get where we need to be, that we are not going to be able to provide the services that we do and I just feel that the strategy is that we know that we need each other to make this work.

- Again, it is by serving every four year old that wants services. It's by transitioning children from birth to three and having the space availability... So there is no two days going to this school and two days here, all the services are held at the one facility. 
- Knowing how well we work together and that there are no barriers and knowing that the success is going to be that the students are going to get the services they need.

-...you have to have that on a professional level and on a personal level because these are children's lives we are working with and it is not just a job, its not just a paycheck, its seeing that children get the services they need.

- First of all, I think we are all here for the children. The bonus for our collaborative partners is, they are doing the job anyway, so we are providing a monetary resource for them as well as they take part in our staff development, any trainings that they need, any materials and resources. So they are getting that as well and they are already providing the services for the children so this is just an added incentive for them to participate These participants exhibited Gardner's concept of "Intrapersonal Intelligence." "Intrapersonal intelligence entails the capacity to understand oneself, to appreciate one's feelings, fears and motivations. In Howard Gardner's view it involves having an effective working model of ourselves, and to be able to use such information to regulate our lives" (Smith, 2002, 2008).

\section{Discussion}

Importance of collaboration due to Policy 2525. At the West Virginia Universal Pre-K Conference held at the Embassy Suites in Charleston, West Virginia on June 23, 2010, Senator Robert Plymale stated, “...in 2002 the legislature passed SB 247 as an ambitious goal for early childhood care for all 4 year olds. This would improve overall readiness, decrease problems with behavior, attendance, repeating grades and special education placement." These quotes are from my notes from the West Virginia Universal Pre-k 2010 Summer Leadership Institute, June 21-22 Embassy Suites, Charleston, West Virginia. 
In order to combat the deficit in school readiness, decrease future problems with behavior, attendance, retention, and special education placement the State of West Virginia became the "institutional authority" which required the state's key stakeholders (WVDE, WVDHHR, and Head Start) to implement policy 2525. WVDE, WVDHHR, and Head Start collaborated to develop procedures and guidelines through "open and frequent communication" in order to optimize blended resources. This was their first level of collaboration created by policy 2525 .

Senator Plymale stated that the benchmark moment occurred when policy included the mandate of counties to ensure the fifty percent collaboration. The intention of the collaboration was to blend funding, resources and services to four-year old children and three-year old children (as mandated by federal law) in order to provide equitable access to quality pre-k programs.

As a direct result of Senate Bill 247 and the creation of Policy 2525, the State of West Virginia mandated that all counties provide universal access to a quality pre-k program by 2013. As of April 2011, according to Building Intentionality in a Collaborative Design and Implementation for West Virginia Universal Pre-k (WVDE, 2010 \{ppt, slide 12\}), thirty-two of West Virginia's fifty-five counties had attained the designated universal status. What does the designation mean? It means that these 32 counties have met the requirements set out in Policy 2525 , and that they are providing quality Pre-K programming to all eligible children in their counties who wish to participate. The thoughtful work of the Local Education Agency, Head Start, and WVDHHR led to a policy that would provide key stakeholders a framework to develop a collaborative program for all eligible pre-k children. Although WVDE Policy 2525 mandated compulsory collaboration among key stakeholders, the design of the collaborative framework is the responsibility of each county collaborative team. Why has it taken nine years 
for this to universality to happen? The collaborative process did not evolve over night. The policy was passed in 2002 and the deadline for meeting the requirements allowed ten years for implementation.

During an interview with Pat-1, she disclosed,

"During the first year, meetings were attended by every principal, every Head Start person... you could imagine just because there was no trust. There was no rapport... nobody knew what to expect. By our second year...we built that rapport and relationships... it is really all about relationship building."

This study provided multiple examples of what collaboration means to the collaborative teams. How do the people providing the Universal programs describe the experience of collaboration? They described themselves as "working as a whole team." They stated that they communicate on a professional and personal level because they are working with children's lives and their priority is seeing that children get the services they need. This research found that building communication and rapport are essential to successful collaboration (Organizational Culture). One member stated, "I could call any of these people and ask them for something and it would happen."

This research provided insight into their successful experience. Collaborative partners in counties who are struggling to meet the requirements/guidelines will gain access to information that provides insight into a successful collaborative process. Mattesich and Monsey (p. 61, 2007) devised a table to describe the elements of cooperation, coordination, and collaboration. This table endorses the findings in this study. Findings include:

- "True collaboration occurs when there is a commitment..." $(2007, \mathrm{p} .61)$ Members were present (indicating their commitment) and voicing thoughts, concerns and ideas throughout the meeting. At the meetings I attended, I observed participants actively 
engaged in problem solving, decision making and discussing salient issues. Passivity does not support a successful collaborative model.

- "One or more projects are undertaken for longer-term results. (2007, p.61)

The Early Childhood Environmental Rating Scale (revised), referred to by the participants as ECERS- $\mathrm{R}$ is a mandated policy component. Result of the ECERS-R was reviewed while discussing new assessment tools. Each county discussed the results of the ECERS-R evaluation. The results of this evaluation require sustained planning and commitment.

- 'Beyond communication roles and channels for interaction, many 'levels' of communication are created as clear information is a keystone of success." (2007, p.61)

Phone calls were made when needed regardless of the time. Communication goes beyond the requirements of policy. Relationships assist in problem solving.

- "Leadership is dispersed, and control is shared and mutual" (2007, p.61)

ECERS R evaluations and child placement were two areas discussed that illustrated shared leadership. A successful collaborative model requires shared leadership and joint decision making that is based on trust and mutual respect.

Implications for collaborative groups. Beyond the field of West Virginia's Universal

Pre-K, the State of West Virginia, other state agencies, federal funding streams, as well as nongovernmental funders of grants require collaboration. Organizations as varied as the West Virginia Department of Health and Human Resources, the Family Resource Center, the Juvenile Mediation Program, and the Multi-Disciplinary Investigative Teams require collaboration (Child Welfare, West Virginia Legislature, 2011). Both non-profit and for profit agencies rely heavily on collaboration. In a recent discussion with Todd Gilbert, the Juvenile Mediation Program Director, he discussed the importance of effective collaboration. "Our agency is entirely dependent on collaboration to be effective. We must trust the school staff, as we are not educators. We must listen to the probation officers, as we are not law enforcement personnel. We must rely on our counselors, as we are not therapists. We must listen to the parents, as we are not parents; we are not these children's parents. 
We then combine these divers opinions and differing areas of expertise and we HOPE we can develop the best plan to divert this child from court and from further trouble, we are like chefs who do not invent the foods but only combine them to make something special."

Collaboration is more than simply sitting in a room together following an agenda. In order for true collaboration, members must trust collaborative partners. The power of trust provides a great sense of purpose for collaborative partners. In this study, collaborative members demonstrated their ability to trust one another through their posture, verbal and non-verbal communication, and voiced their thoughts during the meetings freely. Members were relaxed, sat in round table settings, conversed with colleagues from varying agencies, and interjected when necessary during the meeting. These observable behaviors are a result of relationships developed over a period of time.

On a global scale, the Bill and Melinda Gates Foundation announced a collaborative program in its newsletter of December 2010.

\section{Global Health Leaders Launch Decade of Vaccines Collaboration} Global Vaccine Action Plan to guide discovery, development, and delivery of lifesaving vaccines

NEW YORK-- The World Health Organization (WHO), UNICEF, the National Institute of Allergy and Infectious Diseases (NIAID) and the Bill \& Melinda Gates Foundation have announced a collaboration to increase coordination across the international vaccine community and create a Global Vaccine Action Plan. This plan will build on the successes of current work to achieve key milestones in the discovery, development, and 
delivery of lifesaving vaccines to the most vulnerable populations in the poorest countries over the next decade.

The collaboration follows the January 2010 call by Bill and Melinda Gates for the next ten years to be the Decade of Vaccines. The Global Vaccine Action Plan will enable greater coordination across all stakeholder groups - national governments, multilateral organizations, civil society, the private sector and philanthropic organizations -- and will identify critical policy, resource, and other gaps that must be addressed to realize the lifesaving potential of vaccine.

The structure of the Decade of Vaccines Collaboration includes a Leadership Council to provide oversight for the planning effort, a Steering Committee that holds the primary responsibility for developing the action plan, an International Advisory Committee to assist the Leadership Council in evaluating the action plan, and a Secretariat for administrative support. (2010, December)

First, note that the press announcement was made by all players in the collaboration. This indicated that all partners had ownership of this project and shared a common goal. If we read the press statement carefully, they stated that the "collaboration to increase coordination" preceded the action plan. The increase in coordination jointly launched their second goal of the action plan. The collaboration recognized (and this is confirmed in this research) that an increase in coordination must precede the action plan. Additionally they stated, "This plan will build on the successes of current work. " These Global Health advocates will take advantage of the history of collaboration that already exists among the collaborative partners. This research has found that a history of collaboration strengthens collaborative efforts. 
Mattessich and Monsey (2001) stated, concerning successful collaboration "The relationship includes a commitment to mutual relationships and goals; a jointly developed structure and shared responsibility; mutual authority and accountability for success; and sharing of resources and rewards" (p. 59). The structure of the Decade of Vaccines Collaboration had a clear commitment to mutual relationships and goals through its leadership council and steering committee. It had a jointly developed structure and shared responsibility as represented by its International Advisory Committee that assisted the Leadership council. The Leadership Council provided oversight in evaluating the action plan, which would provide accountability. (2010, December)

This global collaboration demonstrated a formidable, comprehensive collaborative plan. These experts in the field have made the most of their resources through joint efforts. Their passion, commitment, and flexibility have allowed this group to have a positive effect on a global scale.

"Collaboration," the buzzword of the nineties is now a required component of many governmental, non-governmental, and corporate programs. Yesterday’s innovation has become today's standard. With the advent of collaborative programming throughout our local communities, and the world, research into successful collaboration provides information and guidance to the many individuals participating in collaborative efforts.

In his dissertation on Leadership Standards, David Lancaster (2010), credited Lyndon B. Johnson as saying that all problems can be solved working together, but few problems can be solved by ourselves. Lancaster (2010) continued, "School administrators face the issue of solving many problems, and they need individuals working collaboratively with them...it is critical that in a PDS system for site based coordinators to be the lynchpin in organizational 
operations" ( p. 74). Like school administrators, collaborative teams face multiple issues and rely heavily on one another's expertise. One collaborative team highlighted their experience of dealing with an issue concerning transportation and duplicating services. The issue was discussed at a meeting and resolved through open and frequent communication among the collaborative partners. Through the discussion and a constant focus on the children, the issue was resolved through compromise and collaboration. Without trust, open and ongoing communication this issue would have led to duplication of funds, lengthy time on a school bus for the child, and hardship on the staff.

In an interview with Margaret Clifford (personal correspondence, August 25, 2011), Michael Tierney, director of the non-profit Step by Step, reflected on his more than thirty years of experience with non-profits. He stated that

Collaboration makes sense... any healthy non-profit needs to be aware of collaboration so you're not competing and you can share resources... a number of funding streams...almost any federal funding stream expects you to participate in collaboration...but it's important to distinguish true collaboration from collaboration that is 'token'. The only way it really works for the long haul is shared decision making, clear expectations for each party and benefits to each party and you have a real commitment... it must be a genuine commitment. You have to bring something to the table, and make your expectations clear.

During an interview with Pat, she stated "I think it works pretty well because I believe we all need each other I order for children to be successful. My background is education, it is not social work, and I do not claim to be a social worker and I do not have any idea of those kinds of programs that parents 
need. So we need Head Start for that aspect because there are social things... a family may need help with a utility bill and I can't help with that, but Head Start can. Children need child care, I am working with a mother and children needing child care, and we need to ensure they are having a quality experience while they are there."

WVDE Policy 2525 lends itself to establish networks to best meet the needs of the family and child. Everyone brings something to the table.

Tierney continued,

The real problem with some authorities is not really sharing the decision-making. They sometimes want to micro manage the way the local partners collaborate without really understanding the local environment. If the authorities are unwilling to share power and decision-making, true collaboration will not take place.

History really makes a difference. If something isn't working, we can handle it, because we have developed a comfort level. Familiarity builds skills: learning how to handle conflict.....being direct... being able to say this is not working for me. Petty turf stuff....know what's working what's not.....show that you're open to change but be clear on your boundaries. (Personal correspondence)

The vision established in 2002: Universal Access to quality preschool programs for all four-yearold children and three-year-old children as mandated by law is validated by this study. While counties were required to implement the policy, the details of implementation were county based. Each county decided for itself the best way to meet the needs of the families in those counties.

In The Fifth Discipline, Senge (1994) described shared vision. 
A shared vision is not an idea, it is not even an important idea such as freedom. It is, rather a force in people's hearts, a force of impressive power. It may be inspired by an idea, but once it goes further--if it is compelling enough to acquire the support of more than one person--then it is no longer an abstraction. It is palpable. People begin to see it as if it exists. Few, if any, forces in human affairs are as powerful as shared vision. At its simplest level, a shared vision is the answer to the question 'What do we want to create? (1994, p. 192)

Policy was implemented through a thoughtful collaborative plan that allowed partners to develop relationships and determine for themselves the specific implementation.

In an interview at the 21 st Century Teacher Leadership Institute, held in Morgantown, WV on July 21, 2011, Clayton Burch, Assistant Director of the West Virginia Office of School Readiness who has been instrumental in the implementation of WV Policy 2525, stated that The collaborative process is evolving and constantly changing. If collaborative teams feel ownership, the collaboration is strong. Each county decides how to meet the requirements of policy 2525. Every key stakeholder must feel essential to the county pre $\mathrm{k}$ team. It's about families receiving equitable and equal access to a quality program each county decides how to meet the requirements of policy 2525 (personal correspondence).

County collaborative teams were proud of their accomplishments and took time during interviews to credit their collaboration for the successes in their respective county. "We transition more and more (children) into having, I call blended classrooms, whether it be a Head Start or a non-Head Start child, we have them in all the settings, and that is our goal to blend into every pre-k program.” Because of policy, collaborative partners broke down barriers and set 
aside turf issues. Children are experiencing universal pre-k, not Head Start Pre-K, Private Pre-K, school based Pre-K, and it is one universal program for all children.

"Building support for early childhood education requires collaboration, involvement, and a vision of the outcomes. The product of collaboration should be the synergy that occurs where the full complement of stakeholders are involved in the initiative" (Kostelnik \& Grady, 2009, p. 66). Policy 2525 (WVDE, 2010) mandates that collaboration exist in every county in West Virginia. Collaborative teams make concerted efforts to work jointly to achieve the ultimate goal of Universality.Pat-1 stated,

I see that we are stronger...I see the pluses of working as a team because everybody wins especially the children by working together instead of the child care is here, the board of education is over here and the Head Start is over here. We are all just LIGHTNING County.

Clayton Burch, Assistant Director of the West Virginia Office of School Readiness pointed out that this is a unique situation "for a county administrator to rely heavily on collaborative efforts from outside school agencies." He indicated that the biggest barrier for county collaborative teams was getting past the turf issue of protecting each program. "Successful collaborative teams are able to see past each entities program and see the universal process as whole program serving each family and their unique needs through ongoing, transparent communication within the collaborative partnership" (personal correspondence).

Uniting three early childhood entities, which once operated within a silo, has opened the door for many families to partake in a free, quality pre-k program. Shared resources, funding streams, staff, and professional development are examples of the dramatic changes in early childhood education as a direct result of WVDE Policy 2525. 


\section{Researcher Reflections}

As I concluded the research process in this descriptive case study, my findings confirmed the current collaborative models of Mattesich and Monsey, Kostelnik and Grady, Schein, Uchida, Covey, and Grandinetti as mentioned previously. This study confirmed my thoughts concerning collaboration and culture. The collaborative efforts demonstrated by the key stakeholders in each county were affected by our social interpretation of collaboration. My interpretation supported Vygotsky's theory that community plays a central role in the process of "making meaning." Each universal pre-k steering team "made meaning" of how collaboration works in their county.

I found the members' number one priority always focused on the child. One collaborative partner mentioned an incident of a family that became homeless. The child participated in a universal pre-k program. As soon as the teacher reported this finding to her supervisor, the collaborative team members were notified and rallied together to assist the family with shelter, food, and clothes. Harper stated, "we worked together to pick up the pieces and work hand in hand to get this family back in a home." Uchida summed this up perfectly in her research (my paper p. 40) "Leaders came together for the greater good of young children and their families in order to provide seamless service" (Uchida, 2005, p. 142). These powerful statements emphasized that the teams placed great emphasis on the well-being of the family.

Professionalism was another factor demonstrated in each county. Pat-1 stated, "It (collaboration) is just a part of what we do. We don't really say, 'oh, we have to make sure we are really collaborating with this'. We just do it. It was built with the foundation of this program. So it is not something new, that we have to make sure that we are 
collaborating ...it just happens, it's just automatic. We are one committee, we are one team."

This study illustrated the importance of working together to best meet the needs of all eligible pre-k children. One collaborative member stated, "We meet once a month as a whole group, and I think probably a day does not go by that I am not in communication with Head Start.” These members relied on one another and respected one another's viewpoints, ideas and concerns

Covey stated (The Speed of Trust 2006, p. 258) "Nothing is as relevant as the pervasive impact of trust. And if you have on glasses to see, these realities become unarguable when it comes to building trust with the internal stakeholders in your organization."

In Developing Collaboration Between the Figsboro Elementary School, Child Study Committee, and Agencies that Serve Children and Families, Grandinetti (1998) reviewed Mattessich and Monsey’s (1992) research and noted that one of the nineteen factors included mutual respect, understanding, and trust between group members (1998. p. 14).

These characteristics were confirmed by statements from several collaborative members. The members were complimentary to one another and valued each other's expertise by talking about what each team member brings to the table. In one county Harper stated,

"You have to have mutual respect for one another on a professional level and on a personal level because these are children's lives we are working with and it is not just a job, it's not just a paycheck, it's seeing that children get the services they need." These members also reviewed policy and policy requirements throughout their respective meetings. Interpretation of policy required the teams to analyze a particular policy and reach consensus on the guidelines. Various members commented on pieces of policy and policy revisions. Members from the counties commented on the Early Childhood Rating Scale - 
Revised (ECERS-R) and reported what universal sites needed to fulfill ECERS-R. requirements. Brainstorming occurred at meetings searching for funding sources to assist in the ECERS-R evaluation.

Collaboration is hard work it takes personal commitment (explicit values), perseverance and dedication (organizational culture), loyalty and knowledge of policy (institutional authority).

\section{Application}

In chapter one, I stated that the outcome of this research would provide valuable information to four groups of stakeholders.

The outcome of the research has four potential applications.

- The first application is policy. Policy makers have a need to understand how Universal Preschool programs actually work because their decisions affect the financial resources that support the programs.

- The second application will inform county superintendents through rich descriptions of how Universal programs actually work. Superintendents have the power to channel funding directly toward Universal Preschool programs.

- The third application will inform Universal Preschool program stakeholders. Head Start coordinators, LEA coordinators, parents, West Virginia Department of Health and Human Services, preschool special needs groups will be informed about the trials, tribulations, and triumphs of the described models.

- The fourth and final application will inform providers with details of implementation, successes and difficulties or roadblocks that will impede stakeholders groups. This will provide them with the opportunity to use the information to strengthen their current collaborative teams. 
A professional development workshop could be created that would introduce these stakeholders to the "Best Practices of Collaboration" in universal pre-k counties. This workshop will assist policymakers, superintendents, universal pre-school key stakeholders and any providers to understand the dynamics of successful collaboration. The workshop will look at collaboration from three different lenses, corresponding to the emerging themes of this study.

\section{Suggestions for Future Research}

The case study opens the door to several important topics for future research. Findings in this study serve as a tool for any collaborative group. Three potential areas for future research include replication of the same study on a larger scale, replication of the study with noncompulsory collaborative groups, and comparing collaboration of universal pre-k counties on a national level using electronic media compared to face-to-face meetings, etc.

In a fourth application, a future researcher could design an instrument based on the emerging themes and patterns of this study. This instrument would allow counties, schools, or programs to self-report their performance under each pattern. Those entities could then evaluate themselves to assess their strengths and weaknesses and create a strategic plan for improving those areas self-assessed as needing further development.

Specifically, if the instrument were applied to Universal Pre-K counties the results would provide a quantitative aerial view of collaboration that would complement this qualitative study. Additional research on universal pre-k counties could occur throughout West Virginia on a larger scale. This research resulted in similar findings in the same region of West Virginia. It would be beneficial to state key stakeholders to know best practices of collaboration throughout the state in order to assist counties where applicable. If a county were weak in organizational culture for example, the state would have access to intervene and provide 
assistance to support the collaborative process. Opportunities for professional development could be provided by the state based on need and collaborative findings. This information would lend itself to maximizing resources to meet the needs of universal pre-k counties. The collaborative process is ever evolving and needs constant attention even to counties already deemed by the state as universal. A replication of the study with non-compulsory groups would be beneficial to not only educators, but also organizations outside the educational realm. Many groups of people work together toward a goal for many reasons. It would be interesting to find out if similar characteristics and factors occurred in a non-compulsory setting.

The third and final area for future research is the use of electronic media as a means for collaboration. The World Wide Web lends itself for frequent communication through wikis, blogs, chat rooms, personal broadcasts, and webinars. This study would allow the researcher to compare findings from this study to a study strictly using electronic media as a tool for study the dynamics of any collaborative group electronically.

\section{"Coming together is a beginning. Keeping together is progress. Working together is success."}

Beyond the requirements of compulsory collaboration, many organizations collaborate without a mandate. Whether it is the PTA or the Neighborhood Watch Group, the explicit values and organizational culture that allow for successful collaboration will empower other organizations to succeed and thrive. If the organization can define a common concrete goal, the prominent behaviors that will allow the members to succeed are open and frequent communication, and the development of relationships. Once these partners develop a history of collaboration, their collaborative skills will develop exponentially. 


\section{References}

Ackerman, D., Barnett, W., Hawkinson, L., Brown, K. \& McGonigle, E. (2009).

Providing preschool education for all four-year olds: Lessons from six state journeys. National Institute for Early Education Research, March 2009, (18), 2-29.

Altenbaugh, R. (1999). Historical dictionary of American education. New York, NY: Greenwood Publishing.

Alter, C., \& Hage, J.(1993). Organizations working together. Newbury Park, CA: Sage Publications.

Ancient Greece.(2004). Education, Discovery Channel. Retrieved from http://www.yourdiscovery.com/greece/education/index.shtml

Argyris, C., and Schon, D. A. Organizational Learning. Reading, Mass.: Addison-Wesley, 1978

Arnett, J. J. (1999). Adolescent storm and stress, reconsidered. American Psychologist, 54(5), Retrieved from http://uncenglishmat.weebly.com/uploads/1/4/3/4/1434319/arnett.pdf

Beatty, B. (1995). Preschool education in America: The culture of young children from the colonial era to the present. New Haven, CT: Yale University Press.

Bloomberg.com. (2010). http://www.businessweek.com/news/2010-08-25/home-prices-in-u-s-decline-1-6-insecond-quarter-fhfa-says.html

Bondy, E., \& Brownell, M. (1997). Overcoming barriers to collaboration among partners. Intervention in School \& Clinic, 33(2), 112. Retrieved from MasterFILE Premier database.

Bryk, A., \& Schneider, B. (2002). Trust in schools: A core resource for improvement. The Russell Sage Foundation. 
http://www.russellsage.org/publications/books/0-87154-192-0

Burch, C. (June 2010). West Virginia's universal access to quality early education system. Overview of West Virginia Pre-K Classrooms (2009-2010). June 2010, WVDE

Business Week, (2010)

http://www.businessweek.com/news/2010-08-25/home-prices-in-u-s-decline-1-6-insecond-quarter-fhfa-says.html

Cahill, T. (2006). Mysteries of the middle ages. New York, NY: Nan A. Talese. http://scholar.lib.vt.edu/theses/available/etd-113099-123223/unrestricted/chapman.pdf

Comenius. (2010). In Encyclopaedia Britannica. Retrieved from Encyclopædia Britannica Online http://search.eb.com/eb/article-1426

Cooper, R. (2009). Decoding coding via The Coding Manual for Qualitative Researchers by Johnny Saldaña. The Weekly Qualitative Report, 2(42), 245-248. Retrieved from http://www.nova.edu/ssss/QR/WQR/saldana.pdf

Covey, S. R. (1989). The 7 Habits of Highly Effective People. New York, NY: Simon \& Schuster.

Creswell, J. W. (2009).Qualitative, quantitative, and mixed methods approaches (3rd ed.). Sage Publications, Thousand Oaks, CA

Darragh, J. (2010). Introduction to early childhood education. Saddle River, NJ: Pearson Education, Inc.

Davis, D., \& Clifton, A. (1995). Psychosocial theory: Erikson. Retrieved from http://www.haverford.edu/psych/ddavis/p109g/erikson.stage

Dick, B. and Dalmau, T. (2000) Argyris and Schön: some elements of their models. Retrieved from http://www.scu.edu.au/schools/gcm/ar/as/argyris2.html 
DuFour, R., DuFour, D. Eaker, R. \& Many, T. (2006). Learning by doing: A handbook for professional learning communities at work. Bloomington, IN: Solution Tree Press.

DuFour, R., DuFour, D. \& Eaker, R. (2008). Revisiting professional learning communities at work. Bloomington, IN: Solution Tree Press.

Education. (2010). In Encyclopcedia Britannica. Retrieved from Encyclopædia Britannica Online: http://search.eb.com/eb/article-47fifty-five2

Encyclopædia Britannica. Retrieved, from Encyclopædia Britannica Online: http://search.eb.com/eb/article-9070856

Erkens, C., Jakicic, C., Jessie, L.G., King, D., Kramer, S.V., Many T.W., Ranells, M., Rose, A. B., Sparks, S. K., Twadell, E. (2008). The Collaborative teacher working together as professional learning community. Bloomington, IN: Solution Tree Press.

Fancher. R. E., (1998) Classics in the History of Psychology: Introduction to 'The Origin and Development of Psychoanalysis' Sigmund Freud (1910). Retrieved from http://psychclassics.yorku.ca/Freud/Origin/intro.htm

Fink, A. (2005). Conducting Research Literature Reviews. Thousand Oaks, CA: Sage Publications

Freud, Sigmund, (2010). In Encyclopoedia Britannica. Retrieved from http://search.eb.com/eb/article-22604

Froebel Web. (n.d). The whole art of teaching, http://www.froebelweb.org/web7005.html 071510 quotes from John Amos Comenius, The Great Didactic, written 1628-32; published 1649; translated by M.W. Keatinge 1896. http://www.froebelweb.org/web7005.html

Gardner, H. Multiple Lenses on the Mind (2005) Paper presented at the ExpoGestion Conference, 
Bogota Colombia, May 25, 2005

Glesne, C. (2006). Becoming qualitative researchers. Boston, MA: Allyn \& Bacon.

Gordon A., \& Browne, K.W. (2008). Beginnings and beyond: foundations in early childhood education, Belmont, CA: Wadsworth.

Grandinetti, P. H. (1998). Developing collaboration between the Figsboro Elementary School Child Study Committee and agencies that serve children and families (Doctoral dissertation, The Virginia Polytechnic Institute and State University ). Retrieved from http://scholar.lib.vt.edu/theses/available/etd-110198123258/unrestricted/PHGNEWDISSERTATION.PDF

Halsall, P., (2006). Internet Ancient History Sourcebook. Retrieved from http://www.fordham.edu/halsall/ancient/cicero-letters.html

Henry Ford Quotes (n.d.), Thinkexist.com. Retrieved from http://thinkexist.com/quotation/coming_together_is_a_beginningkeeping_together/146314.html

Harvard University. (n.d.). Department of Psychology: Steven Pinker. Retrieved from http://pinker.wjh.harvard.edu/about/index.html.

Jeon, Kyungsoon. (n.d.). A teacher's belief about the nature of mathematics and its manifestation in teaching. Retrieved from Practiceshttp://jwilson.coe.uga.edu/emt669/Student.Folders/Jeon.Kyungsoon/papers/pape r9/paper9.html

Jones, B. (2000a), The history of printing: manuscripts ,books, and maps: The printing press and a Changing World. Retrieved from http://communication.ucsd.edu/bjones/Books/printech.html 
Jones, B. (2000b), The history of printing manuscripts: Luther and the Protestant Reformation. Retrieved from http://communication.ucsd.edu/bjones/Books/luther.html

Kent, T. ( July 21, 2011). Habitat and St. Peter Collaborate on Last Home. Retrieved July 22, 2011 from http://mankatofreepress.com/latestnews/x1241070613/Habitat-for-Humanity-St-Petercollaborate-on-last-home

Kheper. (n.d.). Psychoanalytical psychology. Retrieved from http://www.kheper.net/topics/psychology/Freud.html

Kostelnik, M. J., \& Grady, M. L. (2009). Getting it right from the start: The principal's guide to early childhood education. Thousand Oaks, CA: Corwin Press.

Lancaster, D. (2010). Leadership standards :Professional development schools versus non-professional development schools, (Dissertation, West Virginia University) Retrieved from http://wvuscholar.wvu.edu:8881/R/LNU4PKA8L82XEJ91SGK24Y2ALCR8DTETUAR UNM6H4CM4XBIAE2-00258?func=results-jumpfull\&set_entry $=000002 \&$ set_number $=000077 \&$ base $=$ GEN01-WVU01

Learning-Theories.com. Maslow's hierarchy of needs. Retrieved from http://www.learning-theories.com/maslows-hierarchy-of-needs.html

Leonard, L. \& Leonard, P. (2003). The continuing trouble with collaboration: Teachers talk. Current Issues in Education [On-line], 6(15). Available: http://cie.ed.asu.edu/volume6/number15/ 
Limited SREB, (2002). Final Report, October 2002. Retrieved from http://www.sreb.org/page/1256/2002_final_report.html

Linebarger, D. L. (2001). Learning to read from television: The effects of using captions and narration. Journal of Educational Psychology, 93(2), 288-298.

Marshall, C. \& Rossman, G. B. (1999). Designing qualitative research. Thousand Oaks, CA Sage Publications.

Marshall, C. \& Rossman, G. B. (2011). Designing qualitative research. $5^{\text {th }}$ ed Thousand Oaks, CA: Sage Publications.

Mattessich, P.,Monsey, Barbara R.(1992). Collaboration: What makes it work. St. Paul, MN: Amherst H. Wilder Research ) Retrieved from the ERIC Database (ED 390758)

Mattessich, P. W., Murta-Close, M. \& Monsey, B. R. (2001). Collaboration: What Makes it work? St. Paul, MN: Amherst H. Wilder Research.

Maxwell, J .A.(2005). Qualitative research design: an interactive approach. Thousand Oaks, CA: Sage Publications.

Maykut, P., \& Morehouse, R. (1994). Beginning qualitative research: a philosophic and practical guide. Bristol, PA: The Falmer Press.

Miles, M. B. , \& Huberman, M . (1994). Qualitative data analysis: an expanded sourcebook. Thousand Oaks, CA: SAGE Publications.

Neill, J. (2007). Features of Qualitative \& Quantitative Research: Key Points in a Classic Debate. Retrieved from http://wilderdom.com/research/QualitativeVersusQuantitativeResearch.html 
Patton, M. Q. (2002). Qualitative research and evaluation methods. Thousand Oaks, CA: Sage Publications.

Patton, M. Q. (1999). Enhancing the quality and credibility of qualitative analysis. HSR: Health Services Research. 34 (5).

Payne, R. (1996). A framework for understanding poverty. Highlands, TX: aha! Process, Inc.. Pedagogy. (2010). In Encyclopcedia Britannica. Retrieved from Encyclopædia Britannica Online: http://search.eb.com/eb/article-39084

Reus B. (2006). Customization in the internet economy: Research strategy. Retrieved from http://bottomup.wordpress.com/research-methodology/research-strategy/

Riling, M. (2000). John Watson's paradoxical struggle to explain Freud [Abstract]. The American Psychologist, fifty-five (3), Retrieved from http://psycnet.apa.org/journals/amp/fifty-five/3/301/

Rubin, H. J., \& Rubin, I. S. (2005).Qualitative interviewing: The art of hearing data (2nd ed.). Thousand Oaks, CA: Sage Publications

Ryan-Nicholls, K., \& Will, C. (2009). Rigour in qualitative research: mechanisms for control. Nurse Researcher, 16(3), 70-85. Retrieved from Health Source: Nursing/Academic Edition database.

Saldana, J. (2010). The coding manual for qualitative researchers. Thousand Oaks, CA: SAGE Publications.

Schein,E.H.(1985).Organizational culture and leadership. San Francisco, CA: Jossey-Bass Senge, P. (1994) The fifth discipline (1st ed., p. 192) New York, NY: Currency Doubleday Retrieved from http://books.google.com/books/feeds/volumes?q=0385260954 Smith, M.K. (2002,2008). 
Shafritz, A. M., Ott, S., \& Jang, Y. S. (2005). ). Culture and organizational learning Organizational Culture Theory. In Classics of organization theory Tatom, D., Bush, D., \& Green, R.,( $6^{\text {th }}$ ed.., p. 352-414). Belmont, CA: Wadsworth Pub Co. .Retrieved from http://books.google.com/books/feeds/volumes?q=0534631568

Smith, Mark K. (2002, 2008) Howard Gardner and multiple intelligences', the encyclopedia of informal education, http://www.infed.org/thinkers/gardner.htm.informaleducation. Retrieved from http://www.infed.org/thinkers/gardner.htm.

Stake, R. (2006) Multiple case study analysis. New York, NY: Guilford Publications.

Sullivan, K. (Ed.). (2006) West Virginia Encyclopedia. 2006 Thomson-Shore, Inc, The West Virginia Humanities Council.

Symphony Orchestra Institute, Initials. (n.d.). Organizational culture. Retrieved from http://www.soi.org/reading/change/culture.shtmlTabula Rasa. (2010).

The Bill and Melinda Gates Foundation, (2010, December) Global Health Leaders Launch Decade of Vaccines Collaboration. Retrieved July 22 from http://www.gatesfoundation.org/press-releases/Pages/decade-of-vaccinescollaboration.aspx

TED Talks, (2003) Steven Pinker chalks it up to the blank slate. an interactive text posted 2008. Filmed, Feb.2003, Retrieved from Steven Pinker chalks it up to the blank slate http://www.ted.com/talkes/steven_pinker_chalks_it_up_to_the_blank_slate.html Thomson, J. W. (1963). The Literacy of the laity in the middle ages. New York, NY: B. Franklin. 
Uchida, H. (2005) Making possibilities visible: The process of collaboration between general and special education teachers in an inclusive early childhood education program (Doctoral dissertation, Ohio University). Retrieved from http://etd.ohiolink.edu/send- pdf.cgi?osu1127237508

University of Calgary. (n.d.). The end of Europe's middle ages: language and literature. Retrieved from http://www.ucalgary.ca/applied_history/tutor/endmiddle/FRAMES/langframe.htm University of Calgary. (n.d). The end of Europe's middle ages: the impact of the printing press. Retrieved from http://www.ucalgary.ca/applied_history/tutor/endmiddle/FRAMES/langframe.html

U.S. Census Data. (n.d.). State and County Quick facts: Retrieved from http://quickfacts.census.gov/qfd/states/54000.html

U.S. Department of Health and Human Services. (n.d.).About the office of Head Start. Retrieved from http:/www.acf.hhs.gov/programs/ohs/about/index.html U.S. Department of Education. (n.d.). The Federal role in education. Retrieved from http://www2.ed.gov/about/overview/fed/role.html

U.S. Constitution. (n.d.) The American Colonist's library: A treasury of primary documents: Retrieved from: http://www.constitution.org/primarysources/deluder.html

Vodicka, D. (2006). The Four Elements of Trust. Principal leadership, 7(3), Retrieved from http://www.plcwashington.org/trust/resources/4-elements-of-trust.pdf

Von Marenholtz-Bulow, B. (2007). How kindergarten came to America: Friedrich Froebel's radical vision of early childhood education. New York, NY: The News Press.

Watson, J.B. (2009). Behaviorism. Piscataway, NJ: Transaction Publishers. 
Watson, John B. (2010). In Encyclopcedia Britannica. Retrieved from Encyclopædia Britannica Online: http://search.eb.com/eb/article-9076286

West Virginia Department of Education. (2010). Building Intentionality in a Collaborative Design and Implementation for West Virginia Universal Pre-k \{power point slides\} Retrieved July 22, 2011 from WVDE Web site: WV Pre-K County Coordinators An Overview of WV Universal Pre-K. http://wvde.state.wv.us/osp/wvprek/

West Virginia Department of Education. (2010). Policy 2525. Retrieved from WVDE Web site: http://wvde.state.wv.us/osp/policy2525.html

West Virginia Department of Health and Human Resources. (2009) Policy and procedures manual. Retrieved from West Virginia DHHR Web county: http://www.WestVirginiadhhr.org/bcf/ece/earlycare/policy/2009/ChildCarePolicyJuly200 9Revision.pdf

West Virginia Legislature (2011) WV Code 49-5D Child Welfare, Multidisciplinary Teams. WV Code updated with legislation passed through the 2010 2nd Special Session, Retrieved from http://www.legis.state.wv.us/WVCODE/code.cfm?chap=49\&art=5D

WVU Extension Service (n.d.). Department of Agriculture and Natural Resources retrieved from http://anr.ext.wvu.edu/

Yin, R. K. (1984). Case study research design and methods, (Vol. 5) Thousand Oaks, CA: Sage Publications.

Yin, R .K. (2003). Case study research design and methods, Third Ed. Thousand Oaks, CA: Sage Publications.

Yin, R .K. (2009). Case study research design and methods, Fourth Ed. Thousand Oaks: CA: Sage Publications. 


\author{
Appendix A \\ Policy 2525 (P. 1) \\ TITLE 126 \\ PROCEDURAL RULE \\ BOARD OF EDUCATION \\ SERIES 28
}

West Virginia's Universal Access to a Quality Early Education System (2525)

\title{
\$126-28-1. General.
}

1.1. Scope. - - This procedural rule establishes the criteria for approving and operating programs for four-year-old children and three-year-old children as mandated under federal law and herein after is referred to as WV Pre-k (hereinafter WV Pre-k).

1.2. Authority. - - W. Va. Constitution, Article XII, $\$ 2$ and W. Va. Code $\S \S 16-3-4$, 18-2-5, 18-2E-1 et seq., 18-5-17, 18-5-18c, and 18-5-44. All requirements of this policy are mandated components unless otherwise noted.

1.3. Filing Date. - December 11, 2009

1.4. Effective Date. - January 11, 2010

1.4.1. Unless specified otherwise within the policy.

1.5. Repeal of former rule. This rule amends W. Va. 126CSR28, West Virginia Board of Education (hereinafter WVBE) Policy 2525, West Virginia's Universal Access to Early Education System (hereinafter Policy 2525), filed July 13, 2007 and effective August 13, 2007.

\section{\$126-28-2. Guidelines.}

2.1. WV Pre-k classrooms shall:

2.1.1. be voluntary.

children.

2.1.2. be readiness programs that are designed to meet the needs of all eligible

2.1.3. deliver content through the chosen approved curricular framework and the West Virginia Early Learning Standards Framework W. Va. 126CSR440, WVBE Policy 2520.15, Early Learning Standards Framework Content Standards and Learning Criteria for West Virginia Pre-kindergarten (hereinafter the WVELSF).

2.1.4. provide the building blocks for literacy. 
Appendix A

Policy 2525 (P. 2)

2.1.5. view children within the context of their family.

2.1.6. utilize state approved curricular frameworks and assessments to inform and individualize instruction.

2.1.7. employ staff with strong professional education preparation in child development and early childhood education.

2.1.8. build on what children already know in order to consolidate their learning and foster acquisition of new concepts and skills through hands-on active exploration of their learning environment, problem solving, communication, creativity, and use of their imaginations.

2.1.9. incorporate meaningful ways of communicating with and involving parent/guardian/family.

2.1.10. evaluate program success for meeting the health and safety needs of the child through the use of the Early Childhood Environment Rating Scale - Revised which will be administered by a trained, collaborative county team or outside experienced observer team.

guidelines.

2.1.11. establish staffing requirements and class size according to recommended

2.1.12. maximize existing community, state and federal resources. education and care.

2.1.13. be an integral part of the West Virginia birth to kindergarten system of

2.1.14. take place in safe and healthy environments.

2.1.15. be inclusive of all children.

\section{\$126-28-3. Definitions.}

3.1. Active media means materials that the child can control while participating in an activity such as taking pictures with cameras, making audio or video tapes, playing video games or working on a computer.

3.2. Adequate supervision means the observation, oversight, and guidance of the individual child or groups of children by the staff member taking responsibility for the ongoing activity of each child so that the staff member is close enough to intervene, if necessary, to protect the child from harm. Adequate supervision requires the staff member's physical presence with the children, knowledge of the child's program of activities, individual needs, habits, 
Appendix A

Policy 2525 (P. 3)

interests and special problems, if any, and the acceptance of accountability for the child's or groups of children's care.

3.3. Approved funding sources means any funds used directly to support WV Pre-k classrooms for eligible children including West Virginia State Aid Funding Formula, Head Start funds, Even Start funds, Temporary Assistance to Needy Families, Child Care Development Funds, funds under the Elementary and Secondary Education Act (No Child Left Behind), funds provided by the School Building Authority of West Virginia, funds under the Public Law 108446, Individuals with Disabilities Education Improvement Act of 2004, and any other private or public funds.

3.4. Approved $W V$ Pre-k participating programs includes public school preschool, including preschool special education, and any community provider that contracts with the Local Education Agency (hereinafter LEA) including, but not limited to, childcare, private preschool, Head Start, and community-based programs that meet or exceed all of the requirements of this policy and are a part of a county's collaborative plan. Children participating in approved WV Pre-k participating programs can be counted in the school aid funding formula and the participating programs are eligible to receive funds through contractual agreements with or direct administration by the county school system.

3.5. Collaborative setting means a classroom of WV Pre-k children operated by a community program with resource support from the state through the Local Education Agency (LEA) or a classroom operated jointly by a community program and LEA.

3.6. Contracted community program shall mean any provider of early childhood services that meets all of the requirements of this policy and has a contractual agreement with the county school system to operate a WV Pre-k classroom.

3.7. Core knowledge and core competencies for early care and education professionals shall mean the sets of skills and knowledge that represent common standards of satisfactory practice in the early childhood field as defined in West Virginia State Training And Registry System (hereinafter WV S.T.A.R.S.) Core Knowledge and Core Competencies for Early Care and Education Professionals. 
Appendix A

Policy 2525 (P. 4)

3.8. County collaborative plan means the plan each county school board, in cooperation with the county collaborative team, is required to submit. The plan shall include an analysis of facility and personnel needs, an analysis of demographics of the county related to the early childhood program implementation, financial requirements for implementation and potential sources of funding to assist implementation, details of how the county board will cooperate and collaborate with other early childhood programs, specific timelines for implementation, and any other requirements of this policy.

3.9. Developmentally appropriate means early childhood programming, curricula, and activities that address the stages of each child's cognitive, physical, social/emotional, and cultural development and utilizes a balanced approach of both child initiated and teacher directed instruction. Children should be actively engaged in hands-on, interactive activities for learning for a substantial portion of the day.

3.10. Direct supervision means that a qualified staff member is physically present in the same room, area, or vehicle with the child or group of children, visually monitoring the interactions of the children.

3.11. Eligible child shall mean any child, regardless of ability, who is four prior to September 1 of the year he/she is to enroll. Three year old children can be enrolled in the WV Pre-k System if they have an Individualized Education Program (hereinafter IEP.) Three year olds without IEPs may be present in the collaborative classroom if they qualify under the community program's enrollment guidelines. Children may not be excluded based on developmental delays. Children who are five prior to September 1 shall be enrolled in kindergarten, instead of WV Pre-k, unless the teacher, in cooperation with the parent, uses assessment data to determine that kindergarten placement for that child is not in the child's best interest. A five year old with special needs may be placed in a WV pre-k classroom if the IEP committee deems the setting as the best placement for the child. A child may remain in the WV Pre-k classroom for longer than one year if the decision is in the best interest of the child and based on curricular assessment data with mutual agreement between the teacher and parent/guardian.

3.12. Experienced Early Childhood Environmental Rating Scale - Revised (hereinafter ECERS-R) Observer is a person who has successfully completed modules I, II, and III of the West Virginia Experienced ECERS-R Observer Training.

3.13. Local Education Agency (hereinafter LEA) Pre-k County Contact is the person responsible for implementation of the West Virginia Pre-k System at the local education agency. 
Appendix A

Policy 2525 (P. 5)

3.14. LEA means the county school system as the administrative entity for each county.

3.15. HealthCheck is the screening protocol recommended for the licensed health care providers to be used for all children entering WV Pre-k. HealthCheck meets the requirements for vision, hearing, speech, language, and oral health. The HealthCheck screening form is the preferred documentation method of licensed health care providers to record screenings.

3.16. Passive media means materials the child cannot control while participating in an activity such as watching television, films and video tapes.

3.17. Program availability means each preschool classroom must operate a minimum of 12 hours per week and cannot operate for more than 30 hours per week during the school year calendar. Each preschool classroom must be offered no less than 108 instructional days per school year. Up to six of those 108 days may be used for home visits/parent conferences.

3.18. Staff: child ratio means a relationship which describes the number of children ene qualified staff members or substitutes are permitted to supervise.

3.19. Staff member means any paid personnel, including substitutes, and student teachers.

3.20. Teacher caseloads means the total number of children a teacher in a WV Pre-k classroom is responsible for teaching and assessing each year.

3.21. Trained collaborative ECERS-R team means two or more persons with experience and knowledge of early childhood who have completed, at a minimum, the WV Experienced ECERS-R Observer Training, Module I. One member must be listed as an Experienced Early Childhood Environment Rating Scale-Revised (hereinafter ECERS-R) Observer.

3.22. Universal access shall mean that every eligible child in the county has access to a high quality WV Pre-k classroom that meets or exceeds all of the requirements of this policy.

3.23. Universal application means an enrollment form that may be used by all participating community partners at the county level to determine placement and enrollment of eligible children in the county's pre-k system.

3.24. Universal precautions means procedures to be followed for infection control in all situations to prevent the transmission of blood borne germs that may be spread through blood or body fluids that might contain blood. 
Appendix A

Policy 2525 (P. 6)

3.25. West Virginia Community Program Permanent Authorization is a credential requiring teachers in early childhood community programs to have earned an Associate's degree in early childhood, child development, or occupational development with an emphasis in early childhood/child development and 18 hours of prescribed college coursework.

\section{§126-28-4. Parent/Guardian Involvement and Family Support.}

4.1. Parent/guardian involvement and family support must include:

4.1.1. a minimum of two documented face to face conferences annually with each child's parent/guardian/family. Home visits are recommended for these conferences.

4.1.2. documented methods of communicating with parents/guardians such as newsletters, child activity reports, phone calls, home visits, e-mail and conferences.

4.1.3. services to children and their families necessary to support the child in his/her transition into, participation in, and transition out of the program.

4.1.4. for children who come from homes where languages other than English are spoken, support services including communication that is comprehensible and supportive of both the native language and English language development.

4.1.5. support services pursuant to WV 126CSR16, WVBE Policy 2419 Regulations for the Education of Exceptional Students with Exceptionalities (hereinafter Policy 2419) provided in accordance with the needs specified in the child's Individualized Education Program for preschool children with disabilities who are integrated into the program.

4.1.6. opportunities for parents/guardians/family to participate in decision making about their child's education.

4.1.7. classrooms that are open to parents/guardians/families and where parents/guardians/families are encouraged to observe children in the classroom and to participate in classroom activities.

\section{\$126-28-5. Attendance.}

5.1. Enrollment in an approved participating WV Pre-k program is voluntary; however, once the child is enrolled, attendance must follow W. Va. Code §18-8-1, et seq., which allows the program administrator (i.e. principal, director, executive director), teacher and 
Appendix A

Policy 2525 (P. 7)

parent/guardian to disenroll the child if they concur that requiring further attendance for that school year is not in the best interest of the child. Once a child is disenrolled, re-enrollment is not guaranteed.

5.2. Each county must establish and implement procedures to ensure that the parent/guardian and other family members, as appropriate, understand about the availability of services, the attendance policy and the benefits of childhood education.

5.3. Each county must establish and implement a provision for working with families whose children are chronically absent and/or tardy that does not penalize the family for acting in the best interest of the child.

\section{\$126-28-6. Collaboration and the County Plan.}

6.1. Through joint planning with community partners, each county board of education must submit a county plan to the Secretary of West Virginia Department of Health and Human Resources (hereinafter WVDHHR) and WVBE that reflects meaningful involvement of the county collaborative team.

6.2. The West Virginia Department of Education (hereinafter WVDE), in collaboration with the West Virginia Department of Human Resources has the responsibility of convening a committee to review the quality and content of the county plans by representatives from the WVDE, WVDHHR, and the Head Start Collaboration Office. The committee will make recommendations to the Secretary of WVDHHR and the WVBE regarding approval of the county collaborative plans. Participation on the committee by WVDHHR and Head Start State Collaboration Office will ensure the (1) maximization of federal and other available funds and (2) maximization of Head Start programs and other public and private programs approved by the State Superintendent of Schools.

6.3. Each county early childhood team shall meet regularly throughout the year to ensure that the following outcomes are met.

6.3.1. Joint decisions are made about the location of WV Pre-k classrooms including Preschool Special Education classes.

6.3.2. Decisions are made about responsibilities for sharing resources for each classroom including but not limited to staffing, facilities, food service and transportation. 
Appendix A

Policy 2525 (P. 8)

6.3.3. A county wide joint universal application and enrollment process that includes a selection and placement criteria for children is utilized.

6.3.4. Services for children with identified special needs are provided in least restrictive environment according to the requirements of that child's IEP.

\subsubsection{All approved participating programs are included or represented.}

6.4. If a county plan is not recommended for approval, it will be returned to the county board of education with an explanation and instructions for re-submission. The County Superintendent and LEA county contact shall share this information with the county early childhood collaborative team upon receipt. The changes to the plan shall be signed by all required collaborative partners of the county collaborative team prior to resubmission. Once the county plans are reviewed by the collaborative review committee and recommended for approval or nonapproval, the signature of the Secretary of WVDHHR is secured. The Secretary of WVDHHR then forwards the list of approved and nonapproved plans to the WVBE for the July board meeting of the WVBE. At this meeting, the WVBE will vote to accept or reject the Secretary's list.

6.5. Changes, updates and amendments to the county plans are to be submitted to the WVDHHR and the WVDE in February each year until 2013 or until such time as the county offers universal access to a high quality program, as defined by this policy, for all eligible children in that county. Collaborative settings support the maximization of resources as required by W. Va. Code $\$ 18-5-44$. Counties must maximize early childhood resources by collaborating with existing programs within the county before opening new classrooms operated solely by the LEA, unless those collaborative partners do not exist, or choose not to participate. A county's collaborative plan will reflect the documentation to support maximization of resources, as well as, reflect how this plan identifies both potential resources and the efficient use of currently existing resources.

6.6. All changes of substance to the approved county collaborative plan or approved universal pre-k program structure must be submitted with signatures of all the required collaborative partners for approval to the Secretary of WVDHHR and the WVBE, or their respective designees, 30 days prior to the implementation of the changes. Failure to do so will result in the non-approval of the change.

6.7. In order to support counties in the effort to maximize existing resources by 20122013 or by full implementation, no less than $50 \%$ of the classrooms for eligible children must be provided through contractual agreements with community programs, including but not limited to Head Start and child care, unless the county collaborative team can document that those 
Appendix A

Policy 2525 (P. 9)

programs do not exist in that county, can never meet the mandates of this policy, or choose not to participate. Counties shall explore all feasible supports to enable community partners to meet the requirements of this policy, including providing certified teachers in community programs, before determining that programs cannot meet the mandates. This may not be construed to mean that counties will provide education services in public school settings only and contract out support services but rather that $50 \%$ of the classrooms for eligible children must be contracted with qualifying providers in collaborative settings. This ratio of community to public school providers can only be decreased with the written permission of both the WVBE and the Secretary of WVDHHR. When the county school system includes the eligible children attending in an approved, contracted community program in the count for the school aid funding formula, a portion of the money generated by the formula must be used through the contractual agreement to insure that the requirements of this policy are met and adhered to for the length of the contract. Counties shall phase in classrooms incrementally to meet the requirement for universality by 2012-13. In an instance when the LEA is the Head Start grantee, those settings are considered part of the mandate for collaboration; however, the collaboration does not fulfill these requirements for collaboration with community partners if those partners are available.

6.8. The county collaborative team must include, at a minimum, representation from the county school system preschool program, the county school system preschool special needs program, a licensed community child care program in that county not operated by the county school system, the Head Start program in that county, the local department of health and human resources, and a parent/guardian of a preschool child. Due to the nature of child care, every licensed child care program in that county must be extended an invitation to participate on the planning team. The county must submit a list of invitees with the county plan; however, all responses shall be kept on file at the LEA.

6.9. The county collaborative team shall annually assess the composition of the county collaborative team and should include a representative from the West Virginia Birth to Three System Regional Administrative Unit, the parent/guardian educator resource centers, child care resource and referral agencies, classroom teachers, Family Resource Networks, early parent/guardian education, local apprenticeship for child development specialist council, health, Starting Points, business, faith based early childhood program providers, Community Action, child abuse prevention agencies, higher education, and/or other community organizations and persons interested in, knowledgeable of, working with young children and their families providing support and education.

6.10. Any member of the county collaboration team that will provide services to eligible children in that county must follow all rules and regulations as outlined in this policy. The contract/agreement between the collaborating agencies must address how the collaborative will assure compliance with all applicable regulations and standards. It is the responsibility of the 
Appendix A

Policy 2525 (P. 10)

collaborative partners to ensure that the staff and administrators receive professional development related to the policies and regulations of all the collaborative partners.

6.10.1. In collaborative classrooms where community partners have regulations such as the Head Start Performance Standards or WVDHHR Child Care Licensing, these regulations shall apply in addition to WVBE Policy 2525.

6.10.2. Part-day community programs that are exempt from child care center licensing under W.Va. Code §49-2B-3(e)(1) must be licensed in order to participate in WV Pre-k unless they are located in an approved LEA site.

6.11. The county collaborative plan must include documentation by each participating partner of his or her role in the development of the county collaborative plan.

6.12. The LEA must submit a request with the county collaborative plan to complete the determination process for universality for the following year.

6.13. By August $1^{\text {st }}$ of each year, a comprehensive universal pre-k fiscal report must be submitted to the WVDE Assistant Director of Early Learning and Literacy. This report must include a list of board approved contracts noting collaborative universal pre-k classrooms for the upcoming school year.

6.14. Every county collaborative team must use a universal application and enrollment process that includes the necessary information to support enrollment in Head Start, child care and other community partner programs.

\section{\$126-28-7. Personnel Standards.}

7.1. Teachers employed in a WV Pre-k classroom and hired by the LEA must hold the an appropriate license issued by the WVDE.

7.2. To fully maximize resources, community partners may choose to hire their own personnel for the WV Pre-k collaborative classroom. Teachers employed in a WV Pre-k classroom operated by a community program may hold a Professional Teaching Certificate endorsed in Early Education, Preschool Education, or Preschool Special Needs; OR

7.3. When no fully certified teacher is available within or for hire by the community program, the person employed by a community program should hold the minimum of a bachelor's degree and meet the requirements specified in W. Va. 126CSR136, WVBE Policy 5202, Minimum Qualifications for the Licensure of Professional/Paraprofessional Personnel and 
Appendix A

Policy 2525 (P. 11)

Advanced Salary Classifications (hereinafter Policy 5202), Section 11.7, for the Permanent Authorization, endorsed for Community Programs; OR

7.4. When no fully certified teacher or an individual eligible for the Permanent Authorization endorsed for Community Programs is available within or for hire by the community program, the person employed by the community program must be eligible for a Temporary Authorization for Community Programs.

7.4.1. General Criteria for the Permanent Authorization for Community Programs issued prior to August 1, 2013: The Permanent Authorization for Community Programs may be issued to an individual employed by a community program who has completed 1) the minimum of an associate's degree through an accredited institution of higher education as defined Policy $5202, \S 126-136-4.5 ; 2)$ the general requirements specified in Policy 5202, §126-136-9.1.; 3) the minimum GPA specified in Policy 5202 §126-136-9.8; and the conditions for issuance specified in $\S 126-28-7.3$.

7.4.2. Conditions for issuance: The applicant for the Permanent Authorization for Community Programs must submit evidence of the following:

a. College/University Coursework: The minimum of an associate's degree in child development, early childhood, or occupational development with an emphasis in child development/early childhood; AND

b. Specialized Training: Verification of coursework and/or professional development, approved by the WVDE, in the areas of preschool special education, child development, preschool curriculum, early language and literacy, assessment of young children, and family and community involvement; AND

c. Experience. - Verification of at least one year of early education teaching experience.

program director.

d. Verification of employment- Signature of contracted community

7.4.3. Validity Period. - The Permanent Authorization for Community Programs shall continue to be valid unless surrendered, suspended, or revoked for just cause.

7.5. General Criteria for the Permanent Authorization for Community Programs issued after August 1, 2013. 
Appendix A

Policy 2525 (P. 12)

7.5.1. General Criteria for the Permanent Authorization for Community Programs issued after August 1, 2013: The Permanent Authorization for Community Programs may be issued to an individual employed by a community program who has completed 1) the minimum of a bachelor's degree through an accredited institution of higher education as defined in Policy 5202, §126-136-4.5; 2) the general requirements specified in Policy 5202, §126-136-9.1; 3) the minimum GPA of 2.5 specified in Policy $5202 \S 126-136-9.8$; and the conditions for issuance specified in $\S 126-28-7.3$.

7.5.2. Conditions for Issuance: The applicant for the Permanent Authorization for Community Programs must submit evidence of the following:

a. College/University Coursework: The minimum of a bachelor' degree in early childhood, preschool, child development and family studies, early childhood special education or an early education field; AND

b. Specialized Training: Verification of coursework and/or professional development, approved by the WVDE, in the areas of preschool special education, child development, preschool curriculum, early language and literacy, assessment of young children, and family and community involvement; AND

teaching experience.

c. Experience: Verification of at least one year of early education

program director.

d. Verification of Employment: Signature of contracted community

7.5.3. Validity Period: The Permanent Authorization for Community Programs shall continue to be valid unless surrendered, suspended, or revoked for just cause.

7.6. When no individual who is eligible for the Permanent Authorization for Community Programs is available within or for hire by the community program, the person employed by the community program must be eligible for a Temporary Authorization for Community Programs.

7.6.1. General Criteria for the Temporary Authorization for Community Programs issued prior to August 1, 2013 - The Temporary Authorization for Community Programs may be issued to an individual employed by a community program who has completed 1) the minimum of an associate's degree through an accredited institution of higher 
Appendix A

Policy 2525 (P. 13)

education as defined Policy 5202, Section 5.4;2) the general requirements specified in Policy 5202, Section 9.1.1; 3) the minimum GPA specified in Policy 5202, Section 9.8; and the conditions for issuance specified in Section 7.4.

7.6.2. Conditions for Issuance. - The applicant for the Temporary Authorization for Community Programs must submit evidence of the following:

a. College/University Coursework. - The minimum of an associate's degree in child development, early childhood, or occupational development with an emphasis in child development/early childhood; AND

teaching experience.

b. Experience. - Verification of at least one year of early education

c. Commitment. - Submission of Professional Commitment verifying the applicant's agreement to complete coursework and/or professional development, approved by the WVDE, in the areas of preschool special education, child development, preschool curriculum, early language and literacy, assessment of young children, and family and community involvement.

7.6.3. Validity Period. - The Temporary Authorization for Community Programs shall be valid for one school year and shall expire on June 30. An educator employed on or after January 1 may be issued a Temporary Authorization valid until June 30 of the following school year.

7.6.4. Three Year Limit. - All requirements for the Permanent Authorization for Community Programs must be completed within three years of the original issuance of the Temporary Authorization for Community Programs.

\subsection{Renewal of the Temporary Authorization for Community Programs.}

7.7.1. Conditions of Issuance. - The holder of the Temporary Authorization for Community Programs who continues to be employed by a community program must submit evidence of satisfying the following:

a. College/University Coursework. - Completion of credit approved by the WVDE through either six semester hours of coursework reflecting the minimum 3.0 GPA; AND 
Appendix A

Policy 2525 (P. 14)

b. Commitment. - Submission of Professional Commitment verifying the applicant's agreement to complete coursework and/or professional development, approved by the WVDE, in the areas of preschool special education, child development, preschool curriculum, early language and literacy, assessment of young children, and family and community involvement OR coursework leading to teacher licensure in Early Education, Preschool Education, or Preschool Special Needs.

7.8. When no individual who is eligible for the Permanent Authorization for Community Programs is available within or for hire by the community program, the person employed by the community program must be eligible for a Temporary Authorization for Community Programs.

7.8.1. General Criteria for the Temporary Authorization for Community Programs issued after August 1, 2013. - The Temporary Authorization for Community Programs may be issued to an individual employed by a community program who has completed 1) the minimum of a bachelor's degree through an accredited institution of higher education as defined in Policy 5202, Section 5.4; 2) the general requirements specified in Policy 5202, Section 9.1.1; 3) the minimum GPA of 2.5 as specified in Policy 5202, Section 9.8; and the conditions for issuance specified in Section 7.4.

7.8.2. Conditions for Issuance. - The applicant for the Temporary Authorization for Community Programs must submit evidence of the following:

degree; AND

a. College/University Coursework. - The minimum of a bachelor's

b. Experience. - Verification of at least one year of early education teaching experience.

c. Commitment. - Submission of Professional Commitment verifying the applicant's agreement to complete coursework and/or professional development, approved by the WVDE, in the areas of preschool special education, child development, preschool curriculum, early language and literacy, assessment of young children, and family and community involvement.

7.8.3. Validity Period. - The Temporary Authorization for Community Programs shall be valid for one school year and shall expire on June 30. An educator employed on or after January 1 may be issued a Temporary Authorization valid until June 30 of the following school year. 
Appendix A

Policy 2525 (P. 15)

7.8.4. Three Year Limit. - All requirements for the Permanent Authorization for Community Programs must be completed within three years of the original issuance of the Temporary Authorization for Community Programs OR

7.8.5. Five Year Limit. - All requirements for the Professional Teaching Certificate endorsed for Early Education, Preschool Education, or Preschool Special Needs must be completed within five years of the original issuance of the Temporary Authorization for Community Programs.

7.9. Renewal of the Temporary Authorization for Community Programs.

7.9.1. Conditions of Issuance. - The holder of the Temporary Authorization for Community Programs who continues to be employed by a community program must submit evidence of satisfying the following:

a. College/University Coursework. - Completion of credit approved by the WVDE through either six semester hours of coursework reflecting the minimum 3.0 GPA; AND

b. Commitment. - Submission of Professional Commitment verifying the applicant's agreement to complete coursework and/or professional development, approved by the WVDE, in the areas of preschool special education, child development, preschool curriculum, early language and literacy, assessment of young children, and family and community involvement OR coursework leading to teacher licensure in Early Education, Preschool Education, or Preschool Special Needs .

7.10. Individuals who were issued either a Permanent Authorization endorsed for Community Programs according to Section 7.4 or a Temporary Authorization endorsed for Community Programs in accordance to Section 7.6 continue to be properly credentialed after August 1, 2013.

7.11. Persons who are employed to meet the staff/child ratios but are not certified teachers such as aides, assistants, or paraprofessionals must meet the criteria set forth in the WV S.T.A.R.S. career pathway level II. Level II is defined as persons who are at least 18 years old with a high school diploma or equivalent and one years of experience and possess the ability to understand and practice the core knowledge/core competencies with direction and instruction or through sponsorship of a professional organization or qualified mentor. 
Appendix A

Policy 2525 (P. 16)

\section{\$126-28-8. Health and Safety Requirements.}

8.1. Recognizing that all children within the WV Pre-k System shall be in safe and healthy environments, and that all of the collaborative partners within the WV Pre-k System have rules and regulations governing various aspects of their programming, this policy sets forth a core set of common health and safety standards that must be followed in addition to any existing rules and regulations based on funding sources for individual programs. Classrooms in public schools will be monitored as a part of the Office of Education Performance Audit auditing process in addition to daily supervision by county and school level administrators to assure all health and safety requirements are met. Collaborative Head Start classrooms will also be monitored for compliance with the Head Start Performance Standards in partnership with local and federal Head Start personnel. Classrooms operated by or in collaboration with licensed child care will be licensed under W.Va.§78CSR1, Child Care Centers Licensing

8.2. WV Pre-k classrooms shall limit class size to no more than twenty children per classroom with no less than two adults, one of whom is a teacher. Caseloads for teachers of classrooms with children who have IEPs shall meet the requirements of WVBE Policy 2419.

8.3. Prior to or during the first week of employment in a WV Pre-k classroom, an orientation for new staff will be provided that includes a review of: WVBE Policies 2525 and 2520.15; classroom operational requirements; policies and procedures for confidentiality and information disclosure; behavior management; reporting child abuse and neglect and emergencies; policies and procedures for basic sanitation and infection control; policies and procedures for safety; including prevention of injury both indoors and outdoors; and fire safety; including the use of fire extinguishers; and training in abuse recognition and prevention. Existing staff members shall be knowledgeable of the above policies and procedures.

8.4. When children with IEPs are enrolled in the WV Pre-k classroom, ratios shall be met as set forth in WVBE Policy 2419.

8.5. At least one meals (breakfast and/or lunch) must be provided in accordance with the nutrition guidelines set forth in the WVDE Child and Adult Care Food Program or National School Lunch Program. Meals shall be served in a setting that encourages socialization and selfhelp skills, where the children and staff members are seated together when eating, and classroom staff members provide supervision and encourage positive eating habits and conversation. Breakfast and/or lunch must meet the USDA meal pattern or nutrient standard menu planning requirements. 
Appendix A

Policy 2525 (P. 17)

8.6. All children entering an approved participating WV Pre-k classroom must have age appropriate immunizations upon enrollment as defined by the Centers for Disease Control and Prevention (CDC) Advisory Committee on Immunization Practices (ACIP) and recommended by WVDHHR, located at http://www.wvdhhr.org/immunizations/pdf/PreK_Vacc_Chart final.pdf. Children that are not fully immunized may be provisionally enrolled providing a plan has been developed to assure full immunization, but may not enter WV Pre-k classrooms until they have received the first dose of each required vaccine.

8.7. A WV Pre-k classroom should have on file within 45 days of enrollment or prior to the first day of school attendance a record of a HealthCheck screening, or other comprehensive health screening comparable to the HealthCheck protocol. All screening forms shall be signed and dated by the child's licensed health care provider and completed within the past 12 calendar months. Required special instructions for the WV Pre-k classroom shall be included on the screening form. Counties can retain the right to conduct follow-up screening.

8.8. Children in the WV Pre-k System classroom shall be observed by staff daily for changes that may indicate injury, infestation, fever,_or illness, and record any observed changes in the child's file and notify the family.

8.9. Student information related to all health and medical conditions and documented on HealthCheck form or any other comparable information must be treated as confidential information and be maintained according to The Family Educational Rights and Privacy Act (FERPA) (20 U.S.C. $\$ 1232 \mathrm{~g} ; 34$ CFR Part 99) and in such a manner that no one could view these records without proper authorization as specified in W.Va.126CSR94, WVBE Policy 4350, Procedures for the Collection, Maintenance and Disclosure of Student Data. Failure of school personnel to comply with the above rules shall result in personnel disciplinary actions based on W.Va.126CSR142, WVBE Policy 5310, Performance Evaluation of School Personnel W. Va. 126CSR, and WVBE Policy 5902, Employee Code of Conduct.

8.10. Staff members shall utilize universal precautions when exposed to blood and body fluids that might contain blood, as specified in W.Va.126CSR51, WVBE Policy 2423, Communicable Disease Control.

8.11. The children shall have adequate supervision at all times. When children are on the premises, a WV Pre-k participating program shall ensure that two adults are present with children. The county shall establish policies and procedures for ensuring adequate supervision and safety of children.

8.12. Staff shall ensure that the guidance, behavior management and discipline practices are constructive and educational in nature, appropriate to each child's age and circumstances, and in keeping with the WV Pre-k program's policies and procedures; 
Appendix A

Policy 2525 (P. 18)

8.13. At all times, staff members are responsible for providing positive guidance that is appropriate to each child's age, understanding and circumstances. When a behavior problem arises, qualified staff members shall:

8.13.1. redirect the child to alternative behavior or other activities;

8.13.2. encourage the child to control his or her own behavior, cooperate with others and solve problems by talking through the issues;

8.13.3. speak so the child understands that feelings are acceptable, but inappropriate behaviors and actions are not; and/or

8.13.4. take action that relates to inappropriate behavior and ensure that any action that is taken is without bias and in proportion to the child's act.

8.14. Handling Behavior Problems. Staff members and other adults in a WV Pre-k classroom shall not handle behavior problems by:

8.14.1. subjecting a child to physical punishment of any kind.

8.14.2. putting anything in or on a child's mouth as punishment;

8.14.3. restraining a child by any means other than a firm grasp around a child's arms or legs and then for only as long as is necessary for the child to regain control;

8.14.4. subjecting a child to psychological punishment of any kind, including but not limited to, ridicule, humiliation, or negative remarks about the child or the child's family, including remarks about race, gender, religion or cultural background;

8.14.5. using harsh or profane language, yelling, screaming, or actual or implied threats of physical punishment;

training;

8.14.6. punishing or threatening a child in association with food, rest or toilet

8.14.7. isolating a child without supervision or placing the child in a dark area;

8.14.8. permitting a child to discipline other children;

8.14.9. punishing an entire group for the actions of one child or a few children; or 
Appendix A

Policy 2525 (P. 19)

8.14.10. seeking or accepting parental permission to use physical punishment or other actions prohibited by this rule.

8.15. A WV Pre-k program shall develop, implement and maintain policies and procedures for the reporting of child abuse and neglect that include:

\subsection{1. the definition of child abuse and neglect, and}

8.15.2. the requirement to report immediately, in accordance with W. Va. Code $\S$ 49-6A-1 et seq., any suspected incident of child abuse and neglect to Child Protective Services, or when the staff member believes that the designated person-in-charge would not or has failed to report the suspected incident, to the Child Abuse Hotline, 1-800-352-6513.

8.16. Each WV Pre-k classroom shall provide a minimum of 35 square feet per child of usable classroom space. A WV Pre-k program shall not provide activity space in a basement area unless the basement area is approved by the State Fire Marshal.

8.17. A WV Pre-k program shall provide an outdoor activity area that includes a minimum 75 square feet of space per child, or if the outdoor play area has less than that a WV Pre-k program shall establish an outdoor play schedule for rotating groups of children to meet the minimum space requirement and to ensure that each child has an opportunity to play outdoors each day, weather permitting.

8.18. The WV Pre-k program shall provide one flush toilet and one lavatory per 15 children, excluding children in diapers who are not receiving toilet training. Toilets will be easily accessible to the children and provisions must be made so that pre-k children have adequate supervision during toileting. At no time should pre-k children be without adult supervision in the bathroom.

8.19. A WV Pre-k classroom shall provide appropriate daily opportunity for the children in care to have supervised practice of brushing teeth;

8.20. A WV Pre-k classroom shall provide equipment and materials for indoor activities that are clearly organized within activity areas that support programming goals and allow for adequate supervision.

8.21. Pre-K classroom shall provide an opportunity for a child to nap or rest. If the program operates for more than four hours per day a regular rest period shall be scheduled and utilized when the child desires or exhibits the need to rest. Programs operating for less than four hours daily shall assure that children have access to rest areas as necessary. These rest or nap areas shall be set up to reduce distraction or disturbance from other activities. Appropriate sleeping equipment shall be provided by the program. Children are not allowed to sleep on the 


\section{Appendix A}

Policy 2525 (P. 20)

floor or in a sleeping bag or on linens without mats or cots.

8.22. Outdoor activity shall be considered an extension of the classroom. When children participate in WV Pre-k programming for more than four daytime hours, weather permitting, a WV Pre-k classroom shall provide a minimum of one hour of outdoor activity daily as a part of the curriculum, on days when the temperature is 40 degrees Fahrenheit or more, and may provide outdoor activity on other days, as appropriate. Daily outdoor activity shall support the implementation of the approved WV Pre-k curriculum and the WVELSF. Programs operating less than four hours per day must have 30 minutes of daily outdoor activity, weather permitting.

8.23. Staff members shall wash their hands before starting work; and staff members and children shall wash their hands with soap and warm, running water for at least 20 seconds:

8.23.1. when hands are contaminated with body fluids;

8.23.2. before preparing, handling or serving food, or setting the table;

8.23.3. after toileting, handling diapers or assisting a child with toilet use;

8.23.4. before and after eating meals or snacks;

8.23.5. after handling pets or other animals;

8.23.6. before giving medication;

8.23.7. after playing outdoors;

8.23.8. after handling garbage; and

8.23.9. after removing protective gloves used for any purpose.

8.24. Because of allergies and the potential dangers associated with having animals in the classroom, animals can only be in the pre-k classroom with prior parent awareness and approval.

8.24.1. A WV Pre-k classroom shall not have on the premises ferrets, birds, reptiles, including snakes, lizards and turtles, or any wild or dangerous animals.

8.25. A WV Pre-k classroom shall ensure that the outdoor play area for a child under school age:

8.25.1. is enclosed on all sides by a natural barrier or secure fence that is at least four feet high with a bottom edge that is less than three and one-half inches from the ground; 


\begin{abstract}
Appendix A
Policy 2525 (P. 21)

inches;

8.25.2. if it has a fence, the fence has no openings greater than three and one-half
\end{abstract}

8.25.3. if it has a natural barrier, the barrier has the strength and density to prevent humans and animals from entering or exiting the playground;

8.25.4. if it is attached to a building, that the barrier or fence provides at least two exits from the play area, including one exit that is at a distance from the building;

8.25.5. when it has an exit that does not lead directly indoors, that it is protected by a gate equipped with a closure mechanism that is out of the reach of a small child and prevents the child from leaving the play area, but can be easily opened by an adult, and

8.25.6. has age appropriate equipment to support the curriculum and the children's development.

8.26. For programs participating in the county collaborative plan, transportation is considered a support, not a mandated service, unless it is a related service for children with disabilities in accordance with state and federal requirements. When transportation is provided:

8.26.1. bus drivers are trained in the supervision of young children (in addition to any other staff development received).

8.26.2. children transported by a school bus who attend a pre-k classroom and are not yet enrolled in kindergarten will sit in a segregated area of the vehicle with other pre-k children.

8.26.3. staff shall be available to assist children on and off buses at the WV Pre-k site. If a parent/guardian is unable to meet the bus, there shall be a person designated by the parent/guardian to assist the child. Bus drivers must inspect the bus at all final drop off points to assure that no children are left on the bus and these inspections must be charted. A log of daily inspections shall be maintained on file with the principal/supervisor. At each pre-k site where bus transportation is provided, a designated person must follow-up with the family of any child who is not present or accounted for each day.

8.27. When a WV Pre-k classroom plans an activity that involves active media, the center shall ensure that:

8.27.1. the active media supplements but does not replace traditional early childhood materials;

8.27.2. a child has a choice of other activities and materials; 
Appendix A

Policy 2525 (P.22)

8.27.3. staff members are available to support the activity by discussing the use of the active media with the child;

8.27.4. the computer software chosen is developmentally appropriate and supports creative play and learning; and

8.27.5. no video games or computer software with sexual or violent content, profanity or aggressive behavior are used.

8.28. If passive media is used, a WV Pre-k classroom shall ensure that:

8.28.1. passive media is not routinely part of the daily schedule;

8.28.2. that staff members are available to support the use of it by discussing what is viewed with the child;

8.28.3. the contents of television and movies are designed to benefit the child, with limited viewing time and the child who does not wish to watch has a choice of other activities; and

8.28.4. no television programs, cartoons or movies with sexual or violent content, profanity or aggressive behavior are viewed.

8.29. A WV Pre-k classroom shall ensure that products containing potentially hazardous chemicals, such as identified poisons, medications, certain cleaning supplies, and non toxic art supplies are properly handled and stored. These items should be stored in a locked cabinet away from food and in their original containers. These chemicals shall be used according to manufacturers' instructions, and in a manner that will not contaminate play surfaces or articles.

8.30. Plastic bags and Styrofoam objects shall not be accessible to the child less than four years of age.

8.31. Handling of balloons by pre-k children is prohibited.

\section{§126-28-9. Standards for Preparing Students.}

9.1. The WV Pre-k classroom must implement the WVELSF, which is aligned with Head Start Outcomes Framework and the kindergarten content standards and objectives. The content standards and objectives for programs serving eligible children are written to reflect a developmental continuum that enhances successful transition into kindergarten. Children shall be assessed on their individual developmental progress along the developmental continuum. 
Appendix A

Policy 2525 (P. 23)

9.2. When a WV Pre-k System classroom opens, it shall be equipped as required by the chosen curricular framework.

9.3. Time shall be set aside for joint planning by the teacher, co-teacher and/or other personnel working with the children.

\section{\$126-28-10. Curriculum and Assessment.}

10.1. Only comprehensive curricula systems and comprehensive assessment systems that are included on the approved list shall be used by WV Pre-k classrooms including classrooms that serve children with identified special needs.

10.2. Selection and use of supplemental materials/curricula enhancement, that address core content areas such as language and literacy acquisition or numeracy, must be based on scientifically based research and support the philosophy and techniques of the comprehensive curriculum and the requirements of this section. Guidance provided by the WVDE will provide local county pre-k collaborative teams assistance in collaborative, local decision making processes pertaining to supplemental materials/curricula enhancement. Instructional practices such as worksheets, extended periods of sitting, seat work at desks or tables, flashcards, prescribed sequence of content, content areas taught in isolation, requiring all children to be working on the same skill, lack of individualization, or a high level of teacher directed instruction are not allowed as a part of the supplemental curricula.

10.3. Comprehensive curricula systems and comprehensive assessment systems will be approved following a process similar to the process established by the WVDE, including, preschool special education, for adoption of instructional materials using the Partners Implementing an Early Care Education System (hereinafter PIECES) Advisory Council and appropriate subcommittees.

10.4. A comprehensive curricula system must meet the following standards:

10.4.1. include a philosophy, goals and objectives based on current knowledge of child development and learning styles and reflect an understanding of how children learn and develop by:

a. addressing the developmental needs of eligible children through practices that are consistent with current, nationally recognized, most effective practice;

learning approaches;

b. valuing exploration, creativity and construction as the child's primary

c. engaging children actively in the learning process and providing them with opportunities to make meaningful choices; 
Appendix A

Policy 2525 (P. 24)

d. responding to individual children's interest, strengths and needs based on ongoing observation and assessment; and

community.

e. supporting children so they view themselves as part of a larger

10.4.2. be balanced and designed to achieve the long-range goals for social, emotional, physical, cognitive and academic (early literacy, early numeracy, and language) achievement; by:

a. incorporating a wide variety of learning experiences, materials and equipment, and instructional strategies that are responsive to the differences in prior learning experiences, maturation rates, and learning styles young children bring to the classroom.

b. supporting a balance of large and fine motor activities, quiet and active times, individual and small and large group activities, child initiated and adult initiated activities, planned and spontaneous activities, and indoor and outdoor opportunities.

c. addressing the development of knowledge and understanding, processes and skills, dispositions and attitudes.

10.4.3. integrate development of all domains, abilities, and content that is relevant, engaging, and meaningful to young children; by:

a. meeting the developmental continuum contained in the content standards and objectives for eligible children as prescribed by the WVBE .

b. building on what children already know in order to consolidate their learning and foster the acquisition of new concepts and skills.

c. reflecting the needs and interest of individual children in the group by including the immediate environment and world with which the children are acquainted.

d. supporting integration of curriculum content through use of a planning organizer (such as themes, projects, key experiences, or webs).

e. including materials and activities that reflect a variety of cultures, languages, ages, abilities, and beliefs.

10.4.4. emphasize the development of thinking, reasoning and problem-solving skills through strategies such as open-ended questions, investigation, imaginative and dramatic play, and peer interactions; 


\section{Appendix A}

Policy 2525 (P. 25)

10.4.5. promote flexibility and adaptation to unique needs of children and families where ongoing observation and assessment are used to determine appropriate planning and adaptations for varied learning styles, temperaments, abilities, and languages or modes of communication; by:

a. integrating curriculum and assessment that benefits the child.

b. making opportunities for all children, regardless of ability, to participate in all activities through appropriate adaptations or modifications of activities, assistive technology, materials and/or learning environments.

10.4.6. design a learning environment that supports the curriculum and allows children of all abilities to make choices, to discover, to explore, and to solve problems;

a. assuring children's health and safety.

classroom.

b. clearly defining learning centers and incorporating them into the accessible to all children.

c. organizing and labeling materials and equipment and making them

environment.

d. incorporating non-stereotypical images in all elements of the

e. supplying a sufficient quantity and variety of appropriate materials.

f. rotating the availability of materials.

g. supporting a child's needs for privacy and a safe place to be alone.

h. introducing children to the unfamiliar.

10.4.7. support the importance of learning during routine times of the day and meeting the physiological needs of children; by:

smooth transitions.

a. promoting consistency in schedules and routines and facilitating

b. supporting continuity between home and school.

responsibility and independence.

c. encouraging children's participation in routines to develop 
Appendix A

Policy 2525 (P. 26)

d. recognizing the integral role of adults during routine times.

e. allowing for flexibility and adaptations for individual children.

f. supporting positive health and nutrition practices.

g. providing daily rest times for children in programs operating more than four hours/day and allowing non-nappers to engage in quiet activities.

10.4.8. promote, through a variety of strategies, the essential role of families as partners in planning and implementing their child's care and education;

10.4.9. emphasize the value of social interaction to learning in all domains and promote frequent, responsive, respectful interactions between children, staff and children, and staff and families;

10.4.10. recognize the role of children's psychological safety in learning and include guidance techniques that support children;

10.4.11. promote the use of developmentally appropriate curriculum and assessment principles to determine how technology is incorporated into the classroom environment as a complement to, not substitute for, effective teaching or good curriculum; and

10.4.12. include a comprehensive assessment system that evaluates the program's success in meeting the needs of young children, for helping them be ready to succeed in school, and documents the child's individual progress on the continuum of development by:

a. supporting the child's development and learning without threatening their psychological safety or feelings of self-esteem.

b. supporting the parent/guardian relationships with their children.

c. demonstrating the child's overall strengths and progress.

d. encouraging self-evaluation by the child.

e. relying on demonstrated performance of real, not contrived, activities.

f. utilizing a variety of tools and processes.

g. allowing for differences in learning style and rate. 
parents/guardians.

Appendix A

Policy 2525 (P. 27)

h. incorporating a mechanism for sharing with and feedback from the

i. including the parent/guardian as collaborative partners.

10.5. The curriculum will be a part of the inter-related approach of using curriculum, assessment and content standards and objectives to facilitate the individualization and direction of classroom programming.

10.5.1. Program components must include learning centers, incorporated within the classroom, designed to support literacy, early numeracy, and language, such as:

a. blocks and construction;

b. books;

c. manipulatives;

d. science and nature;

e. writing;

f. role playing;

g. physical activity;

h. art; and/or

i. music.

10.6. Classroom design and program implementation for eligible children must exclude the use of student desks, work sheets, long periods of sitting, use of shaming to discipline, withholding of food or bathroom privileges, or any other practice that is not appropriate for the ages/stages of the children or is harmful psychologically or physically.

\section{\$126-28-11. Transition and Continuity.}

11.1. Each program participating in the county plan must have a written and implemented plan for transitioning children into WV Pre-k and out of WV Pre-k into kindergarten. At a minimum the plan will include:

11.1.1. an opportunity for the child and his/her family to visit the setting into which the child is transitioning. 
Appendix A

Policy 2525 (P. 28)

11.1.2. written information to parent/guardian and/or other family members as appropriate about pre-k or kindergarten registration and what to expect in pre-k or kindergarten.

11.1.3. an opportunity for teachers/providers in the WV Pre-k and into kindergarten and eligible programs in that county to meet annually to discuss how to facilitate successful transition and support the reciprocity of readiness practices.

11.1.4. a county system for transferring assessment data, including but not limited to portfolios, for each child who has participated in a eligible program to the kindergarten teacher to assist the kindergarten teacher in identifying areas of development and areas for growth to meet the individual needs of each child.

11.1.5. policies and procedures for the transition of children with IEPs into and out of the WV Pre-k and will follow all state and federal requirements.

11.1.6. transition planning which follows the West Virginia Childhood Transition Checklist (www.wvearlychildhood.org.)

11.1.7. Programs will be designed to minimize the number of settings in which a child receives education and care services. Parent/guardian should be given options to enroll their child in a program that meets the needs of the family and supports consistency and continuity for the child. Placement shall not be limited to the local school district in which the child lives if openings are available in participating programs within that county that better meet the child and family's needs.

\section{\$126-28-12. Inclusive Environments.}

12.1. County plans will outline the county's process for providing fully inclusive early childhood classrooms with appropriate supports for children with identified special education needs. Proximity does not guarantee inclusion.

12.2. Children with identified special needs must be served in the least restrictive environment which includes utilizing approved participating partners in WV Pre-k.

12.3. Socioeconomic level, ability, and/or funding streams should not be viewed as deterrents to providing fully inclusive programs.

12.4. The IEP placement determination identifies the setting where the IEP will be implemented. Placement decisions must be made consistent with 34 CFR $\$ 300.552$ that requires:

12.4.1. the student's placement decision is made by the student's IEP Committee; 
Appendix A

Policy 2525 (P. 29)

12.4.2. the placement be in the least restrictive environment based on and consistent with the IEP;

12.4.3. that unless the student's IEP requires some other setting, the child be educated in the early childhood setting where the child would have received services if he/she had not been disabled and as close as possible to his/her home school.

12.5. Placement in separate settings designed for students with disabilities should only be used when a child's IEP cannot be implemented in a less restrictive environment as determined by the IEP team and documented through multiple formal and informal assessment process.

\section{§126-28-13. Staff Development and Training.}

13.1. All county pre-k staff including teachers and teacher assistants/aides/paraprofessionals shall participate in 15 hours of staff development as described in the collaborative professional development plan that will be included in the county collaborative plan include a minimum of six hours of education on issues related to young children with special needs. The collaborative training plan will utilize the annual ECERS-R results, along with other professional development needs assessment data and be based on the Core Knowledge and Competencies for Early Care and Education Professionals (www.wvearlychildhood.org).

13.2. Professional development information shall be made available to collaborative partners to facilitate the registration of training sessions on the West Virginia State Training and Registry System (WV S.T.A.R.S.), which can be accessed at www.wvearlychildhood.org.

\section{\$126-28-14. Program Oversight.}

14.1. LEAs have direct responsibility for the public school classrooms in their county. Local program oversight for contracted community programs must be defined in the contracts between the community program and the LEA including, but not limited to, staff evaluation and discipline, will be specified within the resulting collaborative agreements of each participating program in the county plan.

14.2. The WVBE or its designee and the Secretary of the WVDHHR or his/her designee will maintain state oversight.

\section{§126-28-15. Financing.}

15.1. Neither the WVBE nor WVDE may provide any funds to any county for the purpose of implementing this policy unless the county has an approved plan as outlined herein. 
Appendix A

Policy 2525 (P. 30)

15.2. Commencing with the school year beginning on July 1, two thousand four, and thereafter, no county board may increase the total number of students enrolled in the county in early childhood programs until its county collaborative plan is approved by the Secretary of the WVDHHR and the WVBE.

15.3. Each LEA shall enroll Pre-k children in community classrooms and generate funding through the school aid funding formula according to the process and criteria established in the May 28, 2008 WV State Superintendent's Guidance document. Funding generated through community classrooms should be invested in providing quality early education services and local infrastructure to support WV Pre-k classrooms.

15.4. In addition to the resources brought to a pre-k collaboration, community programs participating as partners shall continue using federal and state funding available for these services such as Head Start and Child Care Development Fund monies supporting eligible children.

15.5. WV Pre-k classrooms that provide services to eligible children that can be counted in the county school aid funding formula, must be provide those services at no cost to the parent/guardian of the children, including all instructional activities and field trips.

15.6. In child care, pre-k is an enhancement to the regular program during the designated pre-kindergarten hours. Since pre-k under this policy is part of a free public education, parents/guardians shall only be charged for those hours outside the pre-k designated time. Support for child care centers to offer free public education shall be a part of the contract between the center and LEA.

15.7. The LEA shall provide sufficient assistance/funding to a collaborative community partner to enable the partner to offer services that meet this policy at no cost to parents and at no deficit to the program. In calculating costs and resources, the county collaborative team should consider a number of issues and cost, such as personnel, facility, materials and furniture, current budgets, needed improvements, and professional development.

\section{\$126-28-16. Program Evaluation for Quality Improvement.}

16.1. The Early Childhood Environment Rating Scale-Revised will be utilized by each county collaborative team as a guidance tool to measure program quality in each WV Pre-k classroom. The ECERS-R shall be administered by collaborative teams with representation from the LEA, contracted community partners, and at a minimum one program county administrator or outside observer. The ECERS-R is not intended to be administered by a single individual. One member

of each team must be listed with the WVDE as an "Experienced ECERS-R Observer". The ECERS-R shall not be completed by individuals with direct supervision responsibilities for the classroom or by the teacher of that classroom for purposes of 
Appendix A

Policy 2525 (P. 31)

submitting the observation results to the WVDE. The results from the ECERS-R observation will be submitted to the WVDE annually by August 1 .

16.2. The purpose of the program evaluation is to support continuous quality improvement by identifying strengths and areas for improvement. The ECERS-R is not an evaluation of the teacher for performance purposes, or an assessment of the development of individual student, but rather an assessment of the program. Public school teachers shall continue to be evaluated according to W. Va. 120CSR142, WVBE Policy 5310, Performance Evaluation of School Personnel. Prioritized needs will be identified from the ECERS-R, objectives and action steps developed to be incorporated into the school's strategic plan. Items scored at a level four or below must be identified for improvement and addressed in the school's strategic plan.

16.3. The ECERS-R results will guide state level professional development planning and highlight areas for technical assistance and support.

16.4. When a county has fully implemented their county collaborative plan and all eligible children in that county have access to a WV Pre-k classroom that meets all of the quality requirements as outlined in this policy, the county board of education is required to annually submit a report that includes: verification of the annual submission of the ECERS-R results, a summary of the WV Pre-k services provided in the county, the number of WV Pre-k children with identified special education needs, the staff development opportunities provided through the county collaborative plan and the number of staff who participated in those staff development opportunities, and number of children who transitioned into kindergarten and other information as required by the WVDE to the WVDE Assistant Director of Early Learning and Literacy by August 1.

16.5. The WVDE shall develop and institute a system of longitudinal, scientifically based research to track learner outcomes, family satisfaction, program continuity and related variables in order to evaluate program impact, as funds become available. The system shall be designed in such a way to be of benefit on both the county and state level and improve the quality of programming available for eligible children. 


\author{
Appendix B \\ Request for County Participation
}

\title{
(Date)
}

\section{(address)}

Dear (Superintendent):

I am seeking your assistance with my doctoral research study. My name is Kimberly S. Miller and I am writing to request your county's participation in a case study on collaboration whose purpose is to give a rich description of how Universal preschool stakeholders describe their participation in compulsory collaboration in selected schools in West Virginia. The data will be collected through interviews, observations and document collection from which it may be possible to discover information that may be helpful to Pre-k programs that have not yet earned the designation of universal. All data collected is a critical component of my doctoral dissertation, which will be conducted under the direction of Dr. Paul Chapman, Professor of Educational Leadership Studies at West Virginia University.

By volunteering to have me come visit your county for a period of not more than five days, you will provide valuable data for the research study. The five-day visit will occur at a time you and your staff so indicate. During the visit, I will be interviewing key universal Pre-k stakeholders who wish to volunteer for me to observe what happens within the Pre-K setting. Finally, I will observe the early childcare providers during program changes, before program gatherings and during meetings.

The following assurances, as required by West Virginia University, will be respected: participation in the study is voluntary; information will be kept confidential; and the participant may refuse to participate, quit at any time, or skip any questions with no negative effect in employment status. Further, West Virginia University's Institutional Review Board acknowledgement for this research is on file.

Thank you for considering my presence at your school for approximately three to five days.

Sincerely,

Dr. Paul Chapman, Principal Investigator

Educational Leadership Professor
Kimberly S. Miller, Primary Contact

Doctoral Student 
Appendix C

Request for Universal Pre-k Stakeholder Participation

\section{(Date)}

\section{( address)}

Dear Early Childcare Provider, My name is Kimberly S. Miller and I am writing to request your participation in a case study whose purpose is to give a rich description of how Universal preschool stakeholders describe their participation in compulsory collaboration in selected schools in West Virginia. The data will be collected through interviews, observations and document collection from which it may be possible to discover information that may be helpful to Pre-k programs that have not yet earned the designation of universal. A benefit of your participation in this study is the opportunity for you to provide insight into your experience of collaboration. All data collected is a critical component of my doctoral dissertation, which will be conducted under the direction of Dr. Paul Chapman Professor of Educational Leadership Studies at West Virginia University. By volunteering to participate in this study, you will be interviewed using a set of semistructured questions. In addition, your program settings and meetings will be observed using a checklist with anecdotal notes to record what activities are occurring that are a result of collaboration. This data is crucial in developing common themes across all interviews and observations that will be used in the development of an understanding of the process of collaboration in universal Pre-k. Finally, I will observe the program during class changes, before school gatherings and during meetings.

The following assurances, as required by West Virginia University, will be respected: participation in the study is voluntary; information will be kept confidential; and the participant may refuse to participate, quit at any time, or skip any questions with no negative effect in employment status. Further, West Virginia University's Institutional Review Board acknowledgement for this research is on file.

Thank you for your consideration in this request.

Sincerely,

Dr. Paul Chapman, Principal Investigator

Educational Leadership Professor
Kimberly S. Miller, Primary Contact

Doctoral Student 


\author{
Appendix D \\ Universal Pre-k Stakeholder Protocol
}

\title{
Script:
}

Hello, my name is Kimberly S. Miller. I am a doctoral student in West Virginia University's educational leadership program. I would like to thank you for agreeing to participate in the study. The purpose of the study is to give a rich description of how Universal preschool stakeholders describe their participation in compulsory collaboration. Through the interview process of early childcare providers, I hope to gather information that will assist programs that have not yet earned the designation of universal. Your participation is voluntary and you will not have to answer each question. You have my assurance that your responses will remain anonymous and that confidentiality will be maintained throughout the data collection and reporting processes.

It is my goal to be able to give a rich description of how Universal preschool stakeholders describe their participation in compulsory collaboration by investigating the collaboration process. I have a number of questions that focus around the process of collaboration as implemented by early childcare program providers. The final question will give you the opportunity to include anything you find important about collaboration that was not specifically asked. I may also contact you later, if questions arise about this interview. Please feel free to contact me if you have any questions or additional thoughts.

Do I have your permission to record this interview and take notes to ensure the accuracy of your responses? yes no. Do you have any questions before we begin?

School name: 
Appendix E:

Sample Interview Protocol Form (P. 1)

Stanford University's National Center for Post Secondary Improvement Stanford University NCPI

(http://www.stanford.edu/group/ncpi/unspecified/student_assess_toolkit/sampleInterviewProtocol.html

Sample Interview Protocol Form

Faculty Interview Protocol

Institutions:

Interviewee (Title and Name):

Interviewer:

Survey Section Used:

A: Interview Background

B: Institutional Perspective

$\mathrm{C}$ : Assessment

D: Department and Discipline

E: Teaching and Learning

F: Demographics (no specific questions)

Other Topics Discussed

Documents Obtained

Post Interview Comments or Leads: 


\author{
Appendix E: \\ Sample Interview Protocol Form (P. 2) \\ Stanford University’s National Center for Post Secondary Improvement \\ Stanford University NCPI \\ Teaching, Learning, and Assessment Interviews \\ Introductory Protocol
}

To facilitate our note taking, we would like to audio tape our conversations today. Please sign the release form. For your information, only researchers on the project will be privy to the tapes, which will be eventually destroyed after they are transcribed. In addition, you must sign a form devised to meet our human subject requirements. Essentially, this document states that: (1) all information will be held confidential, (2) your participation is voluntary and you may stop at any time if you feel uncomfortable, and (3) we do not intend to inflict any harm. Thank you for your agreeing to participate.

We have planned this interview to last no longer than one hour. During this time, we have several questions that we would like to cover. If time begins to run short, it may be necessary to interrupt you in order to push ahead and complete this line of questioning.

Introduction

You have been selected to speak with us today because you have been identified as someone who has a great deal to share about teaching, learning, and assessment on this campus. Our research project as a whole focuses on the improvement of teaching and learning activity, with particular interest in understanding how faculty in academic programs are engaged in this activity, how they assess student learning, and whether we can begin to share what we know about making a difference in undergraduate education. Our study does not aim to evaluate your techniques or experiences. Rather, we are trying to learn more about teaching and learning, and hopefully learn about faculty practices that help improve student learning on campus.

A. Interviewee Background

How long have you been ...

in your present position?

at this institution?

Interesting background information on interviewee:

What is your highest degree?

What is your field of study?

1. Briefly describe your role (office, committee, classroom, etc.) as it relates to student learning and assessment (if appropriate).

Probes: How are you involved in teaching, learning, and assessment here? 


\author{
Appendix E: \\ Sample Interview Protocol Form (P. 3) \\ Stanford University's National Center for Post Secondary Improvement
Stanford University NCPI \\ How did you get involved?
}

2. What motivates you to use innovative teaching and/or assessment techniques in your teaching?

B. Institutional Perspective

1. What is the strategy at this institution for improving teaching, learning, and assessment?

Probes: Is it working - why or why not?

Purpose, development, administration, recent initiatives

2. What resources are available to faculty for improving teaching and assessment techniques?

3. What rewards do faculty receive from the institution for engaging in innovative teaching/learning and assessment strategies?

Probe: Do you see a widening of the circle of participants here on campus?

4. What is changing about teaching, learning, and assessment on this campus?

Probe: What is being accomplished through campus-based initiatives?

What kinds of networks do you see developing surrounding teaching/learning reforms?

5. Have you or your colleagues encountered resistance to these reforms in your department? ... on campus?

C. Assessment

1. How do you go about assessing whether students grasp the material you present in class?

Probe: Do you use evidence of student learning in your assessment of classroom strategies?

2. What kinds of assessment techniques tell you the most about what students are learning?

Probe: What kinds of assessment most accurately capture what students are learning? 
Appendix E:

Sample Interview Protocol Form (P. 4)

\section{Stanford University's National Center for Post Secondary Improvement Stanford University NCPI}

3. Are you involved in evaluating teaching, learning, and assessment practices at either the department or campus level? How is this achieved?

4. How is the assessment of student learning used to improve teaching/learning in your department? .... on campus?

\section{Department and Discipline}

1. What are some of the major challenges your department faces in attempting to change teaching, learning, and assessment practices? What are the major opportunities?

Probes: How can barriers be overcome?

How can opportunities be maximized?

2. To what extent are teaching-related activities evaluated at your institutions? . . in your department?

Probe: How is "good teaching" rewarded?

3. To what extent is teaching and assessment valued within your discipline?

E. Teaching and Learning

1. Describe how teaching, learning, and assessment practices are improving on this campus

Probe: How do you know? (criteria, evidence)

2. Is the assessment of teaching and learning a major focus of attention and discussion here?

Probe: why or why not? (reasons, influences)

3. What specific new teaching or assessment practices have you implemented in your classes?

4. Are there any particular characteristics that you associate with faculty who are interested in innovative teaching/learning initiatives? 


\author{
Appendix E: \\ Sample Interview Protocol Form (P. 5) \\ Stanford University's National Center for Post Secondary Improvement \\ Stanford University NCPI
}

What types of faculty development opportunities do you see emerging on your campus that focus on teaching and learning strategies for the classroom? (Institutional or disciplinary?)

Probes: What motivates you to participate in instructional development programs on campus?

How frequently do you attend such programs?

How are these programs advertised to faculty?

F. Demographics

Post Interview Comments and/or Observations: 
Appendix F:

Interview and Observation Forms (p. 1)

\section{Observation Guide: Site}

Date

Site

Description

Ease of access

Arrival time

Departure time

People interviewed

\section{Location}

1
2
3
4
5
6
7

Other interactions 
Appendix F:

Interview and Observation Forms (p. 2)

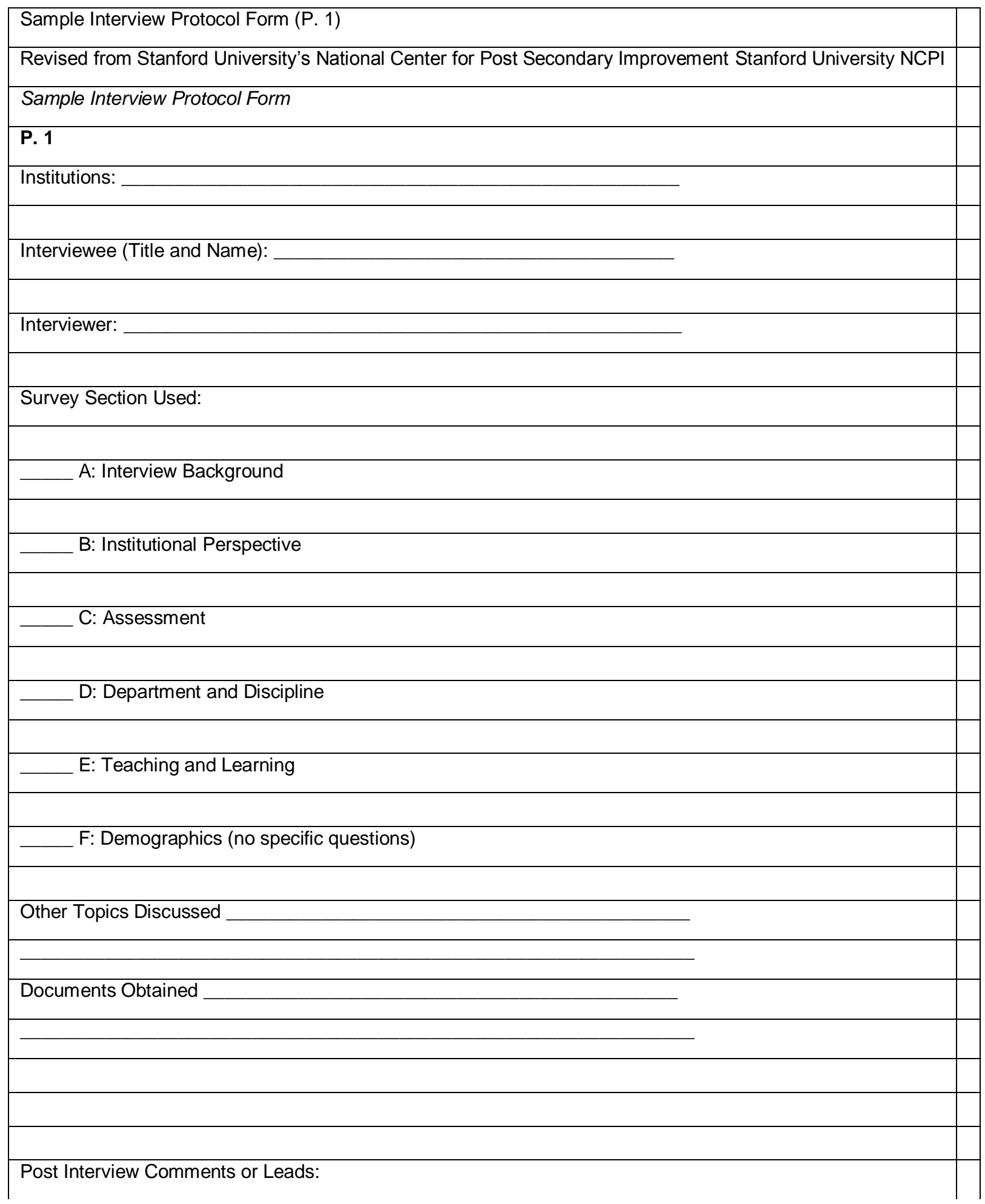


Appendix F:

Interview and Observation Forms (p. 3)

\begin{abstract}
Sample Interview Protocol Form (P. 2) Stanford University NCPI
Introductory Protocol

To facilitate our note toking, we would like to audio tape our conversations today. Please sign the release form. For your information, only researchers on the project will be privy to the tapes, which will be eventually destroyed after they are transcribed. In addition, you must sign a form devised to meet our human subject requirements. Essentially, this document states that: (1) all information will be held confidential, (2) your participation is voluntary and you may stop at any time if you feel uncomfortable, and (3) we do not intend to inflict any harm. Thank you for your agreeing to participate.

We have planned this interview to last no longer than one hour. During this time, we have several questions that we would like to cover. If time begins to run short, it may be necessary to interrupt you in order to push ahead and complete this line of questioning.

Introduction

You have been selected to speak with us today because you have been identified as someone who has a great deal to share about teaching, learning, and assessment on this campus. Our research project as a whole focuses on the improvement of teaching and learning activity, with particular interest in understanding how faculty in academic programs are engaged in this activity, how they assess student learning, and whether we can begin to share what we know about making a difference in undergraduate education. Our study does not aim to evaluate your techniques or experiences. Rather, we are trying to learn
\end{abstract}

\begin{tabular}{|l|l|}
\hline A. Interviewee Background & \\
\hline How long have you been ... & \\
\hline in your present position? & \\
\hline at this institution? & \\
\hline What is your highest degree? & \\
\hline What is your field of study? & \\
\hline & \\
\hline 1. Briefly describe your role (office, committee, classroom, etc.) as it relates to collaboration. \\
\hline & \\
\hline Probes: How are you involved in collaboration here? & \\
\hline 1. How did you get involved? & \\
\hline & \\
\hline 2. What motivates you to use collaborative methods? & \\
\hline B. Institutional Perspective & \\
\hline & \\
\hline
\end{tabular}


Appendix F:

Interview and Observation Forms (p. 4)

\begin{tabular}{|l|l|}
\hline Probes: Is it working - why or why not? & \\
\hline & \\
\hline Purpose, development, administration, recent initiatives & \\
\hline 2. What resources are available to faculty for improving collaboration? & \\
\hline 3. What rewards do faculty receive from the institution for engaging in collaboration? \\
\hline
\end{tabular}

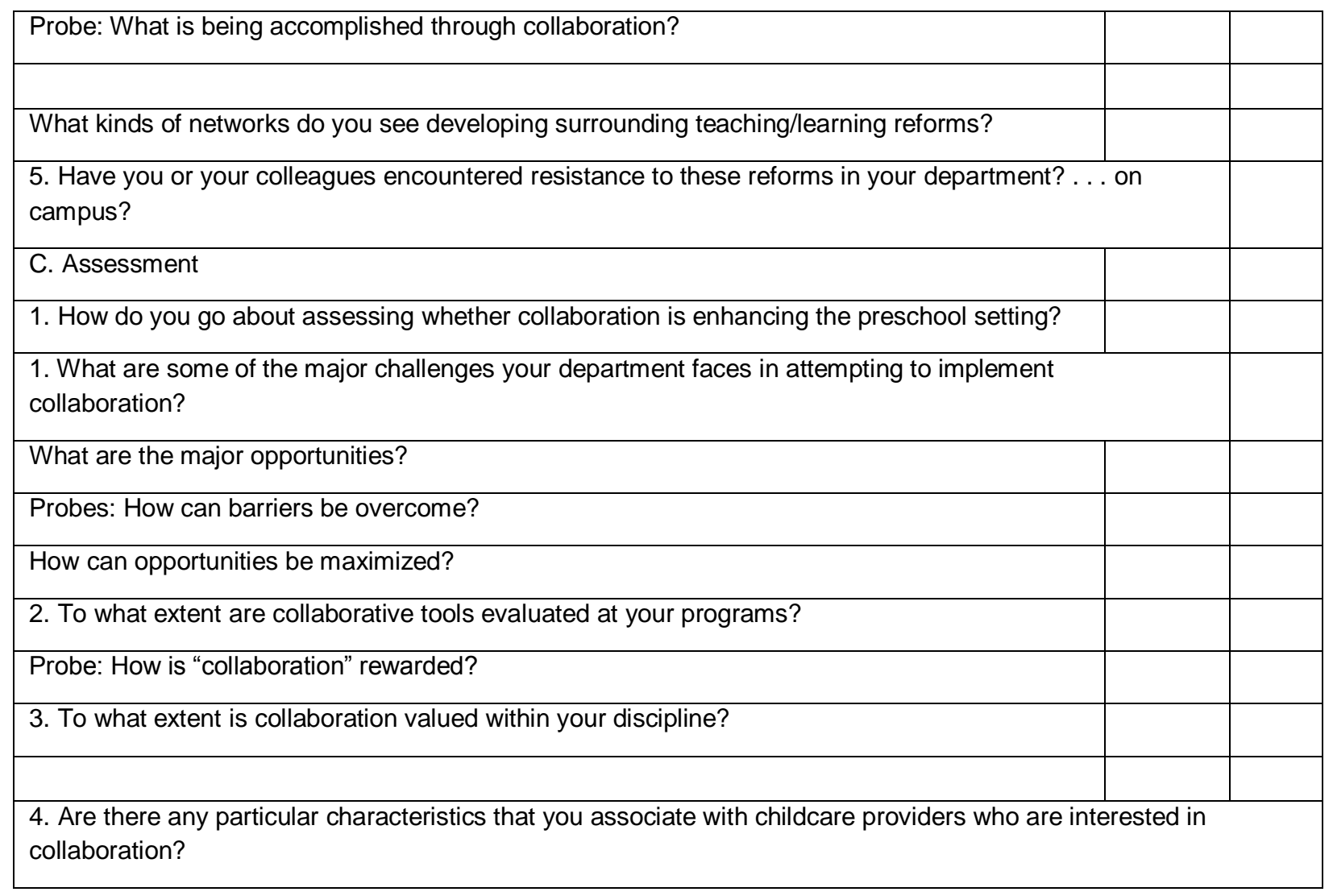


Appendix F:

Interview and Observation Forms (p. 5)

\begin{tabular}{|c|c|c|c|c|c|c|c|c|c|c|c|c|}
\hline & $\stackrel{\bar{v}}{\tilde{u}}$ & - & & 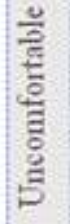 & & 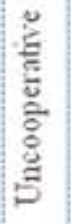 & $\stackrel{3}{\omega}$ & 萝 & 气 & 关 & $\int_{\tilde{E}}^{\vec{E}}$ & $\frac{\text { an }}{\frac{3}{0}}$ \\
\hline $\begin{array}{l}\tilde{y} \\
\stackrel{y}{\circ} \\
\dot{5}\end{array}$ & & $\sim$ & & & & & & 苞 & & & $\frac{\widetilde{d}}{\tilde{u}}$ & 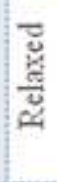 \\
\hline 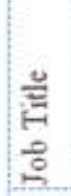 & हू & $m$ & & $\begin{array}{l}\bar{E} \\
\bar{z} \\
z\end{array}$ & & $\frac{\vec{J}}{\stackrel{E}{\Xi}}$ & $\frac{\dddot{\pi}}{\frac{\pi}{\pi}}$ & 㞼 & 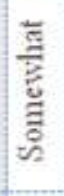 & 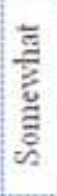 & 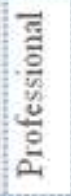 & 胥 \\
\hline 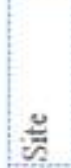 & & $T$ & & & & & & $\frac{\mathscr{S}}{\tilde{U}}$ & & & 丞 & $\frac{\bar{g}}{\omega}$ \\
\hline$\stackrel{\text { ڤ̆ }}{\text { ติ }}$ & $\frac{\vec{s}}{c}$ & wo. & 아 & $\frac{\frac{\pi}{3}}{\frac{\tilde{c}}{3}}$ & & 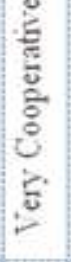 & 혈 & $\frac{y}{5}$ & 5 & : & 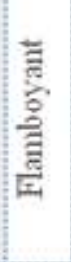 & $\frac{\widehat{E}}{\mathrm{E}}$ \\
\hline 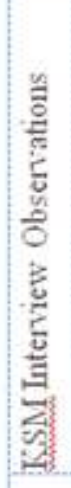 & & & 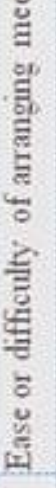 & 节 & $\frac{3}{3}$ & $\frac{\check{\Xi}}{\tilde{z}}$ & $\frac{\frac{1}{5}}{\frac{\pi}{2}}$ & 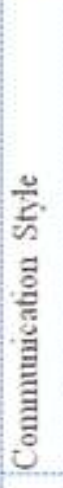 & $\frac{\frac{a}{0}}{\frac{0}{E}}$ & 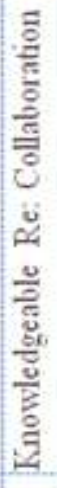 & $\frac{\stackrel{\mathscr{g}}{\mathrm{d}}}{\mathrm{d}}$ & 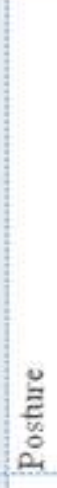 \\
\hline & & & & 竎 & $\bar{z}$ & $\rightarrow$ & 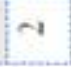 & $m$ & 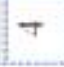 & $r$ & 10 & 1 \\
\hline
\end{tabular}


Appendix F:

Interview and Observation Forms (p. 6)

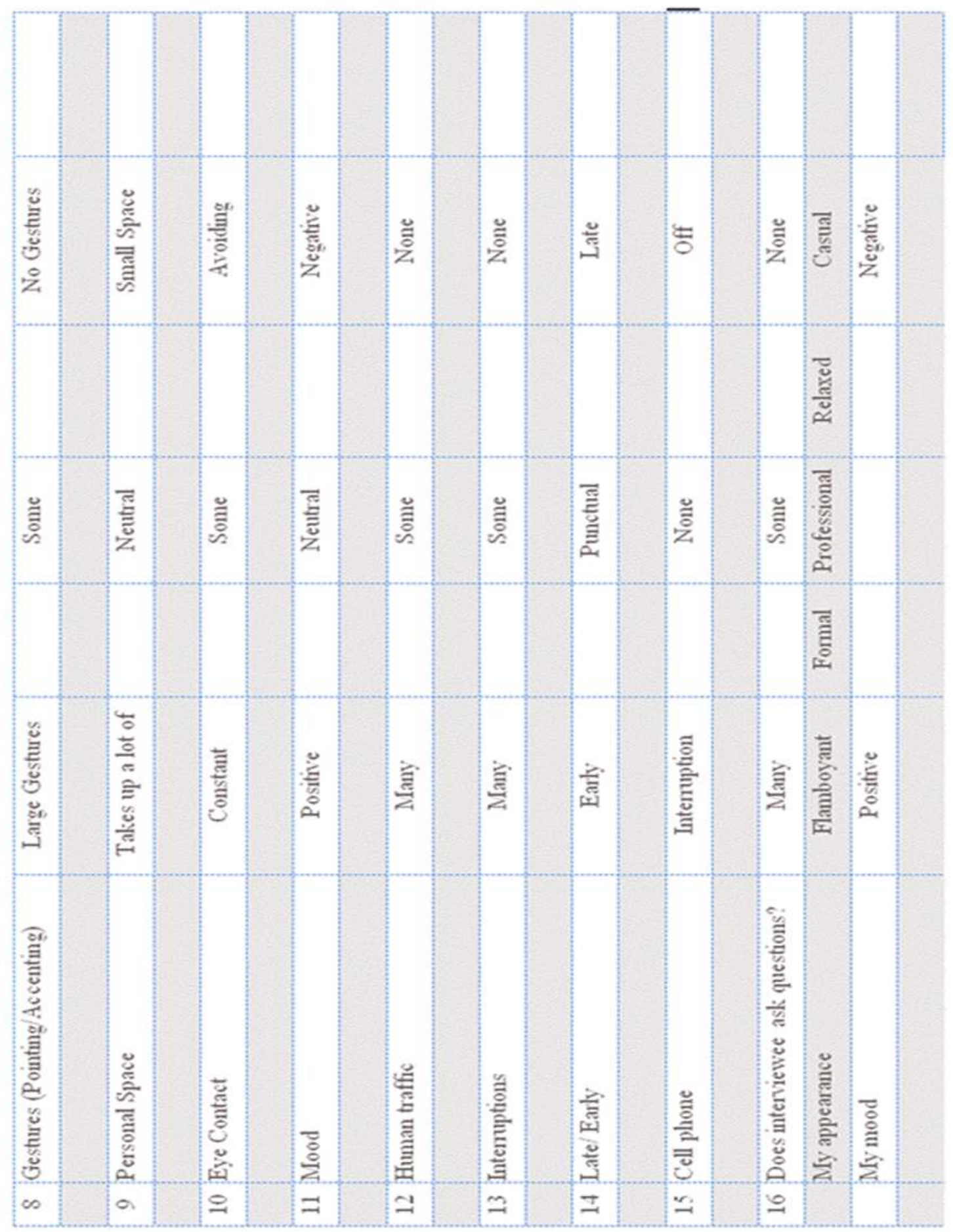


Appendix G

Illustration of Pattern Coding (p.1)

Table 2

Illustration of Pattern Coding

In Vivo / Descriptive Category/ Patterns A/ Theme A / Pattern B/ Theme B/ Pattern C/ Theme C

$\begin{array}{llllllll}1 & 2 & 3 & 4 & 5 & 6 & 7 & 8\end{array}$

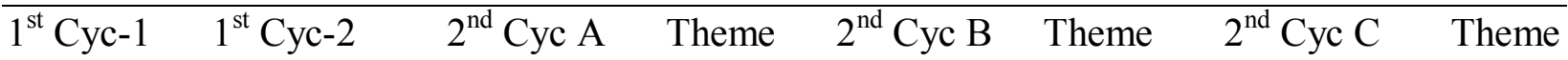

\begin{tabular}{llllllll}
\hline In Vivo & Descriptive & $1^{\text {st }}$ Pattern & Theme & $2^{\text {nd }}$ Pattern & Theme & $3^{\text {rd }}$ Pattern & Theme
\end{tabular}

Note: ${ }^{a}$ Column 1: In Vivo listed a word or word taken directly from the interviews or meetings.

${ }^{\mathrm{b}}$ Column 2: Descriptive Category applied a descriptive label to the words selected in column 1 .

${ }^{\mathrm{c}}$ Columns 3, 5, and 7: Pattern coding grouped the descriptive labels into patterns (three levels).

${ }^{\mathrm{d}}$ Columns 4, 6, and 8: The patterns were organized into emerging themes. 


\section{Appendix G \\ Example of Coding Process (p.2)}

Table 3

Example of Coding Process

Coding Example: "It's about relationship building"

\begin{tabular}{|c|c|c|c|c|c|c|}
\hline Line\# & In Vivo & Descriptive Category & Pattern & Theme A & Pattern B & Theme B \\
\hline 217 & $\begin{array}{l}\text { relations } \\
\text { building }\end{array}$ & Values & $\begin{array}{l}\text { EV } 2 \\
\text { Val }\end{array}$ & $\begin{array}{l}\text { Exp. } \\
\text { Val }\end{array}$ & OC 3 & Org. Cult \\
\hline & & & \multicolumn{2}{|c|}{$\begin{array}{l}\text { 2.Ability to } \\
\text { Communicate } \\
\text { Compromise } \\
\text { Flexibility }\end{array}$} & $\begin{array}{l}3 . \\
\text { Collaboration } \\
\text { in Self- } \\
\text { interest }\end{array}$ & \\
\hline
\end{tabular}

Note: "Pattern A coded as" EV-2" above is Ability to Communicate \& Compromise/Flexibility.

b Pattern B coded as "OC-3" above is Collaboration in Self-interest 


\section{Appendix G \\ Sampling of Coded Representative Statements . (p.3)}

Table 4

Sampling of Coded Representative Statements

"First of all, I think we are all here for the children. The bonus for our collaborative partners is they are doing the job anyway, so we are providing a monetary resource for them as well as they take part in our staff development, any trainings that they need, any materials, and resources. So they are getting that as well and they are already providing the services for the children so this is just an added incentive for them to participate."

\begin{tabular}{|c|c|c|c|c|c|c|}
\hline & 1st Cycle (1) & $\begin{array}{l}1 \text { st Cycle } \\
\text { (2) }\end{array}$ & 2nd Cycle A & $\begin{array}{l}\text { 3rd Cycle } \\
\text { A }\end{array}$ & 2nd Cycle B & $\begin{array}{c}\text { 3rd } \\
\text { Cycle B }\end{array}$ \\
\hline $\begin{array}{c}\text { Line } \\
\#\end{array}$ & In Vivo & $\begin{array}{l}\text { Descriptive } \\
\text { Cat. }\end{array}$ & Pattern A & Theme A & Pattern B & Theme B \\
\hline 72 & $\begin{array}{l}\text { We are all here for the } \\
\text { children }\end{array}$ & Values & $\begin{array}{l}\text { Shared } \\
\text { Vision }\end{array}$ & Exp. Val & $\begin{array}{l}\text { Col/Self- } \\
\text { Interest }\end{array}$ & Org.Cul. \\
\hline 73 & $\begin{array}{l}\text { bonus for collaborative } \\
\text { partners }\end{array}$ & Values & $\begin{array}{l}\text { Shared } \\
\text { Vision }\end{array}$ & Exp. Val & $\begin{array}{l}\text { Col/Self- } \\
\text { Interest }\end{array}$ & Org.Cul. \\
\hline 75 & monetary resource & Resources & Policy & Inst. Auth. & & \\
\hline 76 & staff development & Guidelines & Policy & Inst. Auth. & & \\
\hline 77 & trainings & Policy & Policy & Inst. Auth. & & \\
\hline 78 & materials & procedures & Policy & Inst. Auth. & & \\
\hline 79 & resources & resources & Policy & Inst. Auth. & & \\
\hline 80 & providing services & Values & $\begin{array}{l}\text { Shared } \\
\text { Vision }\end{array}$ & Exp. Val & Goals/Ob. & Org.Cul. \\
\hline 81 & added incentive & Values & $\begin{array}{l}\text { Op/Freq. } \\
\text { Comm. }\end{array}$ & Exp. Val & Goals/Ob. & Org.Cul. \\
\hline
\end{tabular}


Appendix G

Sampling of Coded Representative Statements (p.4)

Table 5

Sampling of Coded Representative Statements

"The rewards of the collaboration is that we are servicing every four year old that wants service. That is a big reward."

\begin{tabular}{ccccccc}
\hline & 1st Cycle (1) & 1st Cycle (2) & 2nd Cycle A & $\begin{array}{c}\text { 3rd Cycle } \\
\text { A }\end{array}$ & 2nd Cycle B & $\begin{array}{c}\text { 3rd } \\
\text { Cycle B }\end{array}$ \\
\hline $\begin{array}{c}\text { Line } \\
\#\end{array}$ & In Vivo & $\begin{array}{c}\text { Descriptive } \\
\text { Cat. }\end{array}$ & Pattern A & Theme A & Pattern B & Theme B \\
\hline 75 & Rewards & Values & Shared Vision & Exp. Val & Shared Vision & Org.Cul. \\
\hline 76 & Servicing & Values & Shared Vision & Exp. Val & Underst/Trusr & Org.Cul. \\
\hline 77 & big reward & Values & Policy & Exp. Val & Shared Vision & Org.Cul. \\
\hline
\end{tabular}


Appendix $\mathrm{H}$

\section{Kimberly S. Miller \\ 31 Maple Avenue, Wheeling, WV 26003 \\ Phone: 304-234-6966 \\ Cell: 304-280-0398 \\ Ksmiller31@comcast.net}

\section{Education:}

West Virginia University, 2011

Ed. D., Educational Leadership

Minor: Instructional Design \& Technology

Salem International University, 2007

Certifications: Superintendent, Supervisor General Instruction, Principal

West Virginia University, 1997

M.A., Elementary Education

West Virginia University, 1992

B.S., Elementary Education

Major: Multi-Subject K

Minor: Pre-K - K

\section{Experience:}

Central Office Administrator

Ohio County Schools

Student Services Director, 2007 - current

Curriculum Coordinator, 2002 - 2007

Elementary Education Teacher, 1993 - 2002

Ohio County Schools

Second Grade Teacher

\section{Presentations:}

- Early Learning Environment (2010)

- The Leap to Universality (2010)

- Focused Observations (2010)

\section{Grants:}

- Community Foundation for the Ohio Valley Arts in Education Grant (2011), \$10,000

- VH1 Save the Music Foundation Grant (2011), \$30,000 
Awards and Honors:

- Milken Educator (2002)

- Brooke High School Sports Hall of Fame (2007)

\section{Skills and Qualifications:}

- Ohio County Schools Universal Pre-K Chairperson

- West Virginia Center for Professional Development Beginning Teacher Mentor

- Ohio County Schools Elementary Textbook Adoption Chairperson

- West Virginia Pre-K Early Learning Scale Assessment Systems Trainer

- West Virginia NxG Standards Trainer

Community Involvement:

- Crittenton Services, Inc. Board President

- Greater Wheeling Sports and Entertainment Authority Board President

- West Virginia Secondary Schools Athletic Commission Cheer Judge

- Ohio Valley Athletic Commission Executive Cheer Committee

- West Virginia University Alumni Cheerleader

\section{References:}

Excellent references available upon request. 